u.S. Army Coust. Eug. Res. Etr. Tech. Rep. CERC-90-10

TECHNICAL REPORT CERC-90-10

\section{SUPERDUCK SURF ZONE SAND TRANSPORT EXPERIMENT}

by

\author{
Julie Dean Rosati, Kathryn J. Gingerich, Nicholas C. Kraus
}

Coastal Engineering Research Center

DEPARTMENT OF THE ARMY

Waterways Experiment Station, Corps of Engineers

3909 Halls Ferry Road, Vicksburg, Mississippi 39180-6199
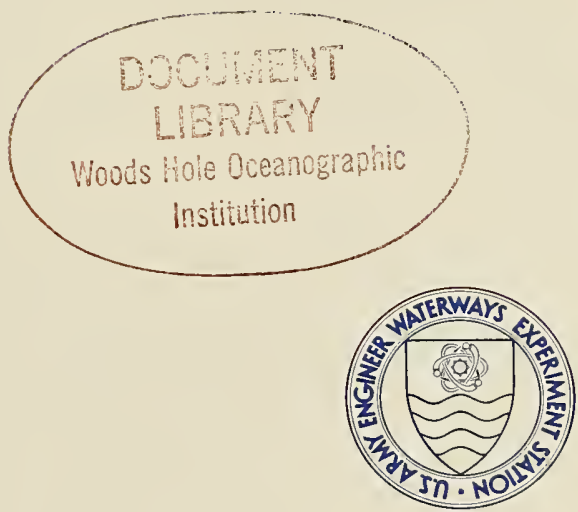

July 1990

Final Report

Approved For Public Release; Distribution Unlimited

Prepared for DEPARTMENT OF THE ARMY

US Army Corps of Engineers

Washington, DC 20314-1000

Under Surf Zone Sediment Transport Processes

Work Unit 34321 
Destroy this report when no longer needed. Do not return it to the originator.

The findings in this report are not to be construed as an official Department of the Army position unless so designated by other authorized documents.

The contents of this report are not to be used for advertising, publication, or promotional purposes. Citation of trade names does not constitute an official endorsement or approval of the use of such commercial products. 
Unclassified

SECURITY CLASSIFICATION OF THIS PAGE

\section{REPORT DOCUMENTATION PAGE}

\begin{tabular}{|c|c|c|c|c|c|}
\hline \multicolumn{2}{|l|}{$\begin{array}{l}\text { 1a. REPORT SECURITY CLASSIFICATION } \\
\text { Unclassified }\end{array}$} & \multicolumn{4}{|c|}{ 1b. RESTRICTIVE MARKINGS } \\
\hline \multicolumn{2}{|l|}{ 2a. SECURITY CLASSIFICATION AUTHORITY } & \multicolumn{4}{|c|}{$\begin{array}{l}\text { 3. DISTRIBUTION/AVAILABILITY OF REPORT } \\
\text { Approved for public release; distribution } \\
\text { unlimited }\end{array}$} \\
\hline \multicolumn{2}{|c|}{$\begin{array}{l}\text { 4. PERFORMING ORGANIZATION REPORT NUMBER(S) } \\
\text { Technical Report CERC-90-10 }\end{array}$} & \multicolumn{4}{|c|}{ 5. MONITORING ORGANIZATION REPORT NUM8ER(S) } \\
\hline $\begin{array}{l}\text { 6a. NAME OF PERFORMING ORGANIZATION } \\
\text { USAEWES, Coastal Engineering } \\
\text { Research Center }\end{array}$ & $\begin{array}{l}\text { 6b. OFFICE SYMBOL } \\
\text { (If applicable) }\end{array}$ & \multicolumn{4}{|c|}{ 7a. NAME OF MONITORING ORGANIZATION } \\
\hline \multicolumn{2}{|l|}{$\begin{array}{l}\text { 6c. ADDRESS (City, State, and ZIP Code) } \\
3909 \mathrm{Ha} 11 \text { s Ferry Road } \\
\text { Vicksburg, MS 39180-6199 }\end{array}$} & \multicolumn{4}{|c|}{ 7b. ADDRESS (City, State, and ZIP Code) } \\
\hline \multicolumn{2}{|l|}{ 8C ADDRESS (City, State, and ZIP Code) } & \multicolumn{4}{|c|}{ 10. SOURCE OF FUNDING NUMBERS } \\
\hline \multicolumn{2}{|l|}{ Washington, DC 20314-1000 } & $\begin{array}{l}\text { PROGRAM } \\
\text { ELEMENT NO. }\end{array}$ & $\begin{array}{l}\text { PROJECT } \\
\text { NO. }\end{array}$ & $\begin{array}{l}\text { TASK } \\
\text { NO. }\end{array}$ & $\begin{array}{l}\text { WORK UNIT } \\
\text { ACCESSION NO. } \\
34321\end{array}$ \\
\hline
\end{tabular}

\section{TITLE (Include Security Classification)}

SUPERDUCK Surf Zone Sand Transport Experiment

\section{PERSONAL AUTHOR(S)}

Rosati, Julie Dean; Gingerich, Kathryn J.; Kraus, Nicholas C.

\begin{tabular}{|l|l|l|l|l|}
\hline 13a. TYPE OF REPORT & $\begin{array}{l}\text { 14. DATE OF REPORT (Year, MONTh, Day) } \\
\text { July } 1990\end{array}$ & 1S. PAGE COUNT \\
Final report & FROM & 76
\end{tabular}

\section{SUPPLEMENTARY NOTATION}

Available from National Technical Information Service, 5285 Port Royal Road, Springfield, VA 22161

\begin{tabular}{|c|c|c|c|}
\hline \multicolumn{3}{|c|}{ COSATI CODES } & \multirow{3}{*}{ 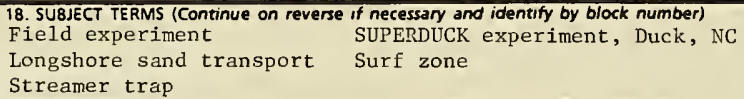 } \\
\hline FIELD & GROUP & SU8-GROUP & \\
\hline & & & \\
\hline
\end{tabular}

\section{ABSTRACT (Continue on reverse if necessary and identify by block number)}

The procedures and results of an experiment performed to measure the longshore sand transport rate in the surf zone as part of the SUPERDUCK field data collection project are described in this report. Cross-shore distributions of the longshore sand transport rate, as well as its variation at a point in the surf zone through time, were measured with portable sand traps. Comparison of measurements made with two closely spaced traps indicates. trap reliability and consistency. The longshore sand transport rate measured at SUPERDUCK was found to be closely related to the product of wave height and longshore current speed, consistent with previously derived theoretical models of transport. The correlation was considerably improved, however, by including corrections due to energy dissipation introduced by breaking waves and the variation in the longshore current speed. A complete listing of the sand transport rate, wave height, longshore current, and sand grain size data is given.

\begin{tabular}{|c|c|c|c|}
\hline $\begin{array}{l}\text { 20. DISTRIBUTION IAVAILABILITY OF ABSTRACT } \\
\text { QUNCLASSIFIEDNNLIMITED } \square \text { SAME AS RPT. }\end{array}$ & 口 OTIC USERS & $\begin{array}{l}\text { 21. ABSTRACT SECURITY CLASSIFICAT } \\
\text { Unclassified }\end{array}$ & \\
\hline 22. NAME OF RESPONSIBLE INDIVIDUAL & & 22b. TELEPHONE (Include Aree Code) & 22C. OFFICE SYMBOL \\
\hline
\end{tabular}




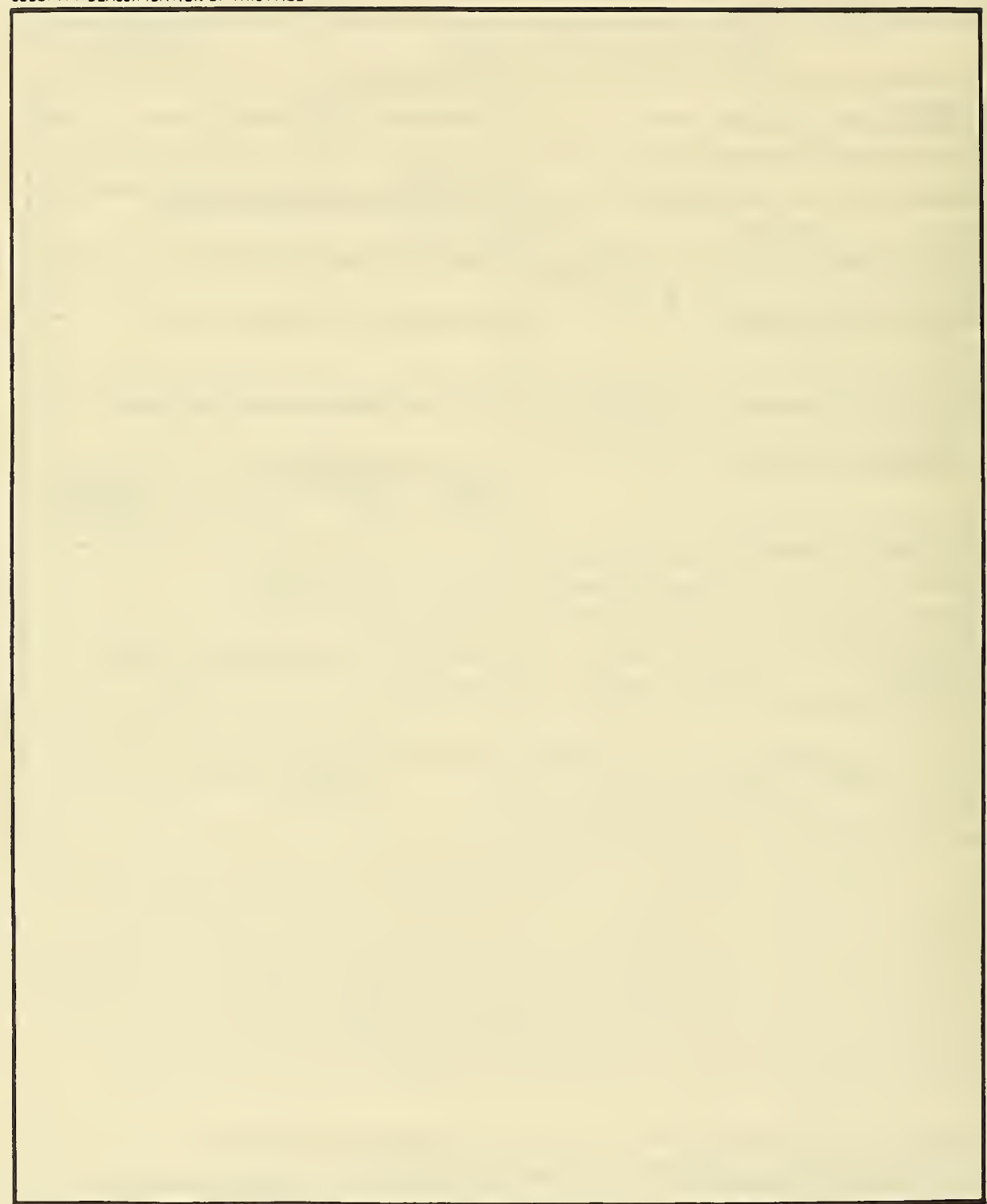




\section{PREFACE}

The investigation described in this report was authorized as part of the Civil Works Research and Development Program by Headquarters, US Army Corps of Engineers (HQUSACE). This study was conducted under the Shore Protection and Restoration Program, Surf Zone Sediment Transport Processes Work Unit 34321, at the Coastal Engineering Research Center (CERC) of the US Army Engineer Waterways Experiment Station (WES). Messrs. John H. Lockhart, Jr., and John G. Housley were HQUSACE Technical Monitors.

The study was performed by CERC in two phases: a field experiment planned and conducted from 1 June 1986 through 30 September 1986, and subsequent analysis of the data conducted from 1 October 1986 to 30 September 1989. Dr. Nicholas C. Kraus, Senior Scientist, Research Division (RD), CERC, was Principal Investigator (PI) of Work Unit 34321 during the first phase of the study; Ms. Kathryn J. Gingerich, Coastal Processes Branch (CPB), RD, was PI during the second phase of the study; and Ms. Julie Dean Rosati, CPB, was PI during preparation of this report.

Key members who assisted in the data collection, their affiliations at the time of the project, and their major function during data collection were Dr. Lindsay Nakashima, Louisiana Geological Survey, sediment processing, surveying, and experiment design; Messrs. Gary L. Howell and C. Ray Townsend, Prototype Measurement and Analysis Branch, CERC, current meter setup and current measurement; Ms. Jane M. Smith, Oceanography Branch (OB), RD, current data collection and trap operator; Ms. Mary A. Cialone, CPB, surveying, sediment processing, and trap operator; Dr. Shintaro Hotta, Tokyo Metropolitan University, Tokyo, Japan, photopole wave measurement team leader; Mr. Bruce A. Ebersole, $\mathrm{CPB}$, and Dr. Steven A. Hughes, $\mathrm{OB}$, photopole camera operators and trap operators. Field assistants were Drs. Hans Hanson and Magnus Larson, University of Lund, Sweden; Mr. Jack Kooistra, Queens University, Canada; Mr. Pascal Collotte, France; Ms. Tamsen S. Dozier, Estuarine Engineering Branch, Hydraulics Laboratory, WES; Messrs. Paul Bowen, Myles Pocta, and Jerry Swean, US Army Engineer (USAE) District, Norfolk; Mr. Ted Bales and Ms. Tril1 Rulison, USAE District, Alaska; Messrs. Rick Champion and John Miller, USAE District, Mobile; Ms. Lynn Koeth Bocamazo and Mr. Joe Vietri, USAE District, 
New York; Messrs. Dave Harris and Ted Hauser, USAE District, Charleston; Messrs. Bill Dennis and Lynn Jack, USAE District, Wilmington; Messrs. Mark Dettle and Tom Kende11, USAE District, San Francisco; Mr. Mike Mohr, USAE District, Buffalo; Mr. Charles Thompson, USAE District, Detroit; Mr. Steve Chesser, USAE District, Portland; Mr. Wes Coleman, USAE District, Baltimore; Mr. Ron Gisondo, USAE District, Los Angeles; Mr. Terry Fox, USAE District, Philadelphia; Mr. Andy Petallides, USAE Division, North Atlantic; and Ms. Pam Rubinoff, USAE Division, New England. Support personnel at the CERC Field Research Facility were Messrs. Curt Mason, Chief; William A. Birkemeier; Peter Howd; Carl Miller; and Ms. Harriet M. Klein.

This report was reviewed by Dr. Kevin R. Bodge, Senior Engineer, Olsen and Associates, Inc; Dr. Mark R. Byrnes, CPB; and Mr. David P. Simpson, CPB. Ms. Carolyn J. Dickson, CPB, prepared many of the computer-generated figures. This report was edited by Ms. Lee $T$. Byrne of the Information Technology Laboratory, WES. The study was performed under the general administrative supervision of Dr. James R. Houston, Chief, CERC; Mr. Charles C. Calhoun, Jr., Assistant Chief, CERC; Dr. Charles L. Vincent, Program Manager, Shore Protection and Restoration Program, CERC; and Mr. H. Lee Butler, Chief, RD, CERC.

COL Larry B. Fulton, EN, was Commander and Director of WES. Dr. Robert W. Whalin was Technical Director. 
PREFACE . . . . . . . . . . . . . . . . . . . . . . . 1

LIST OF TABLES . . . . . . . . . . . . . . . . . . . . . . . . . . . . . 4

LIST OF FIGURES . . . . . . . . . . . . . . . . . . . . . . . . . . . . . 4

PART I： INTRODUCTION . . . . . . . . . . . . . . . . . . . . . . . . 5

Purpose and Scope of Report . . . . . . . . . . . . . . . . . . . . 5

Background . . . . . . . . . . . . . . . . . . . . . . . 5

Sand Transport Measurement Methods . . . . . . . . . . . . . . . . 7

SUPERDUCK Field Data Collection Project. . . . . . . . . . . . . . 7

Report Contents . . . . . . . . . . . . . . . . . . . . . . 9

PART II: BACKGROUND OF THE EXPERIMENT . . . . . . . . . . . . . . . . . 10

Experiment Site . . . . . . . . . . . . . . . . . . . . . . . . . 10

Experiment Arrangement and Measurement Techniques . . . . . . . . . 14

Transport Rate Analysis . . . . . . . . . . . . . . . . . . . 22

PART III: RESULTS . . . . . . . . . . . . . . . . . . . . 25

Orientation to the Measurement Runs . . . . . . . . . . . . . . . . 25

Currents . . . . . . . . . . . . . . . . . . . . 32

Waves and Water Levels . . . . . . . . . . . . . . . . 36

Sand Transport . . . . . . . . . . . . . . . . . . . . 36

PART IV: CONCLUDING DISCUSSION . . . . . . . . . . . . . . . . . . 49

REFERENCES . . . . . . . . . . . . . . . . . . . . . 50

APPENDIX A: DATA . . . . . . . . . . . . . . . . . . . . . . . A1

APPENDIX B: NOTATION . . . . . . . . . . . . . . . . . B B 


\section{LIST OF TABLES}

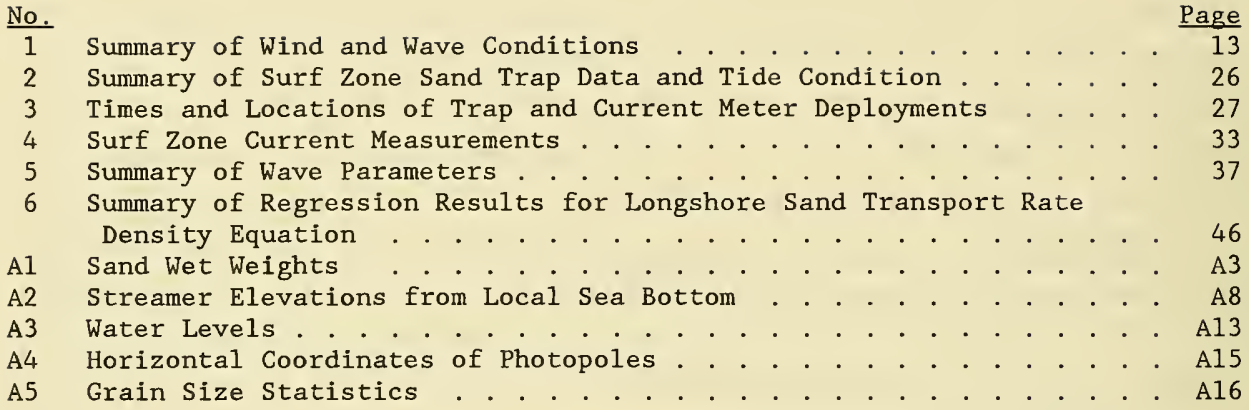

\section{LIST OF FIGURES}

No.

1 Location map for the FRF

Lacation map for the ERFe . . . . . . . . . . . 10

2 Base camp and typical data collection arrangement. $\cdot \dot{1} \cdot \dot{1}^{\cdot}$, and water level recorded at the seaward end of the pier . . . . . . . . 12

4 Photopole line spanning the surf zone . . . . . . . . . . . . . . . . 15

5 Current meter mount with meter installed . . . . . . . . . . . . . . 17

6 Streamer traps used at SUPERDUCK . . . . . . . . . . . . . . . . . . 17

7 Schematic of the streamer trap rack . . . . . . . . . . . . . . . . . 18

8 SUPERDUCK streamer nozzle . . . . . . . . . . . . . . . . . . . . . . 19

9 Streamer traps deployed in a TSM run . . . . . . . . . . . . . . . . 21

10 Traps being removed from the surf zone . . . . . . . . . . . . . . . 22

11 Consistency run 8609160922 . . . . . . . . . . . . . . . . . . . . . 40

12 Consistency run 8609160945 . . . . . . . . . . . . . . . . . . . . . 40

13 Consistency run $8609201500-1$. . . . . . . . . . . . . . . . . . . . 41

14 Consistency run 8609201500-2 . . . . . . . . . . . . . . . . . . . . 41

15 Consistency run 8609211046 . . . . . . . . . . . . . . . . . . . . . 42

16 Consistency run $8609211345-1$. . . . . . . . . . . . . . . . . . . . . . . . 42

17 Consistency run $8609211345-2$. . . . . . . . . . . . . . . . . . . . . . 43

18 Longshore sand transport rate density versus $H_{\mathrm{rms}} V$. . . . . . . . . 45

19 Longshore sand transport rate density versus $H_{\mathrm{rms}} V\left(1+\alpha d H_{\mathrm{rms}} / d \mathrm{x}\right)$. 47

20 Longshore sand transport rate density versus $H_{\mathrm{rms}} V\left(1+\alpha d H_{\mathrm{rms}} / d \mathrm{x}+B \sigma_{\mathrm{v}} / V\right)$. . . . . . . . . . . . . . . . . . 47 


\section{SUPERDUCK SURF ZONE SAND TRANSPORT EXPERIMENT}

\section{PART I: INTRODUCTION}

\section{Purpose and Scope of Report}

1. This report describes procedures and results of field data collection projects performed to measure the longshore sand transport rate in the surf zone as a part of the SUPERDUCK field data collection project. The experiments described herein were conducted from 11 to 23 September 1986. Certain introductory sections of this report have been taken directly from a companion report by Kraus, Gingerich, and Rosati (1989), who describe the DUCK85 field data collection project. The objective of these sand transport experiments was to measure synoptically the longshore sand transport rate together with the physical factors that produce and control the sand movement, including local waves, longshore current, water level, and nearshore bathymetry. A range of wave and current conditions occurred during the SUPERDUCK data collection, resulting in an extensive data set on temporal variations in the longshore sand transport rate at points in the surf zone and vertical distributions through the water column.

2. This report is intended to provide complete documentation of the SUPERDUCK surf zone sand transport experiment, including a compilation of the data. Information is given on experiment equipment and methodology to allow critical examination of techniques used. Data given include transport rates, current speeds, wave heights and periods, grain size distributions, water levels, and arrangement of the experiments. Supplementary data on meteorology and offshore wave conditions are given, and reference is made to sources of more complete information.

\section{Background}

3. Estimates of the longshore sand transport rate are required in a multitude of projects involving shore protection, beach nourishment, and harbor and navigation channel maintenance. In addition, during the past decade considerable progress has been made in numerical modeling of nearshore 
waves, currents, and beach change. Beach morphology response models are moving from the research level to the practical level as engineering design tools. A requirement in making this transition is improved capability for predicting the longshore sand transport rate, not only the total longshore transport rate but also its distribution across the surf zone, through the water column and its variation with time. For example, these distributions are needed for estimating bypassing around, over, and through groins and jetties and behind detached breakwaters.

4. Presently available predictive formulas for the longshore sand transport rate are generally acknowledged as providing only a rough approximation of the actual rate. The number of accepted field measurements comprising the data base is surprisingly small considering the importance of the problem, and scatter in the data is great, reflecting randomness in the physical processes, limitations in measurement techniques, and simplifications in predictive expressions used to describe fluid and sand motion. Presently employed predictive formulas for the transport rate do not incorporate dependencies on grain size, breaking wave type or wave-induced turbulence, properties of the waves or longshore current beyond mean values, or influence of the local bottom shape. The transport rate is expected to greatly depend on location in the surf zone, and its dependency on local conditions must be known to calculate cross-shore and vertical distributions.

5. Recognizing the need for point measurements of the longshore sand transport rate to obtain cross-shore and vertical distributions, the Surf Zone Sediment Transport Processes Research Work Unit was begun in 1985. This work unit, under the Shore Protection and Restoration Program at the Coastal Engineering Research Center (CERC) of the US Army Engineer Waterways Experiment Station, initiated a series of field experiments aimed at collecting comprehensive data sets on sand transport and processes responsible for the sand movement. Field data collection was planned for beaches composed of different materials ranging from fine sand to gravel and for wave climates ranging from small to large wave steepness. This report describes the results of the SUPERDUCK experiment, the second field data collection project in the planned series. 


\section{Sand Transport Measurement Methods}

6. In preparation for the first field data collection project, DUCK85, Kraus (1987) surveyed available sand transport measurement methods (tracer, impoundment, and traps) and concluded that traps offered the best means to obtain transport rate data compatible with the accuracy and detail required by existing numerical models which simulate beach evolution. Traps were also determined to be the least expensive of the three methods.

7. Portable traps allow measurement of the vertical distribution of the transport rate (transport at the bed and through the water column), and simultaneous deployment of traps at intervals across the surf zone enables measurement of the cross-shore distribution of the longshore transport rate. Traps can also be repeatedly deployed at one or two points in the surf zone to obtain temporal variations of the sand transport rate. Traps measure the sand flux, a quantity directly related to the transport rate, and not simply a sediment concentration. As in concentration measurements, transported particles are automatically retained by the traps and made available for analysis. Traps collect the material that actually moves, including sand, shell fragments, and other particles of size nominally larger than the trap mesh, and no assumptions need be made about grain size, as required in tracer studies. Mean wave and current conditions in the surf zone typically change on the order of minutes, and traps are well suited to such a sampling interval as opposed to tracer and impoundment methods. Traps are also inexpensive to construct and maintain, and only a minimum amount of training is necessary to use them. Disadvantages of traps include the potential for scour and, in surf zones, restriction to use with significant breaking wave heights on the order of $1 \mathrm{~m}$ or less.

\section{SUPERDUCK Field Data Collection Project}

8. During September and October 1986, CERC hosted and participated in a major multidisciplinary and multi-institutional nearshore processes field data collection project called SUPERDUCK. The name SUPERDUCK derives from the location of CERC's Field Research Facility (FRF), the site of the experiment, which is located near the village of Duck, North Carolina, on the Outer Banks 
barrier islands (Figure 1). More than 50 researchers from CERC, other Government agencies, universities, and organizations from overseas participated in SUPERDUCK to conduct a wide variety of nearshore process investigations.

9. Patterned after the DUCK85 experiment, the SUPERDUCK project consisted of two parts: a September phase that took advantage of relatively low wave heights to perform labor-intensive experiments in the surf zone and an October phase that used primarily electronic instrumentation and remote sensing to measure storm-related nearshore processes. The surf zone sand transport data collection was performed in September as a self-contained program by CERC researchers with interest in measuring surf zone waves, currents, and sand transport.

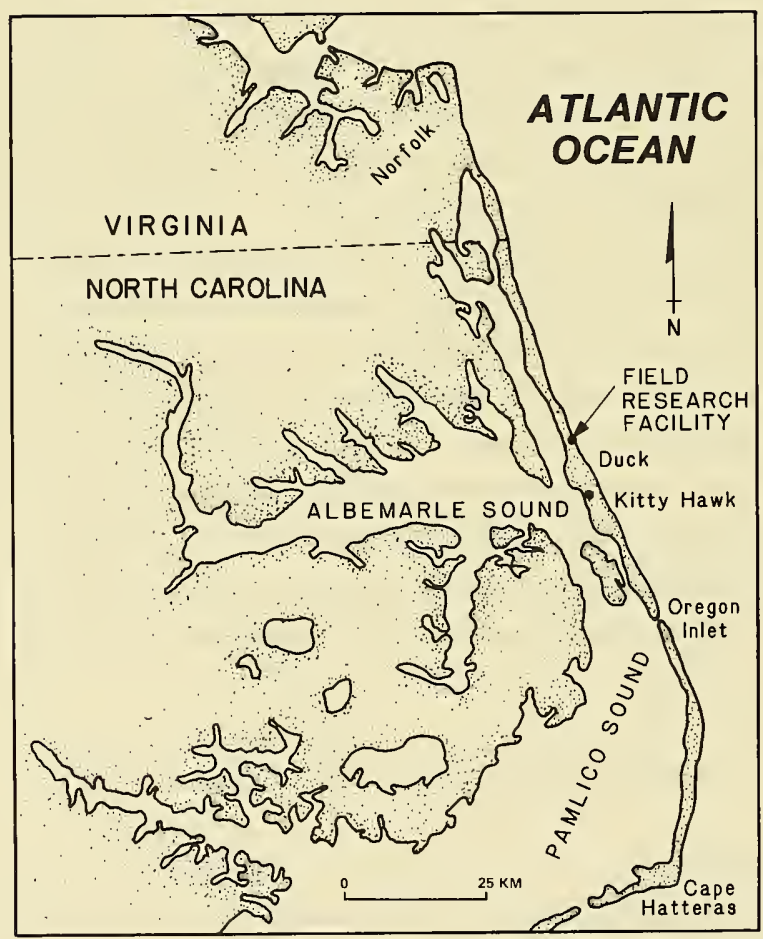

Figure 1. Location map for the FRF 
10. The CERC surf zone data collection effort benefitted from the extended coverage provided by experiments performed concurrently by other research teams, yielding data on beach profiles, offshore waves and currents, and wind. Reports describing results of SUPERDUCK experiments related to the work discussed here include: Birkemeier et al. (1989), a report describing instruments used and data collected at the FRF during both the September and October phases of the SUPERDUCK data collection project; Crowson et al. (1988), a summary report of the 30 different experiments conducted during both phases of SUPERDUCK; Ebersole and Hughes (in preparation), a companion data report describing the surf zone wave measurement method and results, conducted during the September phase; Stauble et al. (in preparation), a report discussing beach foreshore sediment and dynamics during the October phase of SUPERDUCK; Byrnes (1989), a data summary report of sediment characteristics during the October phase of SUPERDUCK; and Kraus, Gingerich, and Rosati (1988), revised values of the DUCK85 total transport rates and discussion of results from SUPERDUCK. Additional data are compiled in an FRF summary data report for September 1986 (FRF 1986). A video documenting the SUPERDUCK experiments was also produced (Hughes, Kraus, and Richardson 1987).

\section{$\underline{\text { Report Contents }}$}

11. An orientation to the study site and description of the experiment equipment, methodology, and analysis procedures are given in Part II. Selected results and characteristics of the data are presented in Part III, and a general evaluation of the field project is given in Part IV. Appendix A contains a listing of the data and explanatory discussion, and Appendix $B$ lists the notation used in this report. 


\section{Experiment Site}

12. Data collection activities were coordinated from a base camp established on the beach near the north property line of the FRF. Figure 2 provides a plan-view sketch of the base camp, FRF coordinate system, and the general physical arrangement of a typical data collection run (bathymetry measured on 23 September 1986). The area near the north property line was selected to avoid possible interference of waves, currents, and nearshore topography in the vicinity of the experiments with the 600-m-long FRF pier located approximately $950 \mathrm{~m}$ to the south. An air-conditioned trailer located behind the duneline provided a protected environment for data recorders and other sensitive instruments.

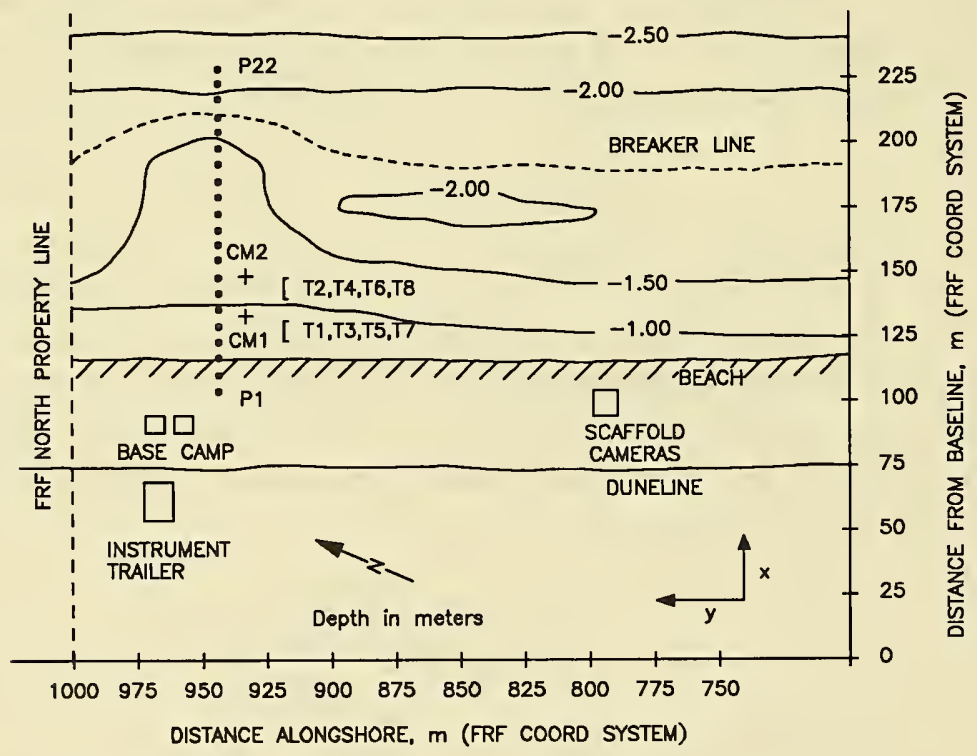

Figure 2. Base camp and typical data collection arrangement 
13. The surf zone data collection group consisted of approximately 15 members, and work was divided into four functional areas: sand trapping, measuring currents, measuring waves, and beach profile surveying. These labor-intensive experiments were performed under a range of wind sea and swell conditions with moderate wave heights. Figure 3 shows the energy-based significant wave height $\mathrm{H}_{\mathrm{mo}}$ and spectral peak period $\mathrm{T}_{\mathrm{p}}$ for 11 to 23 September measured at FRF pressure gage 191. Gage 191 is located at FRF longshore coordinate $990.4 \mathrm{~m}$ and cross-shore coordinate $914.4 \mathrm{~m}$, at a depth of $-7.77 \mathrm{~m}$ relative to National Geodetic Vertical Datum (NGVD), which at the FRF is related to the mean sea level (MSL) datum by $\operatorname{MSL}(m)=\operatorname{NGVD}(m)+0.067$. Tide elevation as recorded on a gage located at the end of the pier is also shown in Figure 3. During the 13 days of intensive data collection (11 to 23 September), $H_{m o}$ ranged from approximately 0.03 to $1.6 \mathrm{~m}$, and $T_{p}$ ranged from approximately 3 to $14 \mathrm{sec}$. During most of the project, waves were observed to arrive from slightly out of the southern quadrant, producing a longshore current moving to the north with a magnitude in the range of 0.1 to $0.7 \mathrm{~m} / \mathrm{sec}$. Table 1 summarizes the wind and offshore wave regime during the sand-trapping data collection period.

14. A small rip current is frequently located just north of the FRF property line. The data collection arrangement was designed to use the southern longshore feeder current of the rip as a dependable source of a steady and unidirectional longshore current when the direction of the current generated by oblique wave incidence became confused. The longshore sand transport rates and the current moving the sand were produced by combined oblique wave incidence and the rip feeder current. In comparisons made to theoretical expressions, it would be invalid to use predictive formulas for either the longshore current or the longshore sand transport rate that are solely functions of parameters related to obliquely incident waves.

\footnotetext{
* For convenience, symbols and abbreviations are listed in the Notation (Appendix B).
} 


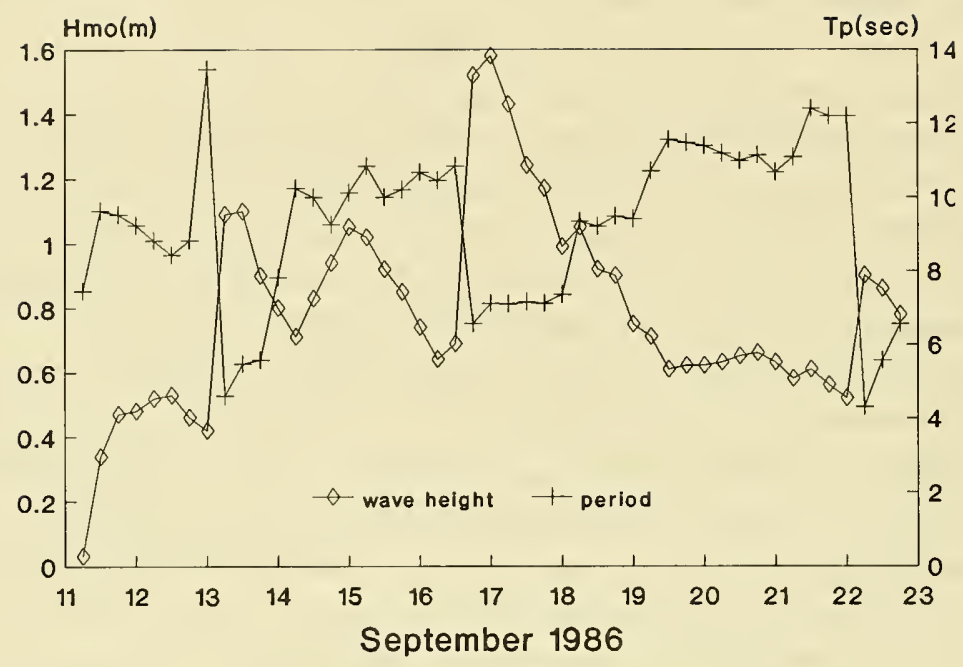

a. Wave height $H_{m o}$ and period $T_{p}$

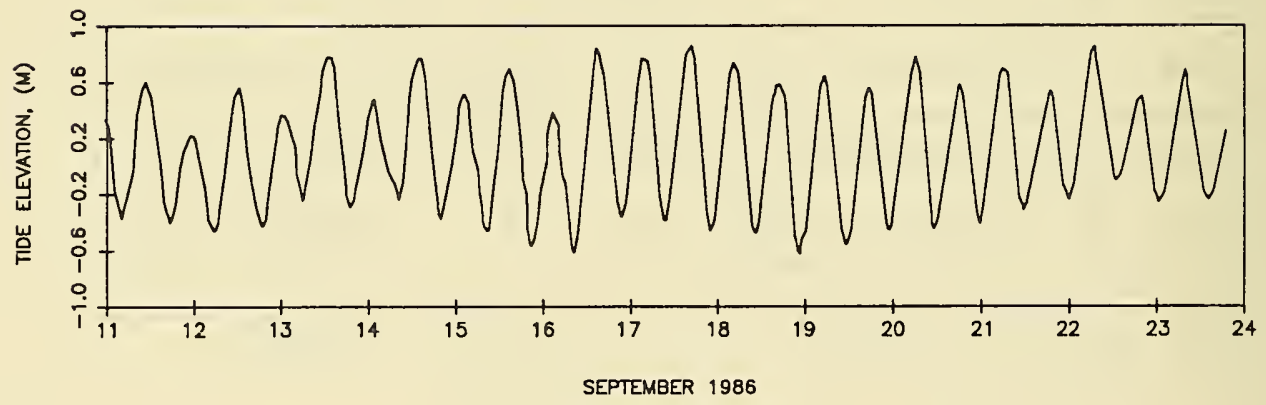

b. Water level

Figure 3. Wave height $H_{m o}$ and period $T_{p}$ measured at FRF gage 191, and water level recorded at the seaward end of the pier (NGVD datum) 
Table 1

Summary of Wind and Wave Conditions

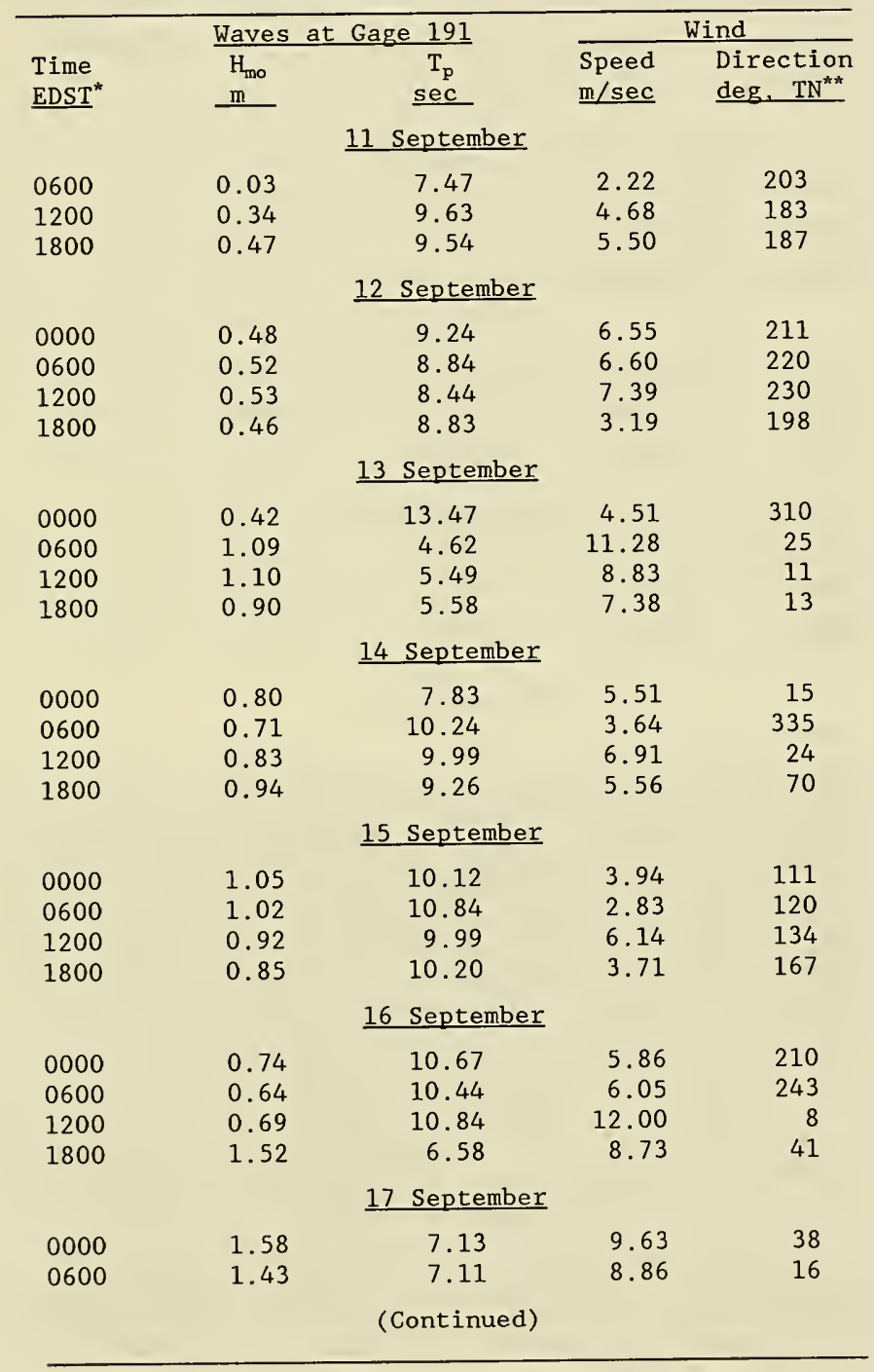

* EDST = Eastern Daylight Savings Time.

** TN $=$ True North (shoreline orientation $\mathrm{N} 20^{\circ} \mathrm{W}$ ). 
Table 1 (Concluded)

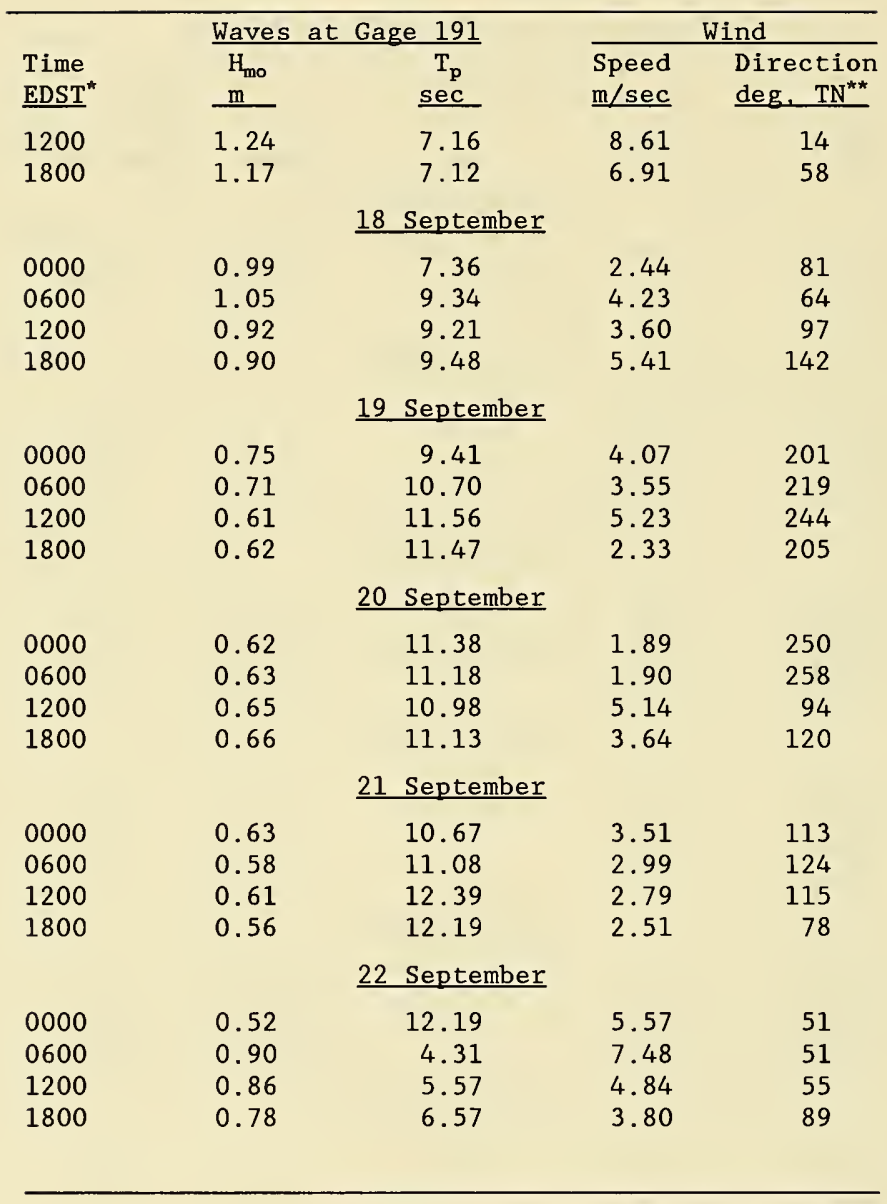

\section{Experiment Arrangement and Measurement Techniques}

Surf zone waves and water level

15. The wave height distribution across the surf zone was measured by filming the water surface elevation at 22 target poles made of stee1 pipe (numbered P1 to P22 in Figure 2) jetted into the sea bottom on a 1 ine crossing the surf zone. The poles were spaced at nominal 6-m intervals and painted 
black to contrast with the white foam on the water surface when reading the films. These poles, called "photopoles," each had two short rods placed horizontally near their top ends and were separated by a known distance (typically, $1 \mathrm{~m}$ ) to calibrate the wave height measurement. Figure 4 shows the photopole line during SUPERDUCK. Pairs of photopoles were filmed with six synchronized 16-mm professional-grade movie cameras mounted on a 4.5-m-high scaffold located on the beach about $125 \mathrm{~m}$ south of the photopole line. The cameras were run in the pulse mode at $5 \mathrm{~Hz}$ for a nominal duration of $12.5 \mathrm{~min}$ which included a sand trap run. Ebersole and Hughes (in preparation) describe the SUPERDUCK photopole experiments and results.

16. The bottom profile along the photopole line was surveyed each day by means of an infrared beam total survey station housed at the main building of the FRF. These surveys were supplemented by standard transit surveys performed from the base camp and by wide-area surveys taken by the CERC Coastal Research Amphibious Buggy (CRAB). Ebersole and Hughes (in preparation) and FRF (1986) present wide-area bathymetry data. Initially, the nearshore bathymetry in the vicinity of the base camp consisted of an alongshore trough

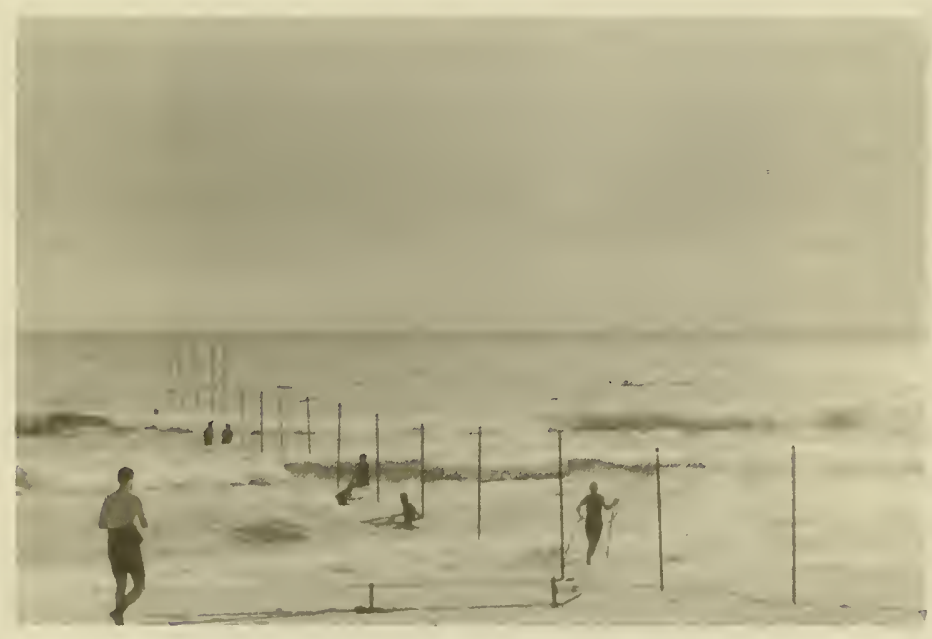

Figure 4. Photopole line spanning the surf zone 
and bar form, with a shallower area existing south of the photopole line and a deeper region just north of the photopoles. Spilling breakers mainly predominated in the south region, while plunging breakers occurred to the north. The bathymetry became smoother during the course of the data collection period, making the breaking wave conditions more uniform from north to south. The surf zone bottom consisted of a fine-grained sand substrate with a median grain size of $0.17 \mathrm{~mm}$.

17. The mean water level referenced to NGVD was obtained at 6-min intervals from a tide gage located at the seaward end of the FRF pier (Appen$\operatorname{dix} A$, Table A3). The maximum tidal variation observed during the project was approximately $1.4 \mathrm{~m}$ (Figure 3). Local mean water levels across the surf zone are tabulated in Ebersole and Hughes (in preparation) for individual data collection runs.

\section{Surf zone currents}

18. Water flow was measured with two 2-component Model 551 MarshMcBirney electromagnetic current meters. The meters were mounted on tripods and connected to shore by cable to recorders located in the instrument trailer. The tripods (Figure 5) were made of $1.9-\mathrm{cm}$ stainless steel rods and stood approximately $1.5 \mathrm{~m} \mathrm{high}$. The lower ends of the tripod legs were sunk into the bed to a depth of about $10 \mathrm{~cm}$ by shaking the tripod back and forth and applying downward pressure. A tripod with current meter attached was easily moved by two individuals, permitting its rapid relocation in the surf zone in response to varying tide level, wave conditions, and current characteristics. An adjustable collar on the tripod held the metal cylinder housing the meter electronics and preamplifier, allowing vertical adjustment of the current meter sensor. The flow meter sensor was placed 20 to $30 \mathrm{~cm}$ above the bed in all deployments. The horizontal axis of the current meter was aligned with its y-component parallel to the trend of the shoreline. The current meters sampled at $5 \mathrm{~Hz}$ and recorded for a 10- to 84-min period, depending on the length of the sand-trapping run.

\section{Data collection procedure}

19. Longshore sand transport rates were measured by means of portable traps such as shown in Figure 6. A schematic of the trap is given in Figure 7 with only two streamers shown for clarity. The sand collection element of the trap consisted of a metal frame or nozzle to which a cylindrical bag of 


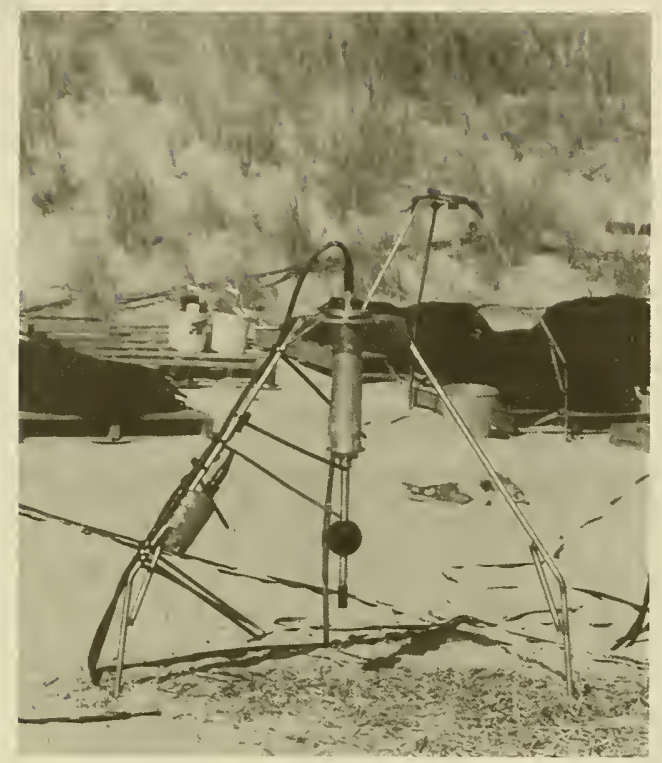

Figure 5. Current meter mount with meter installed

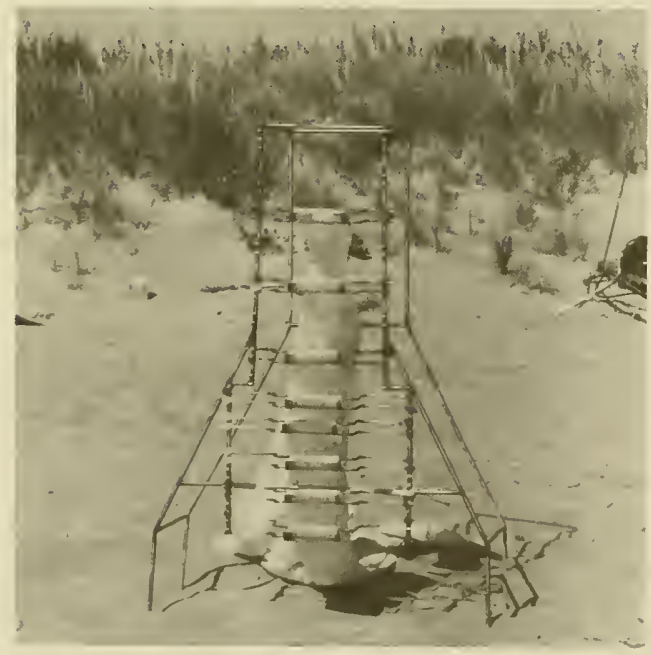

Figure 6. Streamer traps used at SUPERDUCK 


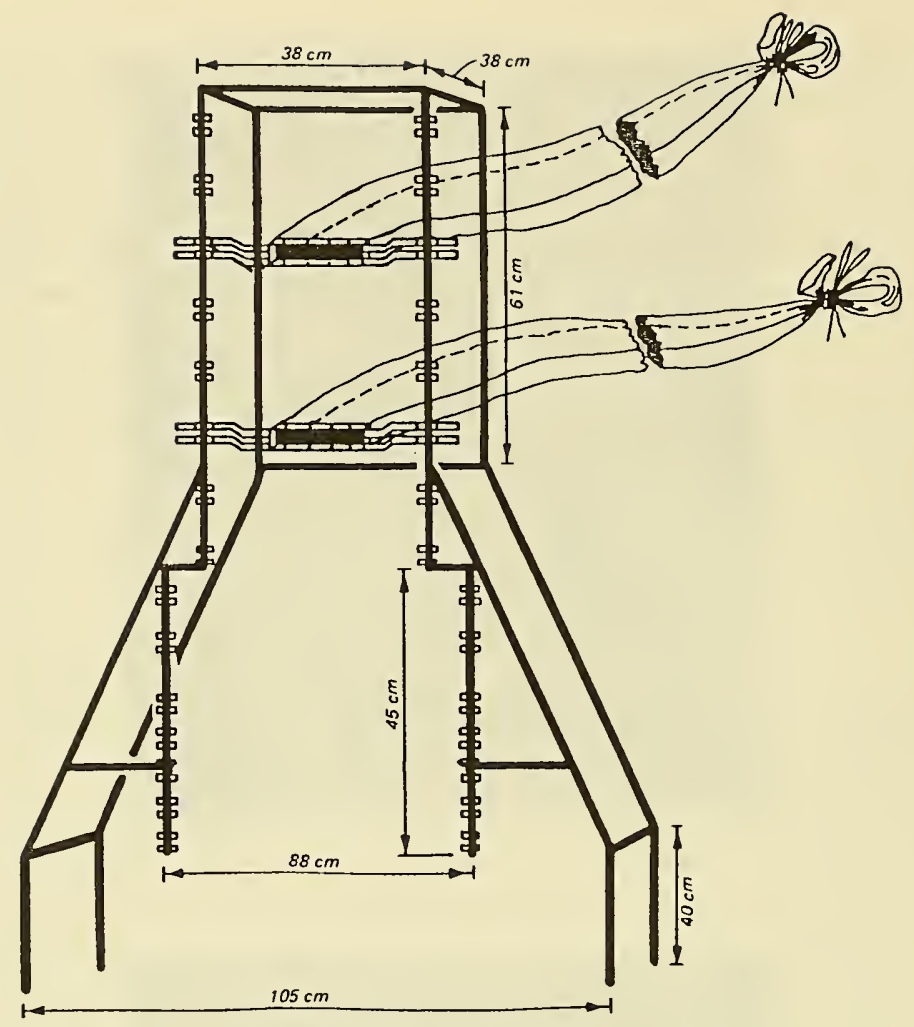

Figure 7. Schematic of the streamer trap rack

flexible filter cloth called a "streamer" was attached. Typically, seven to nine streamers were mounted vertically on stainless steel racks and pointed in the direction of flow. The polyester monofilament cloth allowed water to pass through but retained sediment of nominal diameter greater than the $0.105-\mathrm{mm}$ mesh, which encompasses sand in the fine grain size region and greater. Orifices of the nozzles were located upcurrent of the racks and any sediment clouds due to scour produced by the rack and trap operator. Observation during operation indicated that scoured sediment at the rack did not move upstream and into the streamers. Data collection was always performed in a unidirectional current so that the streamer never reversed direction, a situation which might cause collected sand to be lost. The concept of the streamer-type trapping device for use in the nearshore was introduced by 
Katori (1982, 1983). Development of the trap has continued at CERC, including mounting of the streamers on various types of racks (Kraus 1987) and optimization of the trap nozzle geometry (Rosati and Kraus 1988, 1989). Although the wide-base SUPERDUCK racks shown in Figures 6 and 7 were stable under relatively high waves, trap operators preferred the less awkward rectangular racks used at DUCK85 (see Kraus, Gingerich, and Rosati 1989).

20. The nozzles on the traps used at SUPERDUCK had a width of $15 \mathrm{~cm}$ and a height of $2.5 \mathrm{~cm}$, with a 9.5 -mm-thick stainless steel "hood" $5.1 \mathrm{~cm}$ in length (Figure 8). Nozzles were attached to the trap racks by 6.4-mm stainless steel mounting bars welded to the nozzles that were positioned in circular fasteners on the trap frame and secured in place with duct tape (Figure 7).

21. During the DUCK85 data collection project (Kraus, Gingerich, and Rosati 1989), highly favorable sea conditions characterized by "clean" swell with moderate wave heights facilitated extensive measurements of the variation of the longshore sand transport rate through the surf zone. Traps were positioned from near the shoreline to the breaker line, with two current meters located at representative locations in the surf zone, and sand transport was measured for 5 - and 10 -min periods. These measurements resulted in a highquality data set on the cross-shore distribution of the longshore sand transport rate, which could be integrated to obtain the total transport rate as a function of representative wave and current conditions. This method of measuring sand transport, in which traps are positioned across the surf zone, is referred to as the Spatial Sampling Method (SSM).

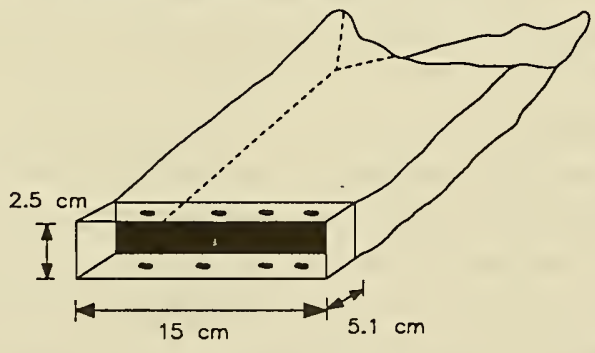

Figure 8. SUPERDUCK streamer nozzle 
22. Recognizing a need for more accurate prediction of sand transport at a point as a function of waves and currents at that position, a Temporal Sampling Method (TSM) was used during the SUPERDUCK experiment. In the TSM, one or two traps were repeatedly deployed at one or two points in the surf zone, with corresponding wave and current measurements made in the same region. If two traps were deployed in close proximity (about $1 \mathrm{~m}$ apart), an indication of reliability between two traps under similar hydrodynamic conditions was obtained, termed a "consistency test." The TSM runs resulted in high-quality measurements of the sand transport rate as a function of local waves and currents through time, at 5-min intervals for as long as an 84-min data collection period.

23. To measure the transport rate during a typical TSM run, two traps (denoted by symbols $\mathrm{T} 1$ and $\mathrm{T} 2$ in Figure 2) were carried to predetermined positions located updrift of current meters (denoted by symbols CM1 and CM2 in Figure 2), and referenced to the photopole line. Usually one person carried and operated one trap; however, two operators were necessary if surf zone conditions were rough or if the traps were positioned at the breaker line. At a signal, the racks were simultaneously thrust into the bed with the nozzles oriented into the longshore current. Horizontal bars along the bottom of two sides of the rack could be stepped on to bury the $40-\mathrm{cm}-1$ ong legs. At complete burial of the rack legs, the horizontal bars prevented further penetration of the legs and kept the lowermost streamer nozzle at the bed. During the course of a trap deployment (typically of 5- to 10-min duration), the trap operator would periodically step on the horizontal bars to keep the trap legs fully buried and to counter wave and current action, which would tend to tilt the trap shoreward and downstream, respectively. In weak longshore currents, the streamers would wrap around the vertical bars of the rack with passage of waves, requiring the trap operator to untangle them. In moderate to strong currents (greater than approximately $20 \mathrm{~cm} / \mathrm{sec}$ ), the streamers would fully extend in the flow and require little attention from the trap operator. Figure 9 shows the traps being deployed in a TSM run.

24. At the end of the first sampling period, a signal was given from the beach, and the two traps were pulled from the bed as the second set (denoted by the symbols T3 and T4 in Figure 2) was deployed at approximately the same locations in the surf zone. The first two traps were lifted above 


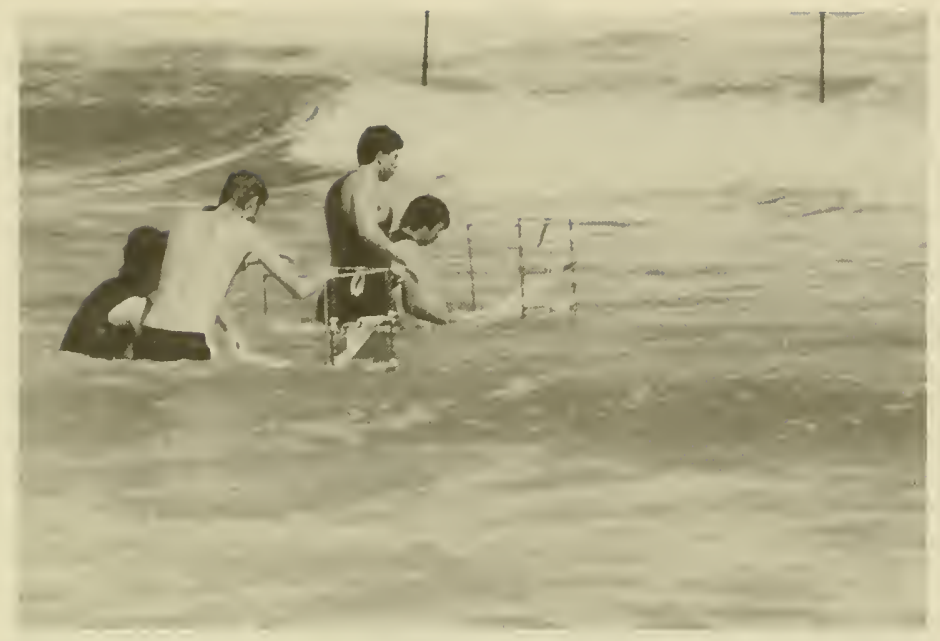

Figure 9. Streamer traps deployed in a TSM run

the water and brought to shore (Figure 10), and collected sand was washed from the streamers with seawater into small patches of filter cloth. The sand sample and cloth (of known weight when wet) were weighed in the drip-free condition (Kraus and Nakashima 1986). Samples from all traps from one run per day were retained for drying and grain size analysis in the laboratory. The dry weights obtained allowed calibration of the drip-free to dry weight conversion factor. Deployment of trap pairs continued (denoted by the symbols T5 through $\mathrm{T} 8$ in Figure 2) for data collection periods from 23 to 84 min in length.

25. Between experiment runs, the trapped sand weights were plotted to understand qualitative aspects of the transport conditions and to design the next series of runs, such as positioning of traps and length of temporal sampling. For example, from inspection of the transport rate distribution through the water column, a supporting cross-bar on the trap frame was found to partially block sand transport into the second streamer above the bed. During succeeding data collection, the second streamer was positioned away from the cross-bar, eliminating the problem. The capability to analyze the 


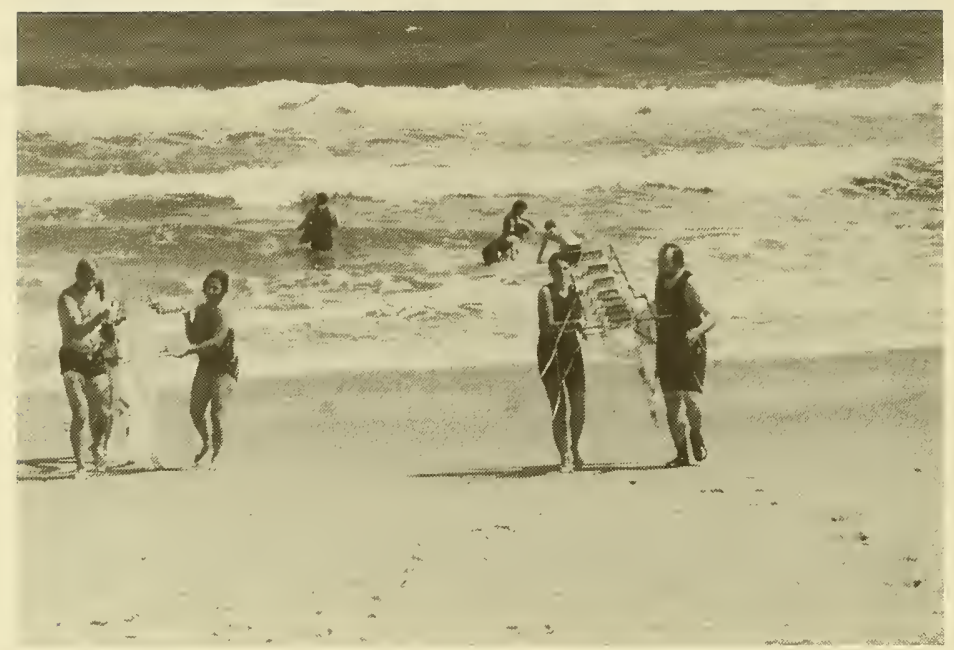

Figure 10. Traps being removed from the surf zone

transport rate data onsite is considered one of the important advantages of using traps, enabling a quality control check on trap operation and early interpretation of results for adjustment of experimental design.

\section{Transport Rate Analysis}

26. Procedures for calculating transport rates from the raw data are described in this section. The streamers measure a sand flux, i.e., the weight of sand passing through the nozzle of a certain cross-sectional area during the sampling interval. If sampling is performed in a unidirectional flow, as was the case in these experiments, no sand coarser than $0.105 \mathrm{~mm}$ is lost once it has entered the streamer, and the flux can be directly associated with the current to develop predictive empirical relations. The raw data of sand weight collected in the streamers are listed in Table Al of Appendix A. 
27. The flux of sand $F$ at streamer $k$ is given by

$$
F(k)=\frac{S(k)}{\Delta h \Delta w \Delta t}
$$

in which

$$
\begin{aligned}
F= & \text { sand flux, } \mathrm{kg} /\left(\mathrm{m}^{2}-\mathrm{sec}\right) \\
k= & \text { streamer number, increasing in order from the bottom }(\mathrm{k}=1) \\
& \text { to the last streamer }(\mathrm{k}=\mathrm{N}) \\
S= & \text { dry weight of sand, } \mathrm{kg} \text { (force) } \\
\Delta h= & \text { height of streamer nozzle }(0.025 \mathrm{~m} \text { for SUPERDUCK) } \\
\Delta w= & \text { width of streamer nozzle }(0.15 \mathrm{~m} \text { for SUPERDUCK) } \\
\Delta t= & \text { sampling time interval, sec }
\end{aligned}
$$

The flux between adjacent streamers $F E(k)$ can be estimated by linear interpolation using adjacent measured values

$$
F E(k)=0.5[F(k)+F(k+1)]
$$

28. The total transport rate per unit width $i$ at a particular trap is calculated by using the determined fluxes and distances $\Delta a(k)$ between nozzles,

$$
i=\Delta h \sum_{k=1}^{N} F(k)+\sum_{k=1}^{N} \Delta a(k) F E(k)
$$

in which $N$ is the total number of streamers on the trap. The first summation term represents the actual measured fluxes, and the second summation term represents the interpolated fluxes between nozzles. If traps were placed on a line across the surf zone (SSM), transport rates per unit width were calculated with Equation 3, and the trapezoid rule was used to compute the total longshore sand transport rate across the surf zone. Elevations of the streamers above the bed are listed in Table A2 of Appendix A.

29. Sand-trapping efficiency tests in uniform flow were performed in a series of experiments (Rosati and Kraus 1989) for nozzle configurations which had near-optimal hydraulic efficiencies (Rosati and Kraus 1988), including the DUCK85 and SUPERDUCK nozzles. It was found that the SUPERDUCK nozzle had a 
sand-trapping efficiency near unity (1.02 \pm 0.03$)$ for suspended sand, but a lower efficiency for a nozzle resting on the bed $(0.68 \pm 0.31)$. Sand fluxes presented herein have been corrected for bottom nozzle efficiency by dividing the quantity of sand obtained by the bed-load trapping efficiency. Sand fluxes were not modified for the suspended nozzles, as the efficiency value for these nozzles is nearly unity.

30. The lower value $(0.68 \pm 0.31)$ of the bed-load trapping efficiency (which includes suspended load within $2.5 \mathrm{~cm}$ of the bottom) is caused by scour and the scour hole created under the nozzle that was occasionally observed to occur during portions of the testing period. The actual efficiency of the streamer trap in intersecting oscillatory and quasi-steady uniform flow in the surf zone is not known, but qualitative evaluation using field observations indicates that efficiencies in the surf zone are similar to those determined in the uniform flow tank under sheet flow conditions. 


\section{PART III: RESULTS}

31. This chapter lists and explains the principal data on transport rates, currents, and waves obtained in the September phase surf zone experiments at SUPERDUCK. Selected results are also presented to introduce the characteristics and potential uses of the data set.

\section{Orientation to the Measurement Runs}

32. Four types of sand transport rate data collection runs were performed using the traps:

a. Measurement of the temporal distribution of the longshore sand transport rate at one or two points in the surf zone (TSM run).

b. Measurement of the cross-shore distribution of the longshore sand transport rate (SSM run).

c. Measurement of transport rates at neighboring locations (typically $1 \mathrm{~m}$ apart) (consistency test).

d. Measurement of the transport rate in a rip current.

Seven to nine streamers mounted on the racks provided the vertical distribution of the sand flux.

33. Data collection runs documented in this report are listed in Table 2. Each run is assigned a number, as shown in the first column, which uniquely identifies it by the date and time the sampling was conducted. The concatenation of numbers comprising a run identification (ID) gives the year (86), month (9), day (11 to 23), and start time of the run in EDST as hours and minutes on a 24-hr clock. Current velocity and wave measurement (photopole) ID numbers are similarly defined. Current meters and movie cameras were often started a minute or two before the corresponding sand trap run began. Trap and current meter deployment intervals and locations in the surf zone relative to the photopole line are given in Table 3 , and locations of the photopoles in the FRF coordinate system are presented in Table A4. 
Table 2

Summary of Surf Zone Sand Trap Data and Tide Condition

\begin{tabular}{lllll}
\hline Run ID No. & Time, EDST & Data Collection & No. Traps & Tide \\
$8609111745^{*}$ & $1745-1755$ & SSM & 6 & Falling \\
8609121037 & $1037-1047$ & Rip Current & 6 & Low \\
$8609151345^{*}$ & $1345-1408$ & TSM & 3 pairs & Rising \\
$8609151630^{*}$ & $1630-1654$ & TSM & 3 & Rising \\
8609160922 & $0922-0932$ & Consistency & 1 pair & Falling \\
$8609160945^{*}$ & $0945-0955$ & Consistency & 1 pair & Falling \\
$8609161116^{*}$ & $1116-1126$ & SSM & 10 & Falling \\
$8609181225^{*}$ & $1225-1249$ & TSM & 4 pairs & Falling \\
$8609181453^{*}$ & $1453-1524$ & TSM & 5 pairs & Falling \\
$8609191016^{*}$ & $1016-1026$ & SSM & 6 & High \\
8609191230 & $1230-1254$ & TSM & 4 pairs & Falling \\
$8609201045^{*}$ & $1045-1133$ & TSM & 8 & High \\
$8609201500^{*}$ & $1500-1548$ & TSM (incl 2 & 10 & Low \\
8609211046 & $1046-1056$ & Consistency & 1 pair & High \\
8609211345 & $1345-1509$ & $\begin{array}{l}\text { TSM (inc1 2 } \\
\text { consistency) }\end{array}$ & 16 & Falling \\
8609220730 & $10730-0810$ & TSM & 5 pairs & Rising \\
8609221600 & $1600-1625$ & TSM & 10 & Low \\
8609221750 & $1750-1756$ & SSM & 5 & Rising
\end{tabular}

* Complete or partial wave data set presently available (presented herein or by Ebersole and Hughes (in preparation)). 
Table 3

Times and Locations of Trap and Current Meter Deployments

\begin{tabular}{|c|c|c|c|}
\hline Run ID No. & $\begin{array}{l}\text { Trap/Current } \\
\text { Meter Number }\end{array}$ & $\begin{array}{l}\text { Time } \\
\text { EDST }\end{array}$ & $\begin{array}{l}\text { Approximate Location } \\
\text { Relative to Photopoles }\end{array}$ \\
\hline 8609111745 & $\begin{array}{l}\text { T1 } \\
\text { T2 } \\
\text { T3 } \\
\text { T4 } \\
\text { T5 } \\
\text { T6 }\end{array}$ & $1745-1755$ & $\begin{array}{l}\text { P4-P5*, north of photopoles } \\
\text { P7-P8, north of photopoles } \\
\text { P8-P9, north of photopoles } \\
\text { P9-P10, north of photopoles } \\
\text { P11-P12, north of photopoles } \\
\text { P13-P14, north of photopoles }\end{array}$ \\
\hline 8609121037 & $\begin{array}{l}\text { T1 } \\
\text { T2 } \\
\text { T3 } \\
\text { T4 } \\
\text { T5 } \\
\text { T6 }\end{array}$ & $1037-1047$ & $\begin{array}{l}45 \mathrm{~m} \text { offshore, rip throat } \\
30 \mathrm{~m} \text { offshore, rip throat } \\
23 \mathrm{~m} \text { offshore, rip throat } \\
5 \mathrm{~m} \text { offshore, north feeder } \\
15 \mathrm{~m} \text { offshore, rip throat } \\
9 \mathrm{~m} \text { offshore, south feeder }\end{array}$ \\
\hline 8609151345 & $\begin{array}{l}\text { T1 } \\
\text { T2 } \\
\text { T3 } \\
\text { T4 } \\
\text { T5 } \\
\text { T6 } \\
\text { CM1 } \\
\text { CM2 }\end{array}$ & $\begin{array}{l}1345-1352 \\
1345-1352 \\
1352-1400 \\
1352-1400 \\
1400-1408 \\
1400-1408 \\
1345-1408 \\
1345-1408\end{array}$ & $\begin{array}{l}\text { P6-P7, south of photopoles } \\
\text { P6-P7, north of photopoles } \\
\text { P6-P7, south of photopoles } \\
\text { P6-P7, north of photopoles } \\
\text { P6-P7, south of photopoles } \\
\text { P6-P7, north of photopoles } \\
\text { P6-P7, south of photopoles } \\
\text { P6-P7, north of photopoles }\end{array}$ \\
\hline 8609151630 & $\begin{array}{l}\text { T3 } \\
\text { T5 } \\
\text { T7 } \\
\text { CM1 } \\
\text { CM2 }\end{array}$ & $\begin{array}{l}1630-1638 \\
1638-1646 \\
1646-1654 \\
1630-1654 \\
1630-1654\end{array}$ & $\begin{array}{l}\text { P3-P4, south of photopoles } \\
\text { P3-P4, south of photopoles } \\
\text { P3-P4, south of photopoles } \\
\text { P4, south of photopoles } \\
\text { P4, north of photopoles }\end{array}$ \\
\hline 8609160922 & $\begin{array}{l}\text { T1 } \\
\text { T2 } \\
\text { CM1 }\end{array}$ & $\begin{array}{l}0922-0932 \\
0922-0932 \\
0922-0932\end{array}$ & $\begin{array}{l}\text { P7-P8, south of photopoles } \\
\text { P7-P8, south of photopoles } \\
\text { P7, south of photopoles }\end{array}$ \\
\hline 8609160945 & $\begin{array}{l}\text { T8 } \\
\text { T9 } \\
\text { CM1 }\end{array}$ & $\begin{array}{l}0945-0955 \\
0945-0955 \\
0945-0955\end{array}$ & $\begin{array}{l}\text { P8-P9, south of photopoles } \\
\text { P8-P9, south of photopoles } \\
\text { P8, south of photopoles }\end{array}$ \\
\hline
\end{tabular}

The notation P4-P5 indicates that trap was located midway between photopoles $\mathrm{P} 4$ and $\mathrm{P} 5$.

(Sheet 1 of 5 ) 
Table 3 (Continued)

\begin{tabular}{|c|c|c|c|}
\hline Run ID No. & $\begin{array}{l}\text { Trap/Current } \\
\text { Meter Number }\end{array}$ & $\begin{array}{l}\text { Time } \\
\text { EDST }\end{array}$ & $\begin{array}{l}\text { Approximate Location } \\
\text { Relative to Photopoles }\end{array}$ \\
\hline 8609161116 & $\begin{array}{l}\text { T1 } \\
\text { T2 } \\
\text { T3 } \\
\text { T4 } \\
\text { T5 } \\
\text { T6 } \\
\text { T7 } \\
\text { T8 } \\
\text { T9 } \\
\text { T10 } \\
\text { CM1 } \\
\text { CM2 }\end{array}$ & $1116-1126$ & $\begin{array}{l}\text { P6-P7, north of photopoles } \\
\text { P7-P8, north of photopoles } \\
\text { P8-P9, north of photopoles } \\
\text { P9-P10, north of photopoles } \\
\text { P10-P11, north of photopoles } \\
\text { P11-P12, north of photopoles } \\
\text { P12-P13, north of photopoles } \\
\text { P13-P14, north of photopoles } \\
\text { P14-P15, north of photopoles } \\
\text { P15-P16, north of photopoles } \\
\text { P9, south of photopoles } \\
\text { P12, south of photopoles }\end{array}$ \\
\hline 8609181225 & $\begin{array}{l}\text { T1 } \\
\text { T2 } \\
\text { T3 } \\
\text { T4 } \\
\text { T5 } \\
\text { T6 } \\
\text { T7 } \\
\text { T8 } \\
\text { CM1 } \\
\text { CM2 }\end{array}$ & $\begin{array}{l}1225-1231 \\
1225-1231 \\
1231-1237 \\
1231-1237 \\
1237-1243 \\
1237-1243 \\
1243-1249 \\
1243-1249 \\
1225-1249 \\
1225-1249\end{array}$ & $\begin{array}{l}\text { P6, south of photopoles } \\
\text { P8, south of photopoles } \\
\text { P6, south of photopoles } \\
\text { P8, south of photopoles } \\
\text { P6, south of photopoles } \\
\text { P8, south of photopoles } \\
\text { P6, south of photopoles } \\
\text { P8, south of photopoles } \\
\text { P6, south of photopoles } \\
\text { P8, south of photopoles }\end{array}$ \\
\hline 8609181453 & $\begin{array}{l}\text { T1 } \\
\text { T2 } \\
\text { T3 } \\
\text { T4 } \\
\text { T5 } \\
\text { T6 } \\
\text { T7 } \\
\text { T8 } \\
\text { T9 } \\
\text { T10 } \\
\text { CM1 } \\
\text { CM2 }\end{array}$ & $\begin{array}{l}1453-1459 \\
1453-1459 \\
1459-1505 \\
1459-1505 \\
1505-1511 \\
1505-1511 \\
1511-1518 \\
1511-1518 \\
1518-1524 \\
1518-1524 \\
1453-1524 \\
1453-1524\end{array}$ & $\begin{array}{l}\text { P7, south of photopoles } \\
\text { P9, south of photopoles } \\
\text { P7, south of photopoles } \\
\text { P9, south of photopoles } \\
\text { P7, south of photopoles } \\
\text { P9, south of photopoles } \\
\text { P7, south of photopoles } \\
\text { P9, south of photopoles } \\
\text { P7, south of photopoles } \\
\text { P9, south of photopoles } \\
\text { P7, south of photopoles } \\
\text { P9, south of photopoles }\end{array}$ \\
\hline 8609191016 & $\begin{array}{l}\text { T3 } \\
\text { T4 } \\
\text { T5 } \\
\text { T6 }\end{array}$ & $1016-1026$ & $\begin{array}{l}\text { P4-P5, south of photopoles } \\
\text { P1-P2, south of photopoles } \\
\text { P2-P3, south of photopoles } \\
\text { P3-P4, south of photopoles }\end{array}$ \\
\hline
\end{tabular}

(Continued)

(Sheet 2 of 5 ) 
Table 3 (Continued)

\begin{tabular}{|c|c|c|c|}
\hline Run ID No. & $\begin{array}{l}\text { Trap/Current } \\
\text { Meter Number }\end{array}$ & $\begin{array}{l}\text { Time } \\
\text { EDST }\end{array}$ & $\begin{array}{c}\text { Approximate Location } \\
\text { Relative to Photopoles }\end{array}$ \\
\hline 8609191016 & $\begin{array}{l}\text { T9 } \\
\text { T10 } \\
\text { CM1 } \\
\text { CM2 }\end{array}$ & $\left.\right|_{v} ^{1016-1026}$ & $\begin{array}{l}\text { P5-P6, south of photopoles } \\
\text { P6-P7, south of photopoles } \\
\text { P5, south of photopoles } \\
\text { P7, south of photopoles }\end{array}$ \\
\hline 8609191230 & $\begin{array}{l}\text { T1 } \\
\text { T2 } \\
\text { T3 } \\
\text { T4 } \\
\text { T5 } \\
\text { T6 } \\
\text { T7 } \\
\text { T8 } \\
\text { CM1 } \\
\text { CM2 }\end{array}$ & $\begin{array}{l}1230-1236 \\
1230-1236 \\
1236-1242 \\
1236-1242 \\
1242-1248 \\
1242-1248 \\
1248-1254 \\
1248-1254 \\
1243-1254 \\
1243-1254\end{array}$ & $\begin{array}{l}\text { P6, south of photopoles } \\
\text { P7-P8, south of photopoles } \\
\text { P6, south of photopoles } \\
\text { P7-P8, south of photopoles } \\
\text { P6, south of photopoles } \\
\text { P7-P8, south of photopoles } \\
\text { P6, south of photopoles } \\
\text { P7-P8, south of photopoles } \\
\text { P6, south of photopoles } \\
\text { P7-P8, south of photopoles }\end{array}$ \\
\hline 8609201045 & $\begin{array}{l}\text { T1 } \\
\text { T2 } \\
\text { T3 } \\
\text { T4 } \\
\text { T5 } \\
\text { T6 } \\
\text { T7 } \\
\text { T8 } \\
\text { CM1 } \\
\text { CM2 }\end{array}$ & $\begin{array}{l}1045-1051 \\
1051-1057 \\
1057-1103 \\
1103-1109 \\
1109-1115 \\
1115-1121 \\
1121-1127 \\
1127-1133 \\
1045-1133 \\
1045-1133\end{array}$ & P5-P6, south of photopoles \\
\hline 8609201500 & $\begin{array}{l}\text { T1 } \\
\text { T2 } \\
\text { T3 } \\
\text { T4 } \\
\text { T5 } \\
\text { T6 } \\
\text { T7 } \\
\text { T8 } \\
\text { T9 } \\
\text { T10 } \\
\text { CM1 } \\
\text { CM2 }\end{array}$ & $\begin{array}{l}1500-1506 \\
1506-1512 \\
1512-1518 \\
1518-1524 \\
1524-1530 \\
1530-1536 \\
1536-1542 \\
1536-1542 \\
1542-1548 \\
1542-1548 \\
1500-1548 \\
1500-1548\end{array}$ & $\begin{array}{l}\text { P8, south of photopoles } \\
\text { P9, south of photopoles }\end{array}$ \\
\hline
\end{tabular}

(Continued) 
Table 3 (Continued)

\begin{tabular}{|c|c|c|c|}
\hline Run ID No. & $\begin{array}{l}\text { Trap/Current } \\
\text { Meter Number }\end{array}$ & $\begin{array}{l}\text { Time } \\
\text { EDST }\end{array}$ & $\begin{array}{c}\text { Approximate Location } \\
\text { Relative to Photopoles }\end{array}$ \\
\hline 8609211046 & $\begin{array}{l}\text { T1 } \\
\text { T2 } \\
\text { CM1 } \\
\text { CM2 }\end{array}$ & $\left.\right|_{i} ^{1046-1056}$ & $\begin{array}{l}\text { P6, south of photopoles } \\
\text { P6, south of photopoles } \\
\text { P5-P6, south of photopoles } \\
\text { P5-P6, south of photopoles }\end{array}$ \\
\hline 8609211345 & $\begin{array}{l}\text { T1 } \\
\text { T2 } \\
\text { T3 } \\
\text { T4 } \\
\text { T5 } \\
\text { T6 } \\
\text { T7 } \\
\text { T8 } \\
\text { T9 } \\
\text { T10 } \\
\text { T11 } \\
\text { T12 } \\
\text { T13 } \\
\text { T14 } \\
\text { T15 } \\
\text { T16 } \\
\text { CM1 } \\
\text { CM2 }\end{array}$ & $\begin{array}{l}1345-1351 \\
1351-1357 \\
1357-1403 \\
1403-1409 \\
1403-1409 \\
1409-1415 \\
1415-1421 \\
1415-1421 \\
1421-1427 \\
1427-1433 \\
1433-1439 \\
1439-1445 \\
1445-1451 \\
1451-1457 \\
1457-1503 \\
1503-1509 \\
1345-1509 \\
1345-1509\end{array}$ & $\begin{array}{l}\text { P8, south of photopoles } \\
\text { P9, south of photopoles }\end{array}$ \\
\hline 8609220730 & $\begin{array}{l}\text { T1 } \\
\text { T2 } \\
\text { T3 } \\
\text { T4 } \\
\text { T5 } \\
\text { T6 } \\
\text { T7 } \\
\text { T8 } \\
\text { CM1 } \\
\text { CM2 }\end{array}$ & $\begin{array}{l}0730-0735 \\
0735-0740 \\
0740-0745 \\
0745-0750 \\
0750-0755 \\
0755-0800 \\
0800-0805 \\
0805-0810 \\
0730-0810 \\
0730-0810\end{array}$ & $\begin{array}{l}\text { P7, south of photopoles } \\
\text { P9, south of photopoles } \\
\text { P7, south of photopoles } \\
\text { P9, south of photopoles } \\
\text { P7, south of photopoles } \\
\text { P9, south of photopoles } \\
\text { P7, south of photopoles } \\
\text { P9, south of photopoles } \\
\text { P7, south of photopoles } \\
\text { P9, south of photopoles }\end{array}$ \\
\hline 8609221600 & $\begin{array}{l}\text { T1 } \\
\text { T2 } \\
\text { T3 } \\
\text { T4 } \\
\text { T5 } \\
\text { T6 } \\
\text { T7 }\end{array}$ & $\begin{array}{l}1600-1605 \\
1600-1605 \\
1605-1610 \\
1605-1610 \\
1610-1615 \\
1610-1615 \\
1615-1620\end{array}$ & P5-P6, south of photopoles \\
\hline
\end{tabular}

(Continued) 
Table 3 (Concluded)

\begin{tabular}{|c|c|c|c|}
\hline Run ID No. & $\begin{array}{l}\text { Trap/Current } \\
\text { Meter Number }\end{array}$ & $\begin{array}{l}\text { Time } \\
\text { EDST } \\
\end{array}$ & $\begin{array}{l}\text { Approximate Location } \\
\text { Relative to Photopoles }\end{array}$ \\
\hline 8609221600 & $\begin{array}{l}\text { T8 } \\
\text { T9 } \\
\text { T10 } \\
\text { CM1 } \\
\text { CM2 }\end{array}$ & $\begin{array}{l}1615-1620 \\
1620-1625 \\
1620-1625 \\
1600-1625 \\
1600-1625\end{array}$ & $\begin{array}{l}\text { P5-P6, south of photopoles } \\
\text { P5-P6, south of photopoles } \\
\text { P5-P6, south of photopoles } \\
\text { P5, south of photopoles } \\
\text { P6, south of photopoles }\end{array}$ \\
\hline 8609221750 & $\begin{array}{l}\text { T1 } \\
\text { T2 } \\
\text { T3 } \\
\text { T4 } \\
\text { T5 } \\
\text { T6 } \\
\text { T7 } \\
\text { T8 } \\
\text { T9 } \\
\text { T10 } \\
\text { CM1 } \\
\text { CM2 }\end{array}$ & $1750-1756$ & $\begin{array}{l}\text { P5, south of photopoles } \\
\text { P6, south of photopoles } \\
\text { P7, south of photopoles } \\
\text { P8, south of photopoles } \\
\text { P9, south of photopoles } \\
\text { P10, south of photopoles } \\
\text { P11, south of photopoles } \\
\text { P12, south of photopoles } \\
\text { P13, south of photopoles } \\
\text { P14, south of photopoles } \\
\text { P7, south of photopoles } \\
\text { P9, south of photopoles }\end{array}$ \\
\hline 8609231035 & $\begin{array}{l}\text { T1 } \\
\text { T2 } \\
\text { T3 } \\
\text { T4 } \\
\text { T5 } \\
\text { CM1 } \\
\text { CM2 }\end{array}$ & $\begin{array}{l}1035-1040 \\
1040-1045 \\
1045-1050 \\
1050-1055 \\
1055-1100 \\
1035-1100 \\
1035-1100\end{array}$ & $\begin{array}{c}\text { P4, south of photopoles } \\
\text { P5, south of photopoles }\end{array}$ \\
\hline
\end{tabular}

(Sheet 5 of 5 )

\section{Temporal Sampling Method (TSM)}

34. Emphasis was placed on measurement of the temporal distribution of the longshore transport rate at one or two points in the surf zone during SUPERDUCK. In measuring the temporal behavior of the transport rate, the vertical distribution of the sand flux was obtained at each trap. Eleven TSM runs were conducted. Complete wave and current data are presently available for six runs conducted on 15, 18, and 20 September.

Cross-shore measurement (SSM)

35. Four runs were conducted to measure the cross-shore distribution of the longshore sand transport rate, three with a northerly directed longshore 
current and one with a southerly directed current. Complete photopole and current data sets are available for two runs (only photopole data are available for Run 8609111745).

\section{Consistency tests}

36. Consistency tests were performed to compare collected quantities of sand from traps placed in close proximity to each other. These tests were used as an indicator of trap reproducibility and reliability in the field. In the consistency tests, two traps were placed in the surf zone approximately $1 \mathrm{~m}$ apart. The seaward trap was located a distance sufficiently downdrift of the shoreward trap (typically, about $1 \mathrm{~m}$ ) so that sand scoured from the seaward trap and transported shoreward with the incoming waves would not be collected by the shoreward trap. Consistency testing was conducted as a part of several TSM runs by deploying trap pairs. Waves and currents were measured during consistency tests, and all current meter data have been analyzed; however, wave data sets are only available for TSM Run 8609201500 (includes two consistency tests) and Consistency Run 8609160945 (partial wave data set) (see Ebersole and Hughes, in preparation).

\section{Rip current measurement}

37. An experiment was performed on 12 September with the objective of measuring sand transport in the rip current located near the north FRF property line. Two traps were placed in the south longshore feeder current of the rip, one trap in the north feeder current, and three traps in the throat of the rip. Streamers on traps placed in the strong offshore current flow in the rip throat extended seaward, directly against the incident waves. Neither current nor wave data are available for the rip current run.

\section{Currents}

38. The two current meters bracketed the deployed traps, and were placed slightly down-current. The meters were moved as necessary as trap deployment location changed with the tide. The basic processed current speed data (mean and standard deviation) are given in Table 4 for 17 runs. Columns in Table 4 represent $x$ - and $y$-components of the current in the experiment coordinate system, for the meters 1 and 2 . The $x$-axis points offshore 
Table 4

Surf Zone Current Measurements

Current Speed, $\mathrm{m} / \mathrm{sec}$

\begin{tabular}{|c|c|c|c|c|c|c|c|c|}
\hline \multirow{2}{*}{$\begin{array}{c}\text { Time } \\
\text { EDST }\end{array}$} & \multicolumn{2}{|c|}{ CY1 } & \multicolumn{2}{|c|}{$\mathrm{CX1}$} & \multicolumn{2}{|c|}{ CY2 } & \multicolumn{2}{|c|}{$\mathrm{CX} 2$} \\
\hline & Mean & $\sigma_{\mathrm{v}}$ & Mean & $\sigma_{\mathrm{v}}$ & Mean & $\sigma_{\mathrm{v}}$ & Mean & $\sigma_{\mathrm{v}}$ \\
\hline \multicolumn{9}{|c|}{ Run 8609151345} \\
\hline \multirow{2}{*}{$\begin{array}{l}1345-135 \\
1353-140 \\
1401-140\end{array}$} & 0.283 & 0.239 & -0.019 & 0.429 & 0.244 & 0.186 & -0.015 & 0.413 \\
\hline & 0.275 & 0.203 & -0.033 & 0.506 & 0.207 & 0.211 & -0.017 & 0.445 \\
\hline $1401-1408$ & 0.343 & 0.233 & -0.061 & 0.468 & 0.241 & 0.189 & -0.036 & 0.406 \\
\hline \multicolumn{9}{|c|}{ Run 8609151630} \\
\hline \multirow{3}{*}{$\begin{array}{l}1630-1638 \\
1639-1646 \\
1647-1654\end{array}$} & 0.540 & 0.336 & -0.242 & 0.707 & 0.564 & 0.234 & -0.162 & 0.668 \\
\hline & 0.577 & 0.370 & -0.259 & 0.764 & 0.523 & 0.237 & -0.173 & 0.659 \\
\hline & 0.620 & 0.325 & -0.273 & 0.767 & 0.576 & 0.240 & -0.141 & 0.629 \\
\hline \multicolumn{9}{|c|}{$\underline{\text { Run } 8609160922}$} \\
\hline $0922-0932$ & 0.303 & 0.195 & -0.047 & 0.351 & -- & -- & -- & -- \\
\hline \multicolumn{9}{|c|}{$\underline{\text { Run } 8609160945}$} \\
\hline $0945-0955$ & 0.289 & 0.187 & 0.071 & 0.379 & -- & $\cdots$ & -- & -- \\
\hline \multicolumn{9}{|c|}{$\underline{\text { Run } 8609161116}$} \\
\hline $1116-1126$ & 0.178 & 0.194 & 0.073 & 0.373 & 0.227 & 0.193 & 0.075 & 0.345 \\
\hline \multicolumn{9}{|c|}{ Run 8609181225} \\
\hline $1225-1231$ & 0.338 & 0.244 & -0.211 & 0.510 & 0.357 & 0.186 & -0.077 & 0.388 \\
\hline $1232-1237$ & 0.382 & 0.244 & -0.203 & 0.561 & 0.356 & 0.206 & -0.061 & 0.407 \\
\hline $1238-1243$ & 0.421 & 0.213 & -0.192 & 0.588 & 0.483 & 0.166 & -0.035 & 0.459 \\
\hline $1244-1249$ & 0.400 & 0.233 & -0.180 & 0.537 & 0.492 & 0.181 & 0.003 & 0.405 \\
\hline \multicolumn{9}{|c|}{ Run 8609181453} \\
\hline $1453-1459$ & 0.344 & 0.154 & -0.073 & 0.417 & 0.394 & 0.161 & 0.060 & 0.368 \\
\hline $1500-1505$ & 0.349 & 0.168 & -0.051 & 0.449 & 0.344 & 0.169 & 0.025 & 0.408 \\
\hline $1506-1511$ & 0.423 & 0.184 & -0.109 & 0.506 & 0.475 & 0.185 & 0.016 & 0.406 \\
\hline $1512-1518$ & 0.404 & 0.159 & -0.088 & 0.434 & 0.336 & 0.170 & 0.051 & 0.382 \\
\hline $1519-1524$ & 0.393 & 0.162 & -0.089 & 0.430 & 0.402 & 0.176 & 0.017 & 0.364 \\
\hline \multicolumn{9}{|c|}{$\underline{\text { Run } 8609191016}$} \\
\hline $1016-1026$ & 0.154 & 0.166 & -0.073 & 0.512 & 0.186 & 0.158 & -0.045 & 0.444 \\
\hline \multicolumn{9}{|c|}{ Run 8609191230} \\
\hline $1230-1236$ & - & -- & $\cdots$ & $-\cdot$ & -- & -- & -- & -- \\
\hline $1237-1242$ & $-\cdots$ & -- & -- & -- & -- & -- & -- & - - \\
\hline
\end{tabular}


Table 4 (Continued)

\begin{tabular}{|c|c|c|c|c|c|c|c|c|}
\hline \multirow{3}{*}{$\begin{array}{l}\text { Time } \\
\text { EDST }\end{array}$} & \multicolumn{8}{|c|}{ Current Speed, $\mathrm{m} / \mathrm{sec}$} \\
\hline & \multicolumn{2}{|c|}{ CY1 } & \multicolumn{2}{|c|}{$\mathrm{CX} 1$} & \multicolumn{2}{|c|}{ CY2 } & \multicolumn{2}{|c|}{$\mathrm{CX} 2$} \\
\hline & Mean & $\sigma_{\mathrm{v}}$ & Mean & $\sigma_{\mathrm{v}}$ & Mean & $\sigma_{\mathrm{v}}$ & Mean & $\sigma_{\mathrm{v}}$ \\
\hline $1243-1248$ & 0.411 & 0.203 & -0.146 & 0.213 & 0.421 & 0.203 & 0.013 & 0.420 \\
\hline $1249-1254$ & 0.364 & 0.165 & -0.085 & 0.461 & 0.336 & 0.160 & 0.040 & 0.423 \\
\hline \multicolumn{9}{|c|}{ Run 8609201045} \\
\hline $1045-1051$ & 0.154 & 0.193 & -0.114 & 0.562 & 0.130 & 0.122 & -0.105 & 0.477 \\
\hline $1052-1057$ & 0.224 & 0.173 & -0.115 & 0.556 & 0.225 & 0.136 & -0.088 & 0.472 \\
\hline $1058-1103$ & 0.209 & 0.191 & -0.115 & 0.520 & 0.247 & 0.132 & -0.075 & 0.422 \\
\hline $1104-1109$ & 0.207 & 0.242 & -0.041 & 0.472 & 0.206 & 0.136 & -0.043 & 0.419 \\
\hline $1110-1115$ & 0.091 & 0.185 & -0.146 & 0.563 & 0.074 & 0.139 & -0.084 & 0.451 \\
\hline $1116-1121$ & 0.190 & 0.179 & -0.216 & 0.549 & 0.192 & 0.123 & -0.083 & 0.480 \\
\hline $1122-1127$ & 0.195 & 0.203 & -0.154 & 0.508 & 0.160 & 0.136 & -0.057 & 0.410 \\
\hline $1128-1133$ & 0.247 & 0.186 & -0.184 & 0.519 & 0.236 & 0.161 & -0.068 & 0.409 \\
\hline \multicolumn{9}{|c|}{ Run 8609201500} \\
\hline $1500-1506$ & 0.596 & 0.159 & 0.018 & 0.389 & 0.603 & 0.175 & -0.070 & 0.394 \\
\hline $1507-1512$ & 0.559 & 0.157 & 0.044 & 0.356 & 0.559 & 0.172 & -0.035 & 0.363 \\
\hline $1513-1518$ & 0.472 & 0.128 & 0.017 & 0.350 & 0.511 & 0.161 & -0.058 & 0.371 \\
\hline $1519-1524$ & 0.550 & 0.152 & 0.036 & 0.337 & 0.554 & 0.172 & -0.054 & 0.371 \\
\hline $1525-1530$ & 0.449 & 0.156 & 0.032 & 0.362 & 0.482 & 0.142 & -0.029 & 0.383 \\
\hline $1531-1536$ & 0.564 & 0.159 & 0.022 & 0.367 & 0.587 & 0.153 & -0.056 & 0.387 \\
\hline $1537-1542$ & 0.357 & 0.024 & 0.032 & 0.379 & 0.392 & 0.135 & 0.001 & 0.369 \\
\hline $1543-1548$ & 0.319 & 0.022 & 0.011 & 0.388 & 0.344 & 0.167 & -0.027 & 0.400 \\
\hline \multicolumn{9}{|c|}{ Run 8609211046} \\
\hline $1046-1056$ & 0.149 & 0.134 & -0.093 & 0.435 & 0.052 & 0.103 & -0.056 & 0.417 \\
\hline \multicolumn{9}{|c|}{ Run 8609211345} \\
\hline $1345-1351$ & 0.185 & 0.214 & -0.019 & 0.365 & 0.138 & 0.109 & -0.054 & 0.339 \\
\hline $1352-1357$ & 0.291 & 0.147 & -0.083 & 0.435 & 0.173 & 0.123 & -0.094 & 0.374 \\
\hline $1358-1403$ & 0.266 & 0.147 & -0.049 & 0.418 & 0.217 & 0.126 & -0.034 & 0.360 \\
\hline $1404-1409$ & 0.255 & 0.146 & -0.001 & 0.436 & 0.199 & 0.132 & -0.033 & 0.365 \\
\hline $1410-1415$ & 0.247 & 0.169 & -0.055 & 0.434 & 0.163 & 0.146 & -0.077 & 0.383 \\
\hline $1416-1421$ & 0.351 & 0.142 & -0.044 & 0.453 & 0.276 & 0.124 & -0.050 & 0.386 \\
\hline $1422-1427$ & 0.293 & 0.149 & -0.039 & 0.437 & 0.163 & 0.122 & -0.037 & 0.387 \\
\hline $1428-1433$ & 0.439 & 0.161 & -0.057 & 0.422 & 0.295 & 0.142 & -0.035 & 0.376 \\
\hline $1434-1439$ & 0.391 & 0.121 & -0.017 & 0.425 & 0.261 & 0.109 & -0.010 & 0.349 \\
\hline $1440-1445$ & 0.419 & 0.137 & -0.028 & 0.397 & 0.250 & 0.132 & -0.020 & 0.342 \\
\hline $1446-1451$ & 0.529 & 0.139 & -0.077 & 0.431 & 0.335 & 0.138 & -0.028 & 0.379 \\
\hline $1452-1457$ & 0.460 & 0.162 & -0.009 & 0.420 & 0.301 & 0.124 & 0.000 & 0.358 \\
\hline
\end{tabular}

(Continued)

(Sheet 2 of 3 ) 
Table 4 (Concluded)

\begin{tabular}{|c|c|c|c|c|c|c|c|c|}
\hline \multirow{3}{*}{$\begin{array}{l}\text { Time } \\
\text { EDST }\end{array}$} & \multicolumn{8}{|c|}{ Current Speed, $\mathrm{m} / \mathrm{sec}$} \\
\hline & \multicolumn{2}{|c|}{$\mathrm{CY} 1$} & \multicolumn{2}{|c|}{$\mathrm{CX} 1$} & \multicolumn{2}{|c|}{$\mathrm{CY} 2$} & \multicolumn{2}{|c|}{$\mathrm{CX} 2$} \\
\hline & Mean & $\sigma_{\mathrm{v}}$ & Mean & $\sigma_{\mathrm{v}}$ & Mean & $\sigma_{\mathrm{v}}$ & Mean & $\sigma_{\mathrm{v}}$ \\
\hline $1458-1503$ & 0.487 & 0.204 & -0.050 & 0.454 & 0.345 & 0.166 & -0.017 & 0.397 \\
\hline $1504-1$ & 0.494 & 0.161 & -0.052 & 0.422 & 0.369 & 0.127 & -0.025 & 0.359 \\
\hline \multicolumn{9}{|c|}{ Run 8609220730} \\
\hline $0730-0735$ & -0.541 & 0.268 & -0.249 & 0.443 & -0.422 & 0.232 & -0.102 & 0.464 \\
\hline $0736-0740$ & -0.549 & 0.295 & -0.251 & 0.426 & -0.481 & 0.215 & -0.097 & 0.464 \\
\hline $0741-0745$ & -0.657 & 0.290 & -0.295 & 0.433 & -0.573 & 0.214 & -0.128 & 0.472 \\
\hline $0746-0750$ & -0.533 & 0.287 & -0.202 & 0.453 & -0.473 & 0.223 & -0.106 & 0.459 \\
\hline $0751-0755$ & -0.597 & 0.290 & -0.083 & 0.486 & -0.465 & 0.245 & -0.105 & 0.479 \\
\hline $0756-0800$ & -0.690 & 0.263 & -0.124 & 0.224 & -0.515 & 0.212 & -0.140 & 0.469 \\
\hline $0801-0805$ & -0.607 & 0.262 & -0.119 & 0.469 & -0.492 & 0.209 & -0.113 & 0.466 \\
\hline $0806-0810$ & -0.512 & 0.264 & -0.151 & 0.457 & -0.399 & 0.252 & -0.126 & 0.456 \\
\hline \multicolumn{9}{|c|}{ Run 8609221600} \\
\hline $1600-1605$ & -0.522 & 0.243 & -0.187 & 0.359 & -0.537 & 0.172 & -0.031 & 0.336 \\
\hline $1606-1610$ & -0.489 & 0.247 & -0.148 & 0.361 & -0.508 & 0.179 & 0.010 & 0.350 \\
\hline $1611-1615$ & -0.356 & 0.247 & -0.177 & 0.385 & -0.367 & 0.185 & -0.098 & 0.369 \\
\hline $1616-1620$ & -0.378 & 0.253 & -0.182 & 0.382 & -0.369 & 0.171 & -0.082 & 0.366 \\
\hline $1621-1625$ & -0.357 & 0.231 & -0.156 & 0.369 & -0.384 & 0.159 & -0.052 & 0.345 \\
\hline \multicolumn{9}{|c|}{$\underline{\text { Run } 8609221750}$} \\
\hline $1750-1756$ & -0.372 & 0.226 & -0.154 & 0.382 & -0.396 & 0.176 & 0.057 & 0.341 \\
\hline \multicolumn{9}{|c|}{$\underline{\text { Run } 8609231035}$} \\
\hline $1035-1040$ & 0.043 & 0.201 & -0.201 & 0.544 & -0.025 & 0.166 & -0.077 & 0.494 \\
\hline $1041-1045$ & 0.042 & 0.166 & -0.203 & 0.533 & -0.020 & 0.141 & -0.131 & 0.468 \\
\hline $1046-1050$ & 0.004 & 0.184 & -0.189 & 0.522 & 0.007 & 0.140 & -0.084 & 0.508 \\
\hline $1051-1055$ & 0.075 & 0.199 & -0.116 & 0.556 & -0.003 & 0.118 & -0.066 & 0.533 \\
\hline $1056-1100$ & -0.026 & 0.154 & -0.071 & 0.502 & 0.015 & 0.122 & -0.037 & 0.451 \\
\hline
\end{tabular}

(Sheet 3 of 3 )

(positive $\mathrm{x}$-component indicates seaward-directed flow), and the $\mathrm{y}$-axis points north. Current meter 1 was located shoreward of current meter 2 .

39. The mean current speed and standard deviation were calculated for the indicated trap sampling interval. Most $\mathrm{x}$-components of the mean current are negative, indicating that the flow was primarily directed onshore at an elevation of approximately $20 \mathrm{~cm}$ from the bed where the current meter sensors were located. The $y$-components of the mean current are positive, except for 
runs conducted on 22 and 23 September, indicating that the longshore current flowed from south to north (toward the rip current) on the majority of experiment days. The streamers were observed to reverse direction only during one TSM run on 23 September. As expected, the mean longshore current (y-component) is larger than the mean cross-shore current (x-component). The standard deviation of the cross-shore component ( $\sigma_{\mathrm{v}}$ of $\mathrm{x}$-component) is larger than the standard deviation of the longshore component ( $\sigma_{v}$ of y-component), because of the oscillatory motion of incident waves.

\section{Waves and Water Levels}

40. The analysis procedure for obtaining wave and water level parameters from the photopole record is described in detail by Ebersole and Hughes (in preparation). In summary, the digitized time series was cleaned through visual inspection and then filtered to remove long-period wave motions. The filter eliminated oscillations with periods greater than $30 \mathrm{sec}$ and preserved oscillations with periods less than $16 \mathrm{sec}$; waves with periods between 16 and $30 \mathrm{sec}$ were partially retained (Ebersole and Hughes, in preparation). Table 5 presents various statistical properties of the filtered record corresponding to each trap deployment interval $(6,7$, or $8 \mathrm{~min}$ ) in the six TSM runs for which photopole data were analyzed. Listed wave properties were calculated through an individual wave zero-down crossing method.

\section{$\underline{\text { Sand Transport }}$}

\section{Consistency runs}

41. Seven consistency tests were conducted during SUPERDUCK, and vertical distributions of the fluxes measured with the two closely spaced traps, designated by "shoreward" and "seaward" locations, have been plotted to the same scales for comparison (Figures 11 through 17). Four of the consistency comparisons were conducted as a part of TSM runs 8609201500 and 8609211345 (Figure 13, 14, 16, and 17) and are differentiated with the notation "-1" and "-2" at the end of the run number. The shape of the vertical distributions of sand flux measured during SUPERDUCK varied more between the shoreward and seaward traps than those measured during DUCK85 (see 


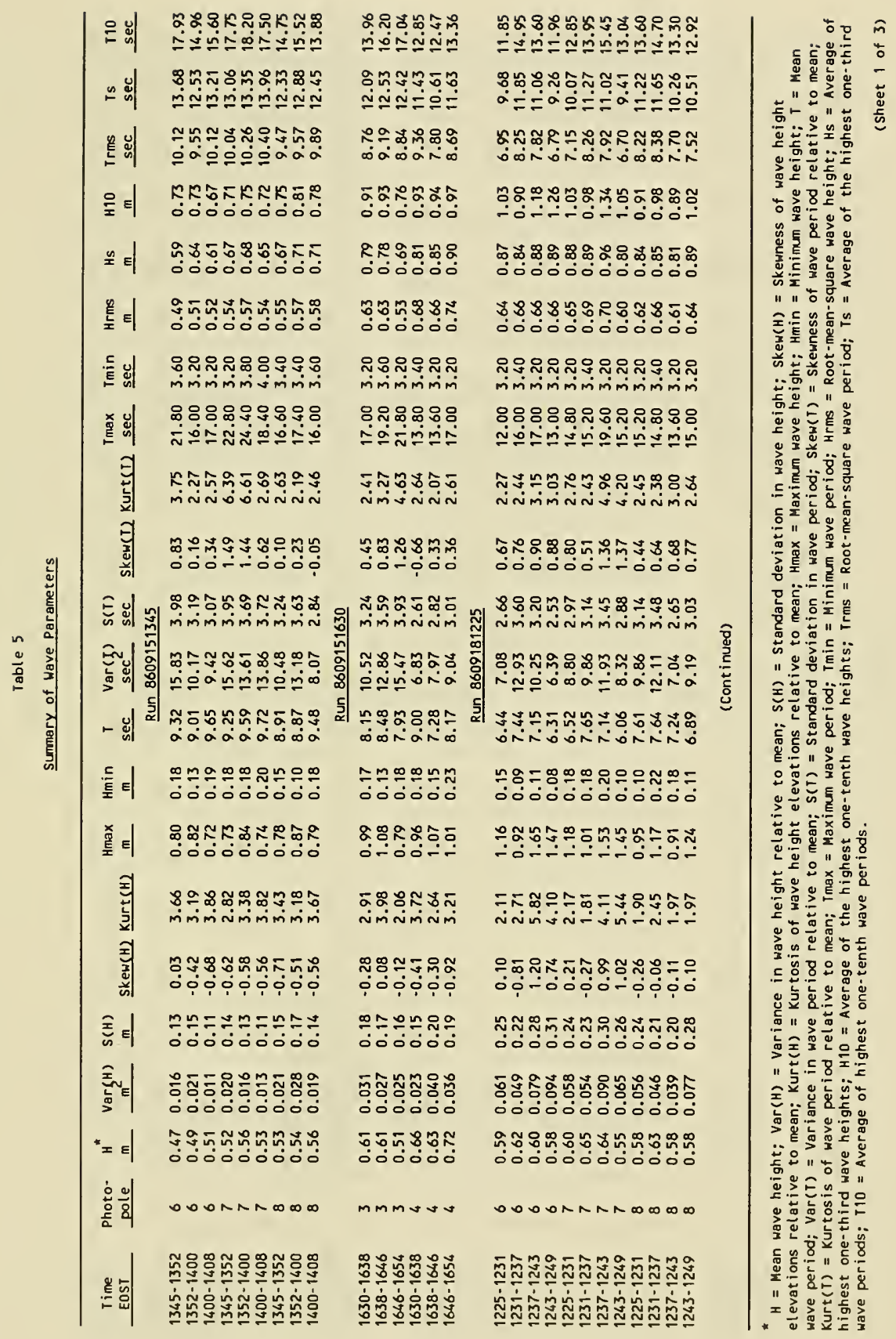




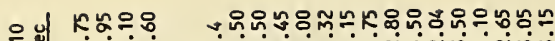

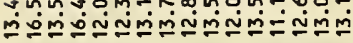

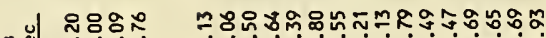

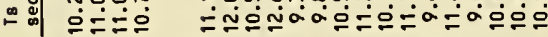

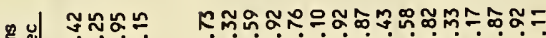

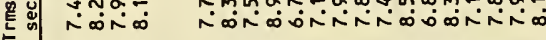

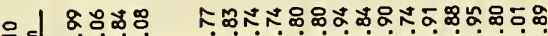

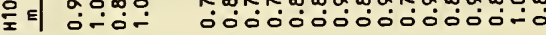

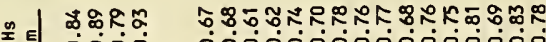

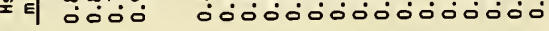

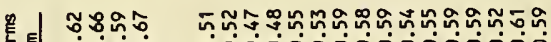

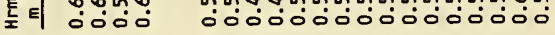

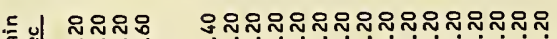

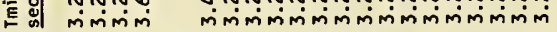

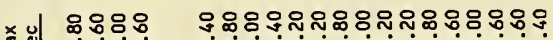
关

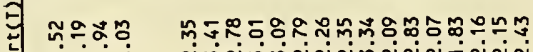
ติ่งกั

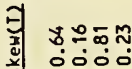

जो

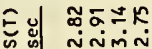

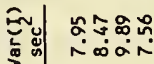

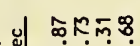
oniti

테 $\cong \frac{\infty}{2} \cong$

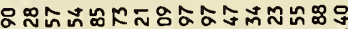

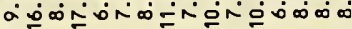

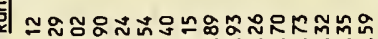

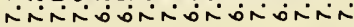

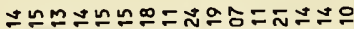

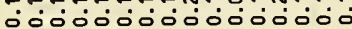

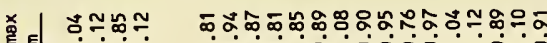

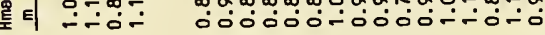

좁 กัน 8 ล

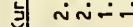

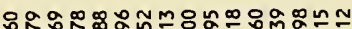

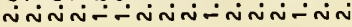

과 $\approx$ 영응 जो 0000

๓ ¿0ं0

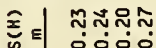

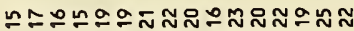

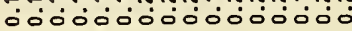

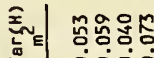
๑ं0ं

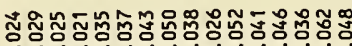
000000000000000

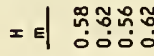

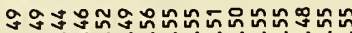
0000000000000

造

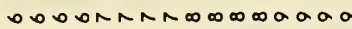

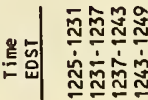

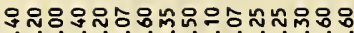

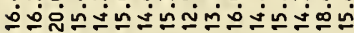

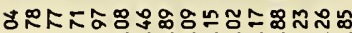

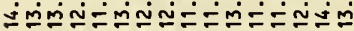

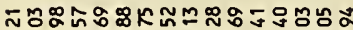

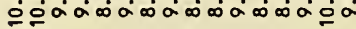

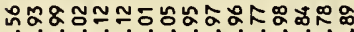

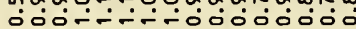

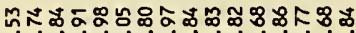

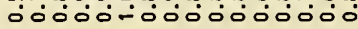

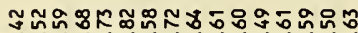

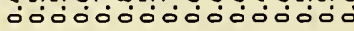

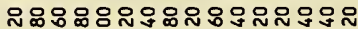
जिंलिंड mimimimimimimim

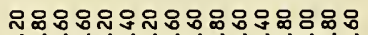

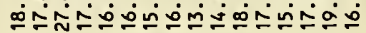

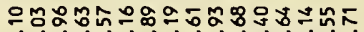
Niñnin-

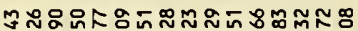

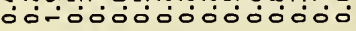

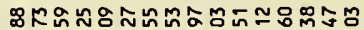
जी mं

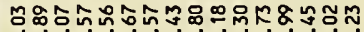

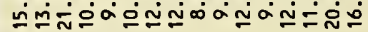

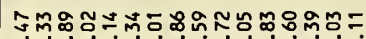

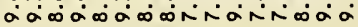

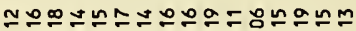

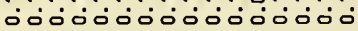

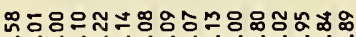

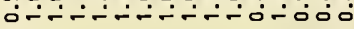

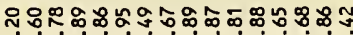
กnー- -

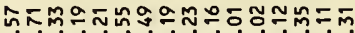
م00

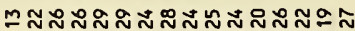
0000000000000000

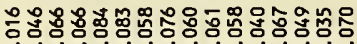
00000000000000

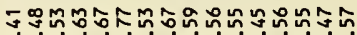

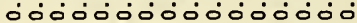

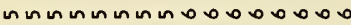

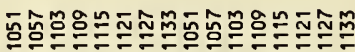

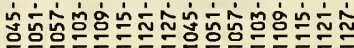




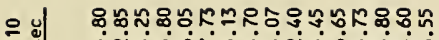

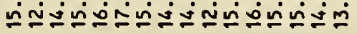

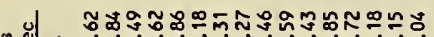

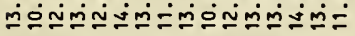

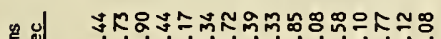

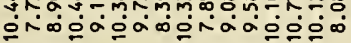

으 =

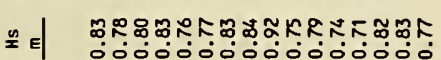

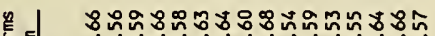

空

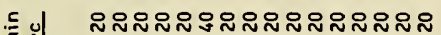

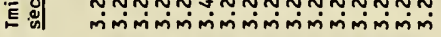

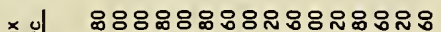

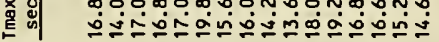

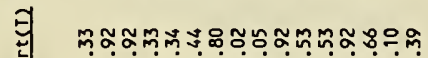

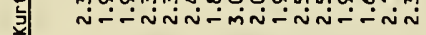

氕

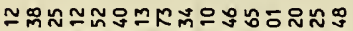

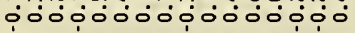

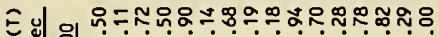

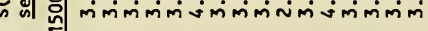

Fiv.

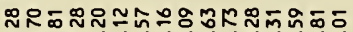

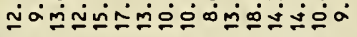

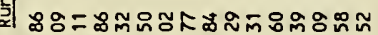

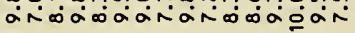

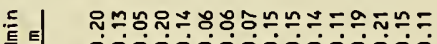
ठ0000000000000

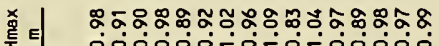

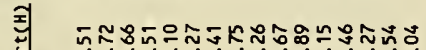

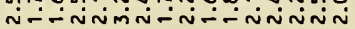

궈 لَ

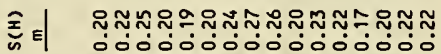

空 -000000000000

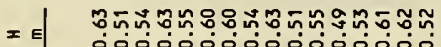

옹용 000000000000000

$\infty \infty \infty \infty \infty \infty \infty \infty \alpha a \alpha a \alpha a \sigma a$

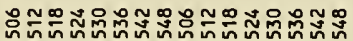
- 
I DIST FROM SEABED TO MID-STREAMER (cm)

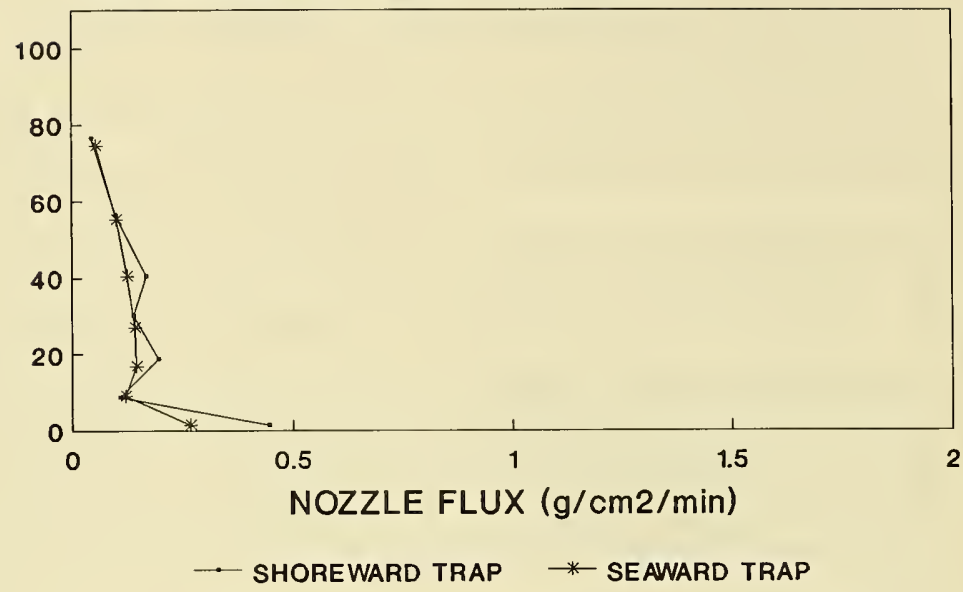

Figure 11. Consistency run 8609160922

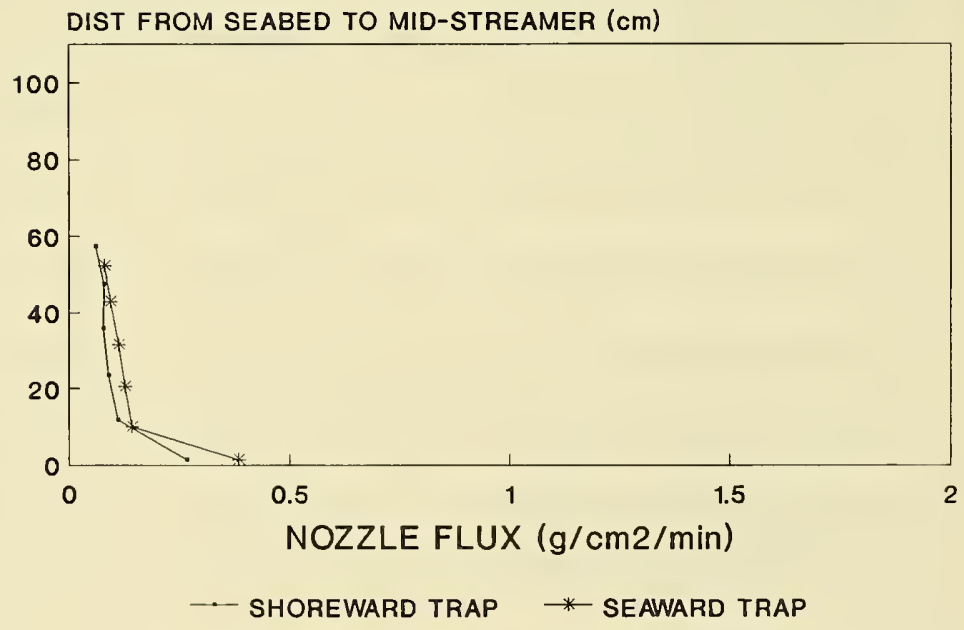

Figure 12. Consistency run 8609160945 


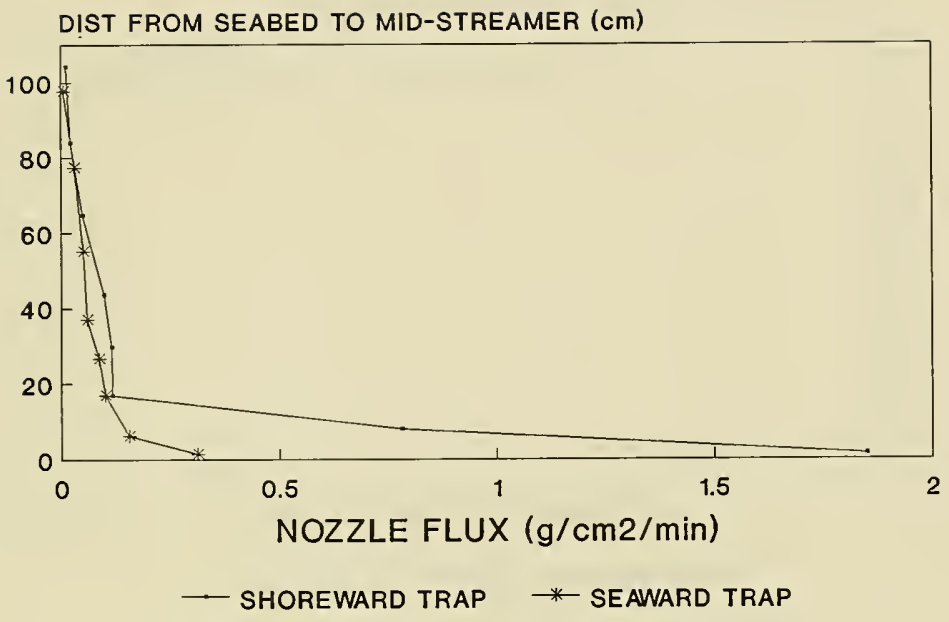

Figure 13. Consistency run 8609201500-1

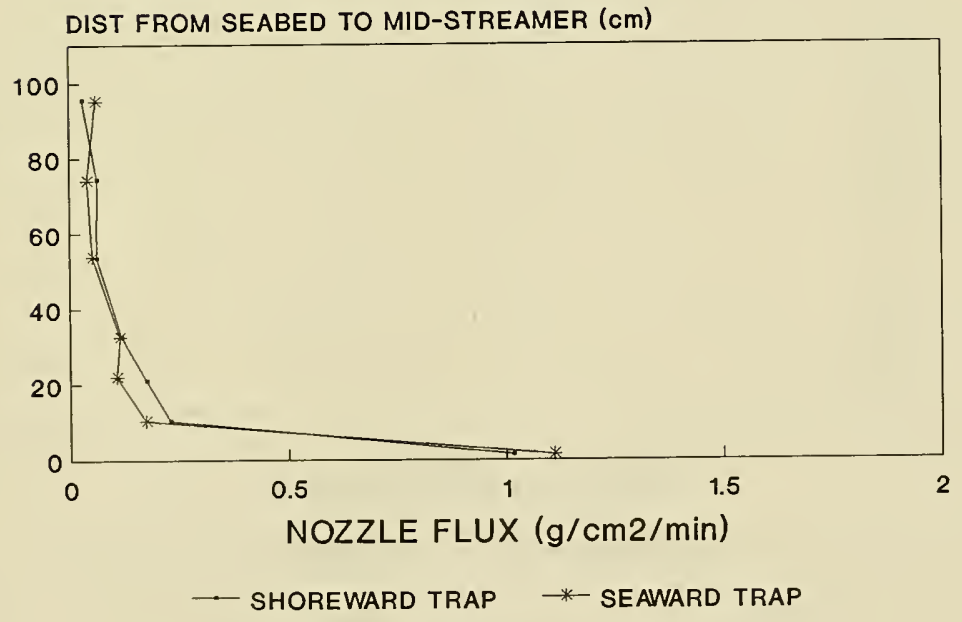

Figure 14. Consistency run 8609201500-2 

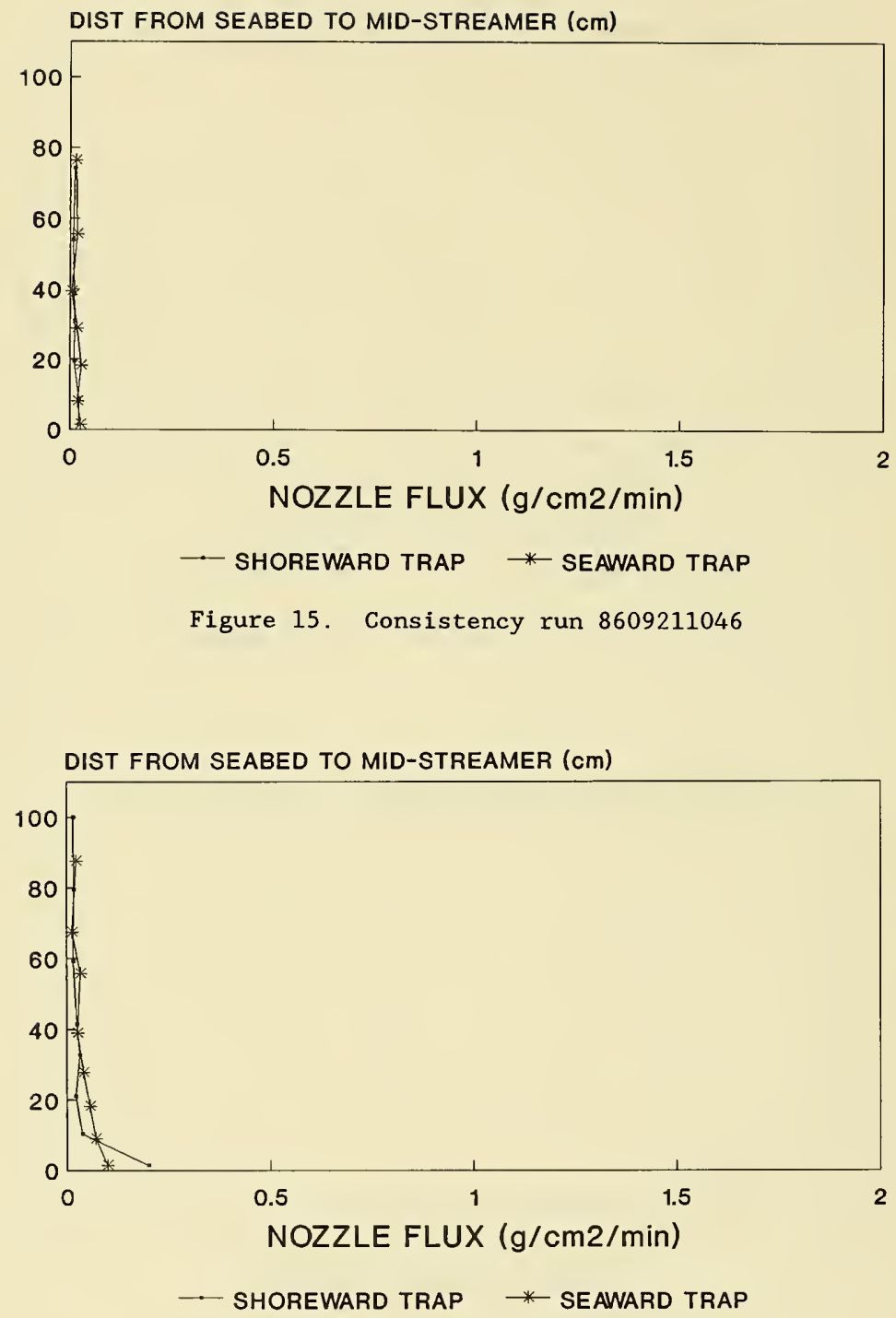

Figure 16. Consistency run 8609211345-1 


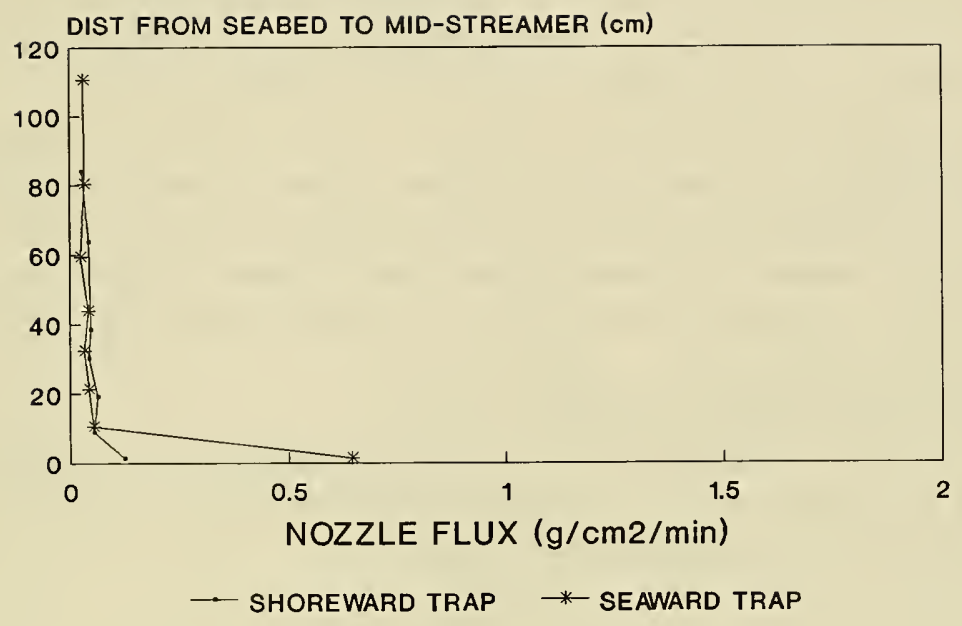

Figure 17. Consistency run $8609211345-2$

Kraus, Gingerich, and Rosati 1989). However, wave conditions were different, with clean swell occurring during DUCK85 and more choppy wind waves during SUPERDUCK. The greatest discrepancy in fluxes in Figures 11 through 17 occurred at the bottom streamer and was probably a result of small differences in the angle of alignment or elevation, which would cause sediment to pass under the lower lip of the streamer nozzle.

42. Rosati and Kraus (1989) evaluated trap consistency by comparing the transport rate density and the shape of the vertical flux distribution measured with the shoreward and seaward traps. The longshore transport rate density $i$ is defined as the total immersed weight of transported material crossing a unit length of a shore-normal line per unit time. Consistency ratios, calculated by dividing the lower value of the transport rate density for a particular run (seaward or shoreward trap) by the higher value for a particular run (seaward or shoreward trap) and then multiplying by 100 , ranged from 50 to 100 percent for the SUPERDUCK consistency runs. The vertical distributions of sand flux for the consistency data sets were fit with linear, 
exponential, and power-law equations. Of the 14 pairs of vertical consistency test sand flux distributions, 10 had the highest squared correlation coefficients with a power-law fit, three were best fit with an exponential relationship, and one was best described linearly. The majority ( 5 out of 7 ) of the shoreward and seaward consistency test data sets had similar coefficients and were described by the same type of equation. These favorable comparisons between the transport rate densities and the form of the vertical flux distributions between two closely spaced traps suggests that the streamer trap and nozzles are consistent and provide reproducible time-integrated measurements of the transport rate.

\section{Temporal Sampling Method (TSM) runs}

43. Thirty-nine transport rate densities measured in six SUPERDUCK TSM runs for which wave data were available (see Table 2) were used to obtain a relationship for the transport rate density

$$
i=\kappa\left[\rho g H_{I m s} V\left(1+\alpha \frac{d H_{I m s}}{d x}+\beta \frac{\boldsymbol{\sigma}_{v}}{V}\right)+\text { const. }\right]
$$

where

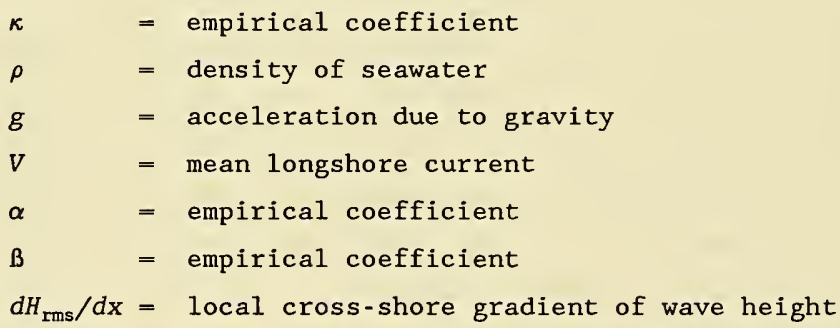

Root-mean-square (rms) wave height was used because correlations were always slightly higher with rms wave height than with significant wave height.

44. Standard formulas for the transport rate density $i$ derived from either a bottom shear stress approach (e.g., Komar 1971) or a wave energetics approach (e.g., Inman and Bagnold 1963) reduce to a leading dependence on the product of wave height and longshore current speed if linear shallow-water wave theory is employed. Thus, as a first step, Kraus, Gingerich, and Rosati (1988) plotted measured transport rate densities with respect to the quantity $\rho g H_{r m s} V$. The result is shown in Figure 18, in which the straight line is a 


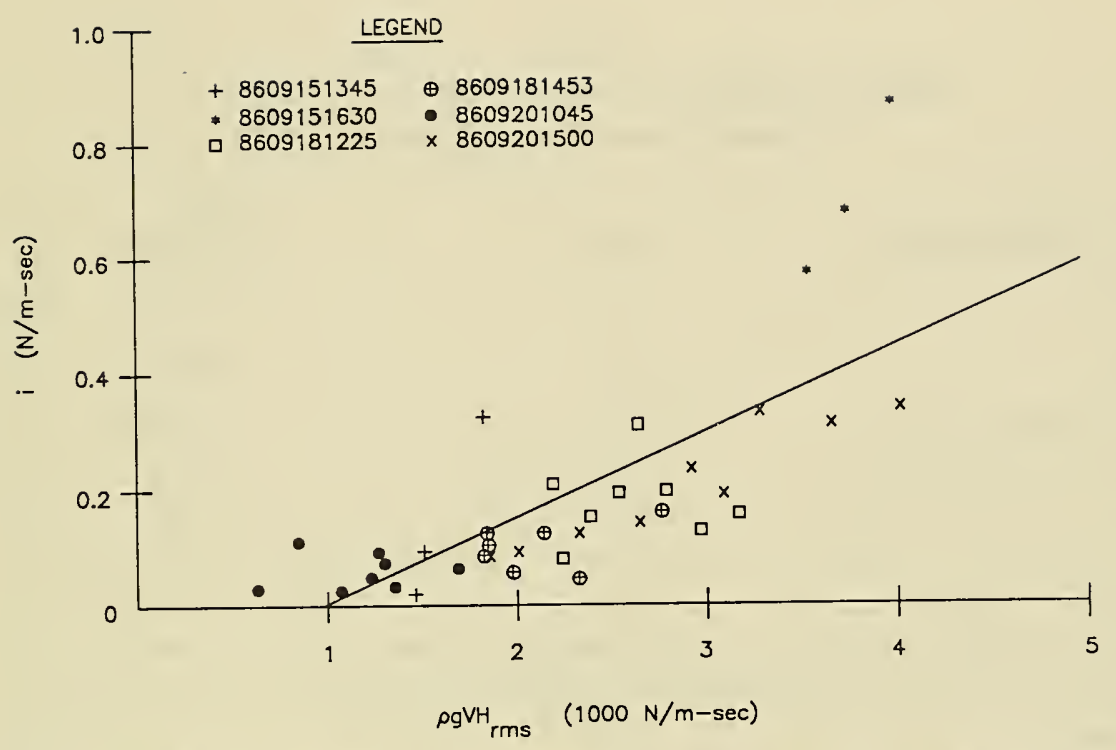

Figure 18. Longshore sand transport rate density versus $H_{\mathrm{rms}} \mathrm{V}$

best fit from linear regression analysis. Values of the determined regression equation coefficients and the correlation coefficient squared $\left(r^{2}\right)$ are listed in Table 6. Figure 18 shows that the measured transport rate densities are fairly well described by a purely linear function of $H_{\mathrm{rms}} \mathrm{V}$. However, scatter is relatively great, suggesting that the transport rate densities may have a power-law dependence on $H_{\mathrm{rms}} \mathrm{V}$, based on the trend of the data.

45. Qualitative observations made during DUCK 85 indicated that the trapped amount of sand depended on the intensity of water agitation occurring at or immediately seaward of a trap. For example, the transport rate appeared to increase in turbulent white water as compared with calmer green water for traps located at approximately the same depth. The white, agitated water was produced by waves breaking at the trap or convected to the trap by waves breaking immediately seaward. The local gradient of the wave height $d H_{\text {rms }} / d x$ was identified as a readily evaluated measure of water agitation, and the SUPERDUCK TSM runs were configured to provide this quantity. The gradient of wave height was calculated from the nearest two photopoles (i.e., over a 6 -m interval). The gradient was usually positive, indicating a decrease in wave 
Table 6

Summary of Regression Results for Longshore Sand

Transport Rate Density Equation

\begin{tabular}{|c|c|c|c|c|c|}
\hline Expression & $\underline{\kappa}\left(10^{4}\right)$ & $\underline{\alpha}$ & $\beta$ & $\begin{array}{l}\text { Const. } \\
\mathrm{N} /(\mathrm{m}-\mathrm{sec})\end{array}$ & $\mathrm{r}^{2}$ \\
\hline$H_{\mathrm{s}} \mathrm{V}$ & 1.8 & 0 & 0 & $-1.2\left(10^{3}\right)$ & 0.45 \\
\hline$H_{\mathrm{rms}} \mathrm{V}$ & 2.5 & 0 & 0 & $-9.9\left(10^{2}\right)$ & 0.51 \\
\hline$H_{\mathrm{rms}} V\left(1+\alpha d H_{\mathrm{rms}} / d x\right)$ & 2.0 & 20 & 0 & $-7.7\left(10^{2}\right)$ & 0.66 \\
\hline$H_{\mathrm{rms}} V\left(1+\alpha d H_{\mathrm{rms}} / d \mathrm{x}+\beta \sigma_{\mathrm{v}} / V\right)$ & 1.5 & 20 & 1.8 & $-2.4\left(10^{3}\right)$ & 0.77 \\
\hline
\end{tabular}

height or energy dissipation as the waves moved toward shore. However, in some cases the gradient was negative, indicating that broken waves were reforming.

46. Kraus, Gingerich, and Rosati (1988) introduced the gradient of wave height as a correction to the quantity $H_{\mathrm{rms}} V$ in the form of $H_{\mathrm{rms}} V\left(1+\alpha d H_{\mathrm{rms}} / d x\right)$ in which the value of the empirical coefficient $\alpha$ was determined by iteration to provide the best linear least squares fit. The resultant plot and regression line are given in Figure 19. Visual agreement and the correlation coefficient are considerably improved over Figure 18, which involved only the product $H_{\mathrm{rms}} \mathrm{V}$.

47. The longshore current speed used in the analysis is the average of a time-varying flow. The sand transport rate should depend on the range of current speed as well as the average. As a measure of the range, Kraus, Gingerich, and Rosati (1988) chose the coefficient of variation of the current speed $\sigma_{v} / V$, in which $\sigma_{\mathrm{v}}$ is the standard deviation of the speed during the averaging interval. The coefficient of variation was conceptualized as providing a correction to the leading term $H_{\mathrm{rms}} V$, and the quantity $H_{\text {rms }} V\left(1+\alpha d H_{\text {rms }} / d x+\beta \sigma_{\mathrm{v}} / V\right)$ was used for regression. The result is shown in Figure 20, and associated values of determined coefficients are given in Table 6. Grouping of the data points about the regression line is improved over previous plots, and the apparent necessity of using a nonlinear or power law function of $H_{\mathrm{rms}} V$, as was suggested by Figure 18, is eliminated. 


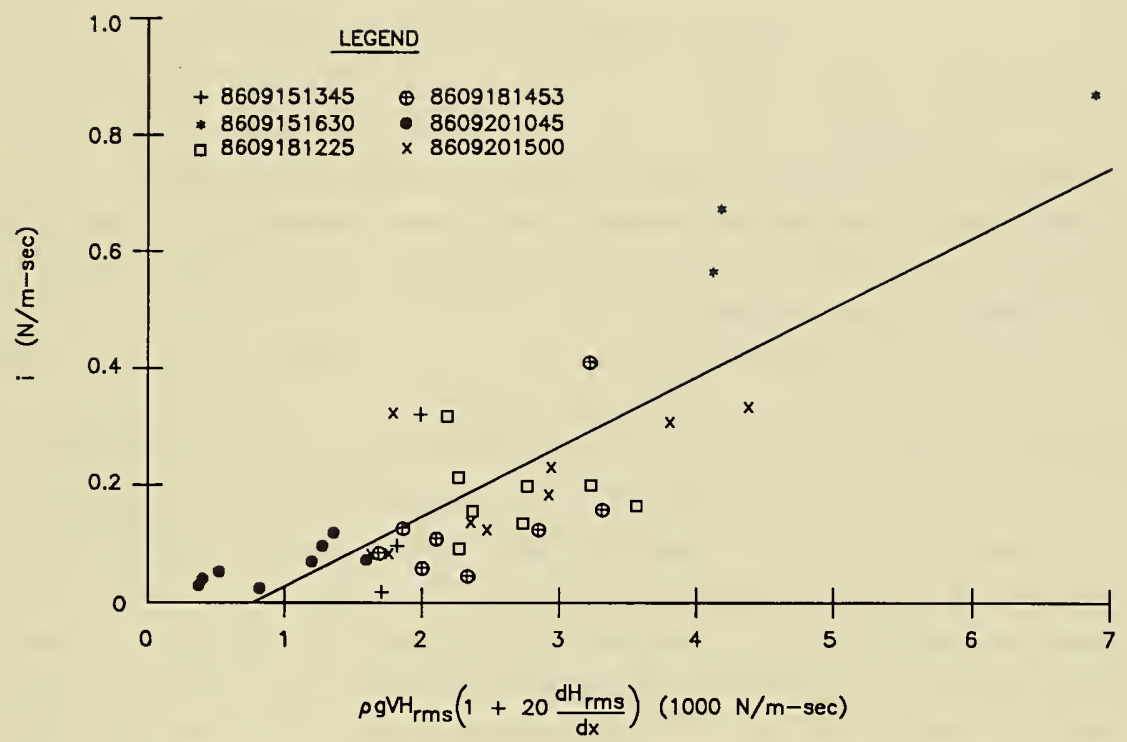

Figure 19. Longshore sand transport density versus $H_{\text {rms }} V\left(1+\alpha d H_{\text {rms }} / d x\right)$

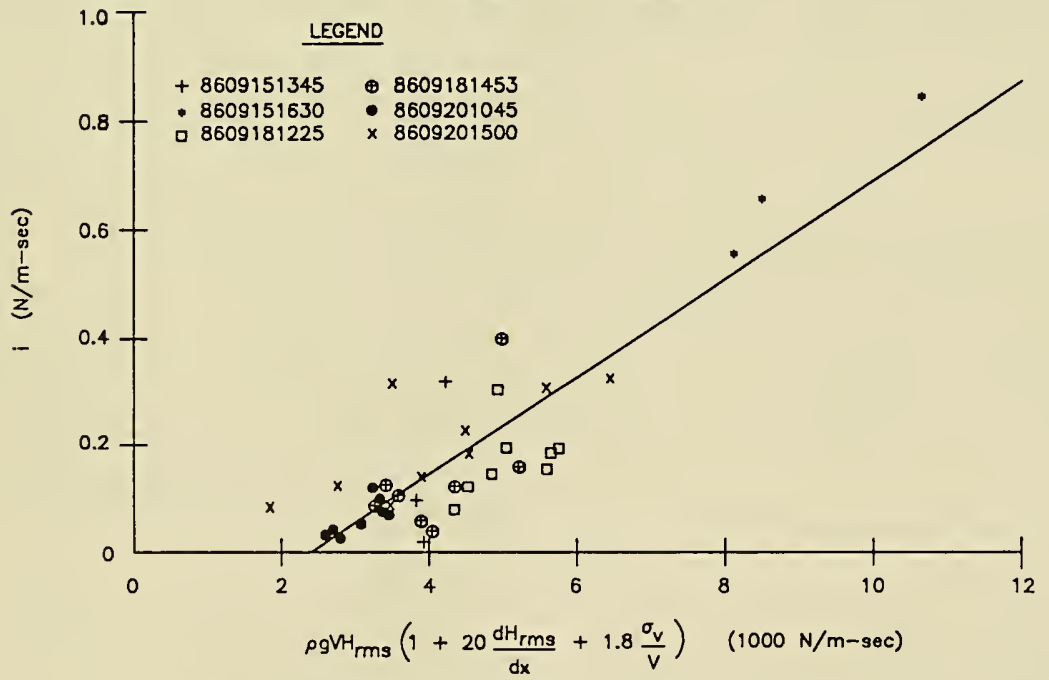

Figure 20. Longshore sand transport rate density versus $H_{\mathrm{rms}} V\left(1+\alpha d H_{\mathrm{rms}} / d \mathrm{x}+\mathrm{B} \sigma_{\mathrm{v}} / V\right)$ 
48. The correlation lines in Figures 18, 19, and 20 all intercept the positive $\mathrm{x}$-axis (the term "const." in Equation 4). The value of the intercept is partially an artifact of the use of a straight-line regression analysis. However, the intercept may be interpreted as an effective cutoff for transport of significance in engineering applications, since transport rates lying below this value evidently have a much weaker dependence on the quantity $H_{\text {rms }} V$ than the plotted measured values.

49. Stepwise correlation analysis indicated that there was no relation between the quantities $H_{\mathrm{rms}}, d H_{\mathrm{rms}} / d \mathrm{x}, V$, and $\sigma_{\mathrm{v}}$. In a situation where the longshore current is produced by obliquely incident waves, the magnitude of the current speed is proportional to the square root of the wave height. In the present case, $V$ and $H_{\text {rms }}$ were not related because the experiments were performed in or near the feeder current of a rip current. Caution should be taken in general use of the correction term proportional to $\alpha$, as most TSM measurements were performed on a plateau with a very mild slope. Values of $d H_{\text {rms }} / d x$ ranged from -0.035 to 0.037 and values of $\sigma_{v} / V$ ranged from 0.07 to 2.03. Use of the relationship with the two correction terms requires detailed knowledge of wave height and current characteristics, and may be applicable only if these data are available. 
50. Previous field data collection efforts aimed at making direct point measurements of longshore sand transport in the surf zone have either measured the suspended sand concentration, from which a rate must be inferred by taking the product with a longshore current speed, or have used traps to measure only bed-load transport. Neither of these two methods taken individually provides the total transport rate. The SUPERDUCK surf zone experiment described in this report successfully measured the longshore sand flux through the water column as it varied with time at one or two points in the surf zone.

51. The portable streamer traps developed in this project were found to give reliable and consistent results by comparison of sand fluxes obtained with traps placed close to each other. The consistency ratio, calculated by dividing the lower value of the transport rate density for a particular run by the higher value for that run and multiplying by 100 , ranged from 50 to 100 percent for the SUPERDUCK consistency tests. Of the 14 vertical distributions of sand flux, the majority of the shoreward and seaward consistency test data sets had similar coefficients and were described by a power-law equation. These favorable comparisons between magnitudes of the transport rate densities and the shape of the vertical flux distributions obtained at two closely spaced traps indicate that the streamer trap and nozzles are indeed consistent and provide reproducible measurements of the transport rate.

52. The transport rate density measured at SUPERDUCK was found to be closely related to the product of wave height and longshore current speed, consistent with previously derived theoretical models of transport. The correlation was considerably improved, however, by including corrections due to energy dissipation introduced by breaking waves and the variation in the longshore current speed. 


\section{REFERENCES}

Birkemeier, W. A., Baron, C. F., Leffler, M. A., Hathaway, K. K., Miller, H. C., and Strider, J. B. 1989. "SUPERDUCK Nearshore Processes Experiment Data Summary CERC Field Research Facility," Miscellaneous Paper CERC-89-16, US Army Engineer Waterways Experiment Station, Coastal Engineering Research Center, Vicksburg, MS.

Byrnes, M. R. 1989. "SUPERDUCK Beach Sediment Sampling Experiment, Report 1: Data Summary and Initial Observations," Miscellaneous Paper CERC-89-18, US Army Engineer Waterways Experiment Station, Coastal Engineering Research Center, Vicksburg, MS .

Crowson, R. A., Birkemeier, W. A., Klein, H. M., and Miller, H. C. 1988. "SUPERDUCK Nearshore Processes Experiment: Summary of Studies, CERC Field Research Facility," Technical Report CERC-88-12, US Army Engineer Waterways Experiment Station, Coastal Engineering Research Center, Vicksburg, MS.

Ebersole, B. A., and Hughes, S. A. "SUPERDUCK Photopole Experiment," Misce1laneous Paper in preparation, US Army Engineer Waterways Experiment Station, Coastal Engineering Research Center, Vicksburg, MS.

Field Research Facility. 1986 (Sep). "Preliminary Data Summary," Monthly Series, US Army Engineer Waterways Experiment Station, Coastal Engineering Research Center, Vicksburg, MS.

Friedman, G. M., and Johnson, K. G. 1982. Exercises in Sedimentology, Wiley, New York.

Hughes, S. A., Kraus, N. C., and Richardson, T. W. 1987. "SUPERDUCK - A Nearshore Process Field Experiment," (video), CERC File No. 87057B, 21Ju187, Log \#6209, 24 min.

Inman, D. L., and Bagnold, R. A. 1963. "Littoral Processes," In: M. N. Hill, Ed., The Sea, Interscience, New York, pp 529-533.

Katori, S. 1982. "Measurement of Sediment Transport by Streamer Trap," Report of the 6 th Cooperative Field Investigation, Report No. 16, TR-81-2, Nearshore Environment Research Center, Tokyo, Japan, pp 138-141. (in Japanese)

1983. "Measurement of Sediment Transport by Streamer Trap," Report of the $7 \mathrm{th}$ Cooperative Field Investigation, Report No. 17, TR-82-2, Nearshore Environment Research Center, Tokyo, Japan, pp 110-117. (in Japanese)

Komar, P. D. 1971. "The Mechanics of Sand Transport on Beaches," Journal of Geophysical Research, Vo1 76, No. 3, pp 713-721. 
Kraus, N. C. 1987. "Application of Portable Traps for Obtaining Point Measurements of Sediment Transport Rates in the Surf Zone," Journal of Coastal Research, Vol 2, No. 2, pp 139-152.

Kraus, N. C., Gingerich, K. J., and Rosati, J. D. 1988. "Toward an Improved Empirical Formula for Longshore Sand Transport," Proceedings, 21st Coasta1 Engineering Conference, American Society of Civil Engineers, pp 1182-1196.

\section{9. "DUCK85 Surf Zone Sand Transport Experiment," Technical}

Report CERC-89-5, US Army Engineer Waterways Experiment Station, Coastal Engineering Research Center, Vicksburg, MS.

Kraus, N. C., and Nakashima, L. 1986. "Field Method for Determining Rapidly the Dry Weight of Wet Sand Samples," Journal of Sedimentary Petrology, Vol 56, No. 4, pp 550-551.

Rosati, J. D., and Kraus, N. C. 1988. "Hydraulic Calibration of the Streamer Trap," Journal of Hydraulic Engineering, Vol 114, No. 12, pp 1527-1532.

1989. "Development of a Portable Sand Trap for Use in the Nearshore," Technical Report CERC-89-11, US Army Engineer Waterways Experiment Station, Coastal Engineering Research Center, Vicksburg, MS .

Stauble, D. K., Holem, G. W., Byrnes, M. R., Anders, F., and Meisburger, E. P. "SUPERDUCK Beach Sediment Sampling Experiment, Report 2: Beach Profile Change and Sediment Dynamics," Miscellaneous Paper in preparation, US Army Engineer Waterways Experiment Station, Coastal Engineering Research Center, Vicksburg, MS . 

APPENDIX A: DATA

1. This appendix contains a listing of the basic data collected during the SUPERDUCK surf zone sand transport experiments. Data are given for the following quantities:

a. Wet weight of collected sand (Table Al).

b. Elevations of individual trap streamers (Table A2).

c. Water levels during the experiments (Table A3).

d. Horizontal coordinates of the photopoles (Field Research Facility (FRF) coordinate system) (Table A4).

e. Grain size data (Table A5).

2. Table Al gives the weight of the sand collected in the streamers as recorded in the field logbooks, without adjustments for trap efficiency. A value of 0.0 indicates that no sand was collected in the streamer, and blank spaces denote no streamer at that elevation. The wet sand was weighed in a drip-free state in small patches of sieve cloth, and the weight of the sieve cloth was subtracted to arrive at the values given in Table Al. The drip-free wet weight $(W W)$ and the dry weight $(D W)$ of samples consisting primarily of sand are linearly related (Kraus and Nakashima $1986^{*}$ ) for a wide range of common grain sizes and sample weights as

$$
D W=c W W
$$

for which the empirical coefficient $c$ must be determined through calibration for the particular field operation and weighing procedure, since judgment of the drip-free state is somewhat subjective. The value $c$ ranged from 0.72 to 0.81 for the SUPERDUCK experiments; an average value obtained from samples analyzed during one run per day was used to convert wet weights to dry weights for samples collected during that day's runs.

3. Table A2 gives the elevation of each streamer on each trap deployed for a particular run. Elevations are given as distances from the bed to the

References cited in Appendix A can be found in the list of references at the end of the main text. 
center of the streamer nozzle.

4. Table A3 1ists water levels relative to the National Geodetic Vertical Datum (NGVD) recorded at a tide gage located at the end of the FRF pier during the times of six Temporal Sampling Method (TSM) experiment runs. The NGVD is related to Mean Sea Level (MSL) at the FRF by the relation $\operatorname{MSL}(\mathrm{m})=\operatorname{NGVD}(\mathrm{m})+0.067$.

5. Table A4 gives the horizontal coordinates of the photopoles in the FRF coordinate system.

6. Table A5 summarizes grain size statistics (calculated using Moment and Folk methods (Friedman and Johnson 1982)) for samples retained from 37 traps representing 11 experiment runs. 
Table Al

Sand Wet Weights, $g$

\begin{tabular}{|c|c|c|c|c|c|c|c|c|c|}
\hline \multirow{2}{*}{$\begin{array}{c}\text { Trap } \\
\text { Number } \\
\end{array}$} & \multicolumn{9}{|c|}{ Streamer Number. } \\
\hline & 1 & 2 & 3 & 4 & 5 & 6 & 7 & 8 & 9 \\
\hline \multicolumn{10}{|c|}{ Run 8609111745} \\
\hline 1 & 1554.4 & 584.4 & 1992.2 & 1518.3 & 1013.4 & 356.3 & 28.1 & & \\
\hline 2 & 21.1 & 84.8 & 33.1 & 26.2 & 32.3 & 25.9 & 18.3 & & \\
\hline 3 & 195.2 & 52.6 & 36.7 & 24.8 & 17.1 & 14.7 & 3.1 & & \\
\hline 4 & 216.9 & 22.3 & 25.3 & 20.2 & 26.1 & 15.6 & 10.8 & 3.1 & \\
\hline 5 & 63.6 & 45.0 & 43.8 & 37.6 & 25.6 & 27.4 & 13.3 & 6.7 & \\
\hline 6 & 21.5 & 11.1 & 6.6 & 6.3 & 6.3 & 5.0 & 5.4 & 1.1 & \\
\hline \multicolumn{9}{|c|}{$\underline{\text { Run } 8609121037}$} & \\
\hline 1 & 125.8 & 28.8 & 76.3 & 50.6 & 54.0 & 37.4 & 24.1 & & \\
\hline 2 & 481.5 & 79.4 & 102.2 & 43.5 & 51.3 & 20.3 & 20.6 & & \\
\hline 3 & 834.2 & 142.5 & 62.7 & 29.6 & 14.6 & 9.9 & 4.6 & & \\
\hline 4 & 378.4 & 50.3 & 37.9 & 32.0 & 33.8 & 19.5 & 1.0 & 1.2 & \\
\hline 5 & 94.0 & 65.9 & 68.8 & 50.4 & 33.9 & 33.5 & 18.8 & 8.8 & \\
\hline 6 & 102.9 & 150.3 & 17.3 & 38.1 & 24.1 & 17.4 & 9.7 & 8.7 & \\
\hline \multicolumn{9}{|c|}{ Run 8609151345} & \\
\hline 1 & 51.0 & 28.1 & 24.2 & 22.2 & 14.1 & 4.6 & 4.6 & & \\
\hline 2 & 28.7 & 16.9 & 16.7 & 17.0 & 17.9 & 11.5 & 19.5 & & \\
\hline 3 & 177.5 & 103.4 & 88.1 & 139.3 & 76.0 & 14.1 & 1.8 & & \\
\hline 4 & 41.8 & 40.2 & 22.4 & 9.2 & 24.5 & 12.3 & 15.1 & 8.5 & \\
\hline 5 & 884.9 & 360.1 & 305.7 & 227.3 & 124.9 & 48.2 & 7.5 & 4.0 & \\
\hline 6 & 55.1 & 31.3 & 27.8 & 20.9 & 29.3 & 22.1 & 17.1 & 14.2 & \\
\hline \multicolumn{9}{|c|}{ Run 8609151630} & \\
\hline 1 & 1655.5 & 391.5 & 447.7 & 269.7 & 101.8 & 18.1 & 3.5 & & \\
\hline 2 & 1431.8 & 537.7 & 717.0 & 553.2 & 316.9 & 2.5 & 21.2 & 9.8 & \\
\hline 3 & 2641.3 & 717.2 & 608.9 & 457.9 & 374.2 & 236.8 & 69.6 & 18.6 & \\
\hline \multicolumn{9}{|c|}{ Run 8609160922} & \\
\hline 1 & 148.5 & 52.3 & 94.0 & 67.1 & 81.6 & 47.7 & 21.5 & & \\
\hline 2 & 89.1 & 58.7 & 70.6 & 68.5 & 60.5 & 48.5 & 26.3 & & \\
\hline \multicolumn{9}{|c|}{$\underline{\text { Run } 8609160945}$} & \\
\hline 1 & 88.5 & 53.3 & 43.3 & 37.4 & 38.4 & 28.9 & & & \\
\hline 2 & 127.9 & 68.6 & 60.9 & 54.6 & 44.8 & 38.9 & & & \\
\hline
\end{tabular}

(Continued)

(Sheet 1 of 5 ) 
Table A1 (Continued)

\begin{tabular}{|c|c|c|c|c|c|c|c|c|c|}
\hline \multirow{2}{*}{$\begin{array}{c}\text { Trap } \\
\text { Number } \\
\end{array}$} & \multicolumn{9}{|c|}{ Streamer Number } \\
\hline & 1 & 2 & 3 & 4 & 5 & 6 & 7 & 8 & 9 \\
\hline \multicolumn{10}{|c|}{ Run 8609161116} \\
\hline 1 & 496.8 & 356.4 & 246.1 & 93.0 & 25.1 & 3.9 & 0.0 & & \\
\hline 2 & 542.0 & 63.2 & 73.9 & 43.3 & 17.3 & 3.4 & 7.8 & & \\
\hline 3 & 187.3 & 29.7 & 51.5 & 38.1 & 21.3 & 1.9 & 1.5 & & \\
\hline 4 & 430.4 & 112.2 & 86.5 & 63.5 & 58.9 & 24.3 & 4.1 & 1.1 & \\
\hline 5 & 195.2 & 123.8 & 105.3 & 94.7 & 55.9 & 24.8 & 6.4 & 0.7 & \\
\hline 6 & 643.3 & 237.1 & 345.0 & 308.9 & 250.3 & 104.6 & 18.3 & 2.1 & 3.4 \\
\hline 7 & 1793.4 & 472.1 & 1054.7 & 805.2 & 929.7 & 253.2 & 64.4 & 16.2 & 7.8 \\
\hline 8 & 1648.1 & 1549.6 & 1267.7 & 1023.4 & 773.4 & 461.3 & 69.7 & 14.3 & \\
\hline 9 & 18.2 & 6.5 & 22.2 & 10.0 & 16.1 & 17.1 & 7.3 & & \\
\hline 10 & 16.9 & 15.3 & 16.3 & 16.8 & 8.7 & 8.7 & 10.7 & & \\
\hline \multicolumn{10}{|c|}{ Run 8609181225} \\
\hline 1 & 268.4 & 214.6 & 187.5 & 149.4 & 113.2 & 41.6 & 8.4 & & \\
\hline 2 & 108.6 & 52.6 & 63.9 & 46.7 & 48.0 & 25.2 & 21.9 & & \\
\hline 3 & 302.9 & 80.8 & 154.9 & 129.2 & 74.1 & 35.4 & 7.4 & & \\
\hline 4 & 318.5 & 115.0 & 76.2 & 51.7 & 55.0 & 24.9 & 23.4 & 11.6 & \\
\hline 5 & 284.9 & 156.9 & 151.8 & 114.1 & 95.0 & 48.0 & 8.2 & 7.6 & \\
\hline 6 & 114.8 & 93.0 & 98.8 & 88.2 & 81.0 & 48.1 & 18.5 & 3.2 & \\
\hline 7 & 500.8 & 191.7 & 212.1 & 160.4 & 125.3 & 77.0 & 13.4 & 1.2 & \\
\hline 8 & 142.2 & 139.1 & 127.1 & 103.7 & 92.1 & 51.5 & 24.2 & 7.2 & 7.1 \\
\hline \multicolumn{10}{|c|}{$\underline{\text { Run } 8609181453}$} \\
\hline 1 & 151.6 & 98.0 & 86.7 & 77.3 & 65.2 & 29.8 & 14.7 & & \\
\hline 2 & 69.3 & 22.7 & 28.3 & 26.1 & 23.5 & 15.2 & 8.1 & & \\
\hline 3 & 115.5 & 50.4 & 82.4 & 69.6 & 44.1 & 27.9 & 4.5 & & \\
\hline 4 & 205.7 & 45.0 & 32.3 & 29.5 & 28.4 & 17.4 & 17.6 & 5.5 & \\
\hline 5 & 516.9 & 314.1 & 287.4 & 223.7 & 198.4 & 145.3 & 38.7 & 5.1 & \\
\hline 6 & 105.3 & 96.0 & 84.6 & 85.5 & 87.9 & 54.6 & 45.8 & 18.0 & 0.0 \\
\hline 7 & 178.5 & 48.8 & 98.8 & 84.8 & 62.8 & 14.9 & 0.0 & 3.3 & \\
\hline 8 & 67.6 & 49.3 & 43.1 & 34.8 & 32.2 & 24.9 & 19.3 & 11.6 & \\
\hline 9 & 381.2 & 170.2 & 148.8 & 124.7 & 97.5 & 57.6 & 14.3 & & \\
\hline 10 & 267.4 & 53.6 & 45.4 & 36.7 & 24.2 & 25.5 & 16.8 & & \\
\hline \multicolumn{10}{|c|}{ Run 8609191016} \\
\hline 1 & 698.7 & 74.0 & 13.1 & 0.0 & 0.9 & 2.5 & 8.9 & 5.3 & \\
\hline 2 & 1418.0 & 257.2 & 114.1 & 39.5 & 0.3 & 5.5 & 13.6 & 4.1 & \\
\hline 3 & 61.0 & 53.8 & 36.6 & 43.2 & 42.0 & 28.1 & 25.2 & 20.6 & \\
\hline 4 & 20.6 & 13.0 & 19.8 & 17.4 & 70.6 & 21.2 & 10.8 & & \\
\hline 5 & 36.6 & 25.0 & 16.7 & 15.4 & 6.9 & 10.9 & 9.4 & & \\
\hline 6 & 86.4 & 165.9 & 132.5 & 86.7 & 136.4 & 75.0 & 79.9 & & \\
\hline
\end{tabular}

(Continued) 
Table Al (Continued)

\begin{tabular}{|c|c|c|c|c|c|c|c|c|c|}
\hline \multirow{2}{*}{$\begin{array}{c}\text { Trap } \\
\text { Number } \\
\end{array}$} & \multicolumn{9}{|c|}{ Streamer Number } \\
\hline & 1 & 2 & 3 & 4 & 5 & 6 & 7 & 8 & 9 \\
\hline \multicolumn{10}{|c|}{ Run 8609191230} \\
\hline 1 & 351.7 & 283.6 & 230.0 & 195.9 & 166.2 & 85.1 & 32.1 & & \\
\hline 2 & 119.7 & 41.4 & 45.6 & 35.7 & 33.7 & 22.8 & 26.7 & 20.0 & \\
\hline 3 & 402.1 & 234.2 & 245.2 & 173.8 & 109.9 & 31.3 & 9.6 & & \\
\hline 4 & 377.2 & 67.5 & 41.3 & 36.3 & 29.4 & 17.8 & 3.4 & & \\
\hline 5 & 1186.8 & 93.1 & 227.3 & 164.2 & 129.6 & 18.8 & 5.8 & 3.1 & \\
\hline 6 & 156.1 & 63.9 & 43.1 & 42.9 & 35.3 & 25.1 & 17.9 & 13.8 & 4.1 \\
\hline 7 & 339.0 & 197.2 & 212.1 & 176.6 & 151.3 & 86.8 & 22.9 & 3.6 & \\
\hline 8 & 54.0 & 32.5 & 31.0 & 24.0 & 19.1 & 12.1 & 11.6 & 6.1 & \\
\hline \multicolumn{10}{|c|}{$\underline{\text { Run } 8609201045}$} \\
\hline 1 & 96.3 & 101.7 & 95.4 & 80.7 & 80.3 & 42.2 & 34.3 & & \\
\hline 2 & 116.5 & 25.9 & 58.6 & 49.2 & 14.4 & 23.1 & 18.8 & 14.5 & \\
\hline 3 & 183.3 & 11.3 & 58.0 & 39.3 & 32.7 & 32.6 & 21.7 & & \\
\hline 4 & 65.0 & 36.8 & 39.5 & 38.3 & 25.6 & 24.8 & 19.5 & & \\
\hline 5 & 28.3 & 27.8 & 28.9 & 20.5 & 18.2 & 23.2 & 13.0 & 7.7 & \\
\hline 6 & 36.7 & 38.4 & 16.3 & 30.0 & 23.2 & 14.2 & 6.0 & 6.7 & \\
\hline 7 & 34.5 & 19.6 & 24.0 & 19.2 & 19.2 & 14.3 & 9.9 & 6.4 & \\
\hline 8 & 52.0 & 55.5 & 55.0 & 47.8 & 42.2 & 30.6 & 16.9 & 12.6 & \\
\hline \multicolumn{10}{|c|}{ Run 8609201500} \\
\hline 1 & 1322.2 & 269.2 & 166.3 & 114.0 & 81.2 & 44.9 & 24.8 & & \\
\hline 2 & 496.8 & 124.9 & 103.5 & 75.4 & 64.2 & 40.0 & 11.6 & 4.1 & \\
\hline 3 & 1003.7 & 84.1 & 72.1 & 40.1 & 22.9 & 11.1 & 2.9 & & \\
\hline 4 & 1076.6 & 210.1 & 84.6 & 63.6 & 34.8 & 21.4 & 6.6 & & \\
\hline 5 & 368.6 & 75.0 & 73.8 & 50.8 & 34.3 & 15.2 & 4.5 & 4.1 & \\
\hline 6 & 963.1 & 174.1 & 84.3 & 82.5 & 43.7 & 26.7 & 9.7 & 2.7 & \\
\hline 7 & 369.2 & 22.6 & 33.7 & 33.4 & 28.4 & 14.1 & 6.2 & 3.4 & \\
\hline 8 & 62.4 & 44.8 & 29.1 & 24.9 & 17.1 & 14.6 & 8.6 & 1.9 & \\
\hline 9 & 203.1 & 66.0 & 50.7 & 34.1 & 17.8 & 18.5 & 8.8 & & \\
\hline 10 & 222.3 & 50.7 & 30.8 & 33.1 & 15.1 & 11.7 & 17.3 & & \\
\hline \multicolumn{10}{|c|}{ Run 8609211046} \\
\hline 1 & 7.1 & 10.6 & 5.4 & 5.6 & 5.1 & 3.6 & 5.9 & 4.4 & \\
\hline 2 & 8.8 & 9.1 & 13.4 & 8.6 & 2.4 & 8.9 & 7.4 & & \\
\hline
\end{tabular}

(Continued)

(Sheet 3 of 5) 
Table A1 (Continued)

\begin{tabular}{|c|c|c|c|c|c|c|c|c|c|}
\hline \multirow{2}{*}{$\begin{array}{l}\text { Trap } \\
\text { Number }\end{array}$} & \multicolumn{9}{|c|}{ Streamer Number } \\
\hline & 1 & 2 & 3 & 4 & 5 & 6 & 7 & 8 & 9 \\
\hline \multicolumn{10}{|c|}{ Run 8609211345} \\
\hline 1 & 16.6 & 3.6 & 7.8 & 4.1 & 4.4 & 3.4 & 4.1 & & \\
\hline 2 & 64.0 & 21.1 & 9.3 & 15.6 & 7.1 & 3.6 & 8.6 & 2.7 & \\
\hline 3 & 37.5 & 21.5 & 14.2 & 9.4 & 10.4 & 7.3 & 5.9 & & \\
\hline 4 & 71.6 & 15.1 & 9.8 & 12.2 & 4.6 & 4.3 & 5.9 & & \\
\hline 5 & 23.6 & 10.0 & 8.8 & 8.2 & 8.1 & 6.5 & 9.0 & 4.2 & \\
\hline 6 & 33.3 & 8.6 & 16.4 & 15.2 & 15.3 & 9.4 & 6.9 & 6.6 & 4.2 \\
\hline 7 & 40.1 & 10.9 & 6.5 & 9.3 & 7.2 & 4.7 & 5.2 & 4.8 & \\
\hline 8 & 19.8 & 20.4 & 16.4 & 11.6 & 7.7 & 9.9 & 3.8 & 6.8 & \\
\hline 9 & 54.0 & 42.8 & 23.9 & 17.2 & 13.3 & 10.9 & 4.6 & & \\
\hline 10 & 30.7 & 21.7 & 18.1 & 14.8 & 11.0 & 10.0 & 5.2 & & \\
\hline 11 & 24.7 & 16.0 & 18.3 & 12.5 & 13.9 & 12.5 & 7.9 & & \\
\hline 12 & 128.8 & 15.3 & 12.6 & 9.9 & 12.1 & 7.4 & 9.5 & 9.1 & \\
\hline 13 & 97.0 & 30.8 & 34.1 & 22.8 & 16.7 & 16.6 & 38.7 & & \\
\hline 14 & 162.9 & 60.1 & 47.2 & 33.2 & 18.7 & 15.0 & 11.2 & & \\
\hline 15 & 137.1 & 28.5 & 32.1 & 22.7 & 22.8 & 13.7 & 6.7 & 4.5 & \\
\hline 16 & 144.5 & 56.1 & 28.7 & 28.6 & 29.2 & 20.7 & 14.9 & 13.6 & 11.7 \\
\hline \multicolumn{10}{|c|}{$\underline{\text { Run } 8609220730}$} \\
\hline 1 & 361.3 & 389.7 & 430.9 & 388.8 & 357.6 & 250.4 & 76.7 & & \\
\hline 2 & 485.3 & 321.8 & 364.6 & 348.5 & 322.8 & 193.9 & 104.7 & 36.4 & \\
\hline 3 & 962.9 & 629.2 & 682.1 & 595.4 & 359.5 & 289.7 & 97.0 & & \\
\hline 4 & 702.1 & 514.3 & 477.5 & 485.4 & 349.3 & 315.9 & 197.9 & & \\
\hline 5 & 665.2 & 496.3 & 510.0 & 421.9 & 405.3 & 342.3 & 209.5 & 70.8 & \\
\hline 6 & 405.1 & 360.8 & 308.4 & 283.0 & 255.3 & 166.1 & 110.3 & 61.9 & 28.4 \\
\hline 7 & 495.8 & 454.1 & 419.6 & 396.1 & 373.3 & 218.4 & 116.8 & 47.0 & \\
\hline 8 & 361.4 & 355.4 & 344.5 & 333.7 & 294.4 & 196.7 & 91.0 & 43.4 & \\
\hline \multicolumn{10}{|c|}{ Run 8609221600} \\
\hline 1 & 194.1 & 157.5 & 151.5 & 142.1 & 134.8 & 113.3 & 61.8 & & \\
\hline 2 & 125.5 & 67.7 & 44.1 & 48.5 & 40.0 & 29.2 & 27.0 & 27.2 & \\
\hline 3 & 206.8 & 107.1 & 108.1 & 89.1 & 65.5 & 44.3 & 15.9 & & \\
\hline 4 & 80.0 & 36.0 & 41.4 & 41.5 & 28.7 & 36.6 & 36.2 & & \\
\hline 5 & 106.3 & 73.0 & 82.4 & 65.3 & 61.1 & 56.3 & 32.3 & 15.9 & \\
\hline 6 & 81.7 & 44.3 & 27.6 & 24.0 & 27.3 & 20.6 & 16.1 & 20.8 & 9.8 \\
\hline 7 & 141.8 & 87.2 & 102.6 & 93.7 & 81.9 & 61.1 & 36.8 & 15.0 & \\
\hline 8 & 80.5 & 52.5 & 36.1 & 28.5 & 24.6 & 16.9 & 14.7 & 6.1 & \\
\hline 9 & 75.1 & 56.9 & 45.6 & 38.4 & 30.5 & 23.0 & 10.6 & & \\
\hline 10 & 68.3 & 38.8 & 32.5 & 22.7 & 22.2 & 17.1 & 14.7 & & \\
\hline
\end{tabular}

(Continued) 
Table Al (Concluded)

\begin{tabular}{|c|c|c|c|c|c|c|c|c|c|}
\hline \multirow{2}{*}{$\begin{array}{c}\text { Trap } \\
\text { Number } \\
\end{array}$} & \multicolumn{9}{|c|}{ Streamer Number } \\
\hline & 1. & 2 & 3 & 4 & 5 & 6 & 7 & 8 & 9 \\
\hline \multicolumn{10}{|c|}{$\underline{\text { Run } 8609221750}$} \\
\hline 1 & 508.2 & 563.9 & 436.9 & 199.8 & 61.8 & 6.0 & 6.6 & & \multirow{10}{*}{8.1} \\
\hline 2 & 1505.8 & 1338.1 & 979.3 & 1026.2 & 599.7 & 269.8 & 35.8 & & \\
\hline 3 & 363.3 & 247.1 & 281.7 & 239.8 & 177.0 & 80.5 & 20.7 & & \\
\hline 4 & 111.6 & 31.7 & 40.3 & 33.4 & 23.9 & 20.8 & 14.8 & 5.1 & \\
\hline 5 & 79.2 & 29.7 & 24.3 & 22.1 & 21.1 & 22.2 & 14.3 & 9.3 & \\
\hline 6 & 26.0 & 19.5 & 20.7 & 28.0 & 24.4 & 20.4 & 17.6 & 13.8 & \\
\hline 7 & 19.0 & 27.7 & 29.4 & 24.5 & 47.2 & 22.3 & 14.5 & 11.7 & \\
\hline 8 & 33.9 & 22.7 & 29.0 & 22.3 & 11.7 & 17.0 & 11.9 & 13.1 & \\
\hline 9 & 57.5 & 34.8 & 40.0 & 37.4 & 38.4 & 28.2 & 17.1 & & \\
\hline \multirow[t]{2}{*}{10} & 44.6 & 44.0 & 36.5 & 36.6 & 33.5 & 22.2 & 26.2 & & \\
\hline & \multicolumn{8}{|c|}{ Run 8609231035} & \\
\hline 1 & 60.3 & 44.4 & 19.3 & 3.6 & 14.6 & 11.3 & 8.8 & & \\
\hline 2 & 27.5 & 22.7 & 7.2 & 10.4 & 6.9 & 8.9 & 6.2 & 6.0 & \\
\hline 3 & 30.0 & 12.6 & 13.5 & 16.0 & 15.0 & 7.1 & 3.2 & & \\
\hline 4 & 30.6 & 38.4 & 19.7 & 10.2 & 9.6 & 12.3 & 21.8 & & \\
\hline 5 & 70.2 & 10.2 & 10.3 & 3.4 & 10.3 & 8.8 & 3.7 & 2.0 & \\
\hline
\end{tabular}


Table A2

Streamer Elevations from Local Sea Bottom, m

\begin{tabular}{|c|c|c|c|c|c|c|c|c|}
\hline \multirow{2}{*}{$\begin{array}{l}\text { Trap } \\
\text { Number }\end{array}$} & \multicolumn{8}{|c|}{ Streamer Number } \\
\hline & 1 & 2 & 3 & 4 & 5 & 6 & 7 & 8 \\
\hline & \multicolumn{8}{|c|}{ Run 8609111745} \\
\hline 1 & 0.014 & 0.099 & 0.210 & 0.321 & 0.410 & 0.537 & 0.743 & \\
\hline 2 & 0.014 & 0.095 & 0.091 & 0.308 & 0.403 & 0.518 & 0.632 & \\
\hline 3 & 0.014 & 0.095 & 0.210 & 0.305 & 0.426 & 0.540 & 0.743 & \\
\hline 4 & 0.014 & 0.111 & 0.206 & 0.318 & 0.394 & 0.530 & 0.749 & 0.978 \\
\hline 5 & 0.014 & 0.111 & 0.200 & 0.324 & 0.426 & 0.552 & 0.756 & 0.968 \\
\hline 6 & 0.014 & 0.108 & 0.203 & 0.305 & 0.397 & 0.524 & 0.730 & 0.943 \\
\hline
\end{tabular}

Run 8609121037

$\begin{array}{lllllllll}1 & 0.014 & 0.105 & 0.219 & 0.340 & 0.451 & 0.603 & 0.822 & \\ 2 & 0.014 & 0.095 & 0.197 & 0.311 & 0.403 & 0.565 & 0.762 & \\ 3 & 0.014 & 0.086 & 0.197 & 0.292 & 0.407 & 0.559 & 0.781 & \\ 4 & 0.014 & 0.099 & 0.200 & 0.321 & 0.429 & 0.562 & 0.784 & 0.981 \\ 5 & 0.014 & 0.121 & 0.203 & 0.318 & 0.426 & 0.603 & 0.803 & 1.016 \\ 6 & 0.014 & 0.086 & 0.187 & 0.286 & 0.394 & 0.556 & 0.769 & 0.984\end{array}$

\section{Run 8609151345}

$\begin{array}{lllllllll}1 & 0.014 & 0.089 & 0.194 & 0.301 & 0.400 & 0.568 & 0.775 & \\ 2 & 0.014 & 0.095 & 0.187 & 0.298 & 0.400 & 0.553 & 0.746 & \\ 3 & 0.014 & 0.092 & 0.194 & 0.292 & 0.410 & 0.619 & 0.829 & \\ 4 & 0.014 & 0.121 & 0.219 & 0.340 & 0.419 & 0.546 & 0.768 & 0.965 \\ 5 & 0.014 & 0.111 & 0.206 & 0.324 & 0.432 & 0.603 & 0.807 & 1.022 \\ 6 & 0.014 & 0.111 & 0.210 & 0.308 & 0.435 & 0.588 & 0.699 & 0.797\end{array}$

\section{Run 8609151630}

$\begin{array}{lllllllll}1 & 0.014 & 0.108 & 0.213 & 0.314 & 0.435 & 0.648 & 0.861 & \\ 2 & 0.014 & 0.121 & 0.210 & 0.321 & 0.403 & 0.584 & 0.743 & 0.908 \\ 3 & 0.014 & 0.121 & 0.238 & 0.330 & 0.422 & 0.552 & 0.708 & 0.860\end{array}$

Run 8609160922

$\begin{array}{llllllll}1 & 0.014 & 0.086 & 0.187 & 0.301 & 0.400 & 0.565 & 0.765 \\ 2 & 0.014 & 0.089 & 0.168 & 0.270 & 0.400 & 0.553 & 0.746\end{array}$

Run 8609160945

$\begin{array}{lllllll}1 & 0.014 & 0.118 & 0.235 & 0.359 & 0.476 & 0.575 \\ 2 & 0.014 & 0.099 & 0.200 & 0.315 & 0.429 & 0.524\end{array}$

(Continued) 
Table A2 (Continued)

\begin{tabular}{|c|c|c|c|c|c|c|c|c|c|}
\hline \multirow{2}{*}{$\begin{array}{c}\text { Trap } \\
\text { Number }\end{array}$} & \multicolumn{9}{|c|}{ Streamer Number } \\
\hline & 1 & 2 & 3 & 4 & 5 & 6 & 7 & 8 & 9 \\
\hline \multicolumn{10}{|c|}{ Run 8609161116} \\
\hline 1 & 0.014 & 0.095 & 0.200 & 0.283 & 0.384 & 0.546 & 0.753 & & \\
\hline 2 & 0.014 & 0.092 & 0.203 & 0.314 & 0.406 & 0.565 & 0.753 & & \\
\hline 3 & 0.014 & 0.102 & 0.203 & 0.305 & 0.422 & 0.600 & 0.746 & & \\
\hline 4 & 0.014 & 0.121 & 0.213 & 0.330 & 0.410 & 0.540 & 0.759 & 0.911 & \\
\hline 5 & 0.014 & 0.118 & 0.206 & 0.334 & 0.429 & 0.556 & 0.711 & 0.864 & \\
\hline 6 & 0.014 & 0.095 & 0.194 & 0.314 & 0.403 & 0.527 & 0.686 & 0.838 & 1.057 \\
\hline 7 & 0.014 & 0.111 & 0.210 & 0.334 & 0.441 & 0.546 & 0.705 & 0.861 & 1.073 \\
\hline 8 & 0.014 & 0.089 & 0.197 & 0.305 & 0.400 & 0.530 & 0.762 & 0.978 & \\
\hline 9 & 0.014 & 0.105 & 0.206 & 0.327 & 0.445 & 0.540 & 0.768 & & \\
\hline 10 & 0.014 & 0.118 & 0.226 & 0.330 & 0.435 & 0.537 & 0.734 & & \\
\hline \multicolumn{10}{|c|}{ Run 8609181225} \\
\hline 1 & 0.014 & 0.092 & 0.197 & 0.312 & 0.403 & 0.572 & 0.776 & & \\
\hline 2 & 0.014 & 0.088 & 0.200 & 0.310 & 0.402 & 0.561 & 0.752 & & \\
\hline 3 & 0.014 & 0.096 & 0.195 & 0.295 & 0.410 & 0.579 & 0.789 & & \\
\hline 4 & 0.014 & 0.118 & 0.219 & 0.326 & 0.402 & 0.536 & 0.746 & 0.955 & \\
\hline 5 & 0.014 & 0.115 & 0.204 & 0.321 & 0.426 & 0.601 & 0.801 & 1.007 & \\
\hline 6 & 0.014 & 0.099 & 0.191 & 0.295 & 0.422 & 0.549 & 0.759 & 0.958 & \\
\hline 7 & 0.014 & 0.099 & 0.198 & 0.315 & 0.426 & 0.585 & 0.792 & 0.994 & \\
\hline 8 & 0.014 & 0.092 & 0.207 & 0.298 & 0.403 & 0.559 & 0.769 & 0.978 & 1.120 \\
\hline \multicolumn{10}{|c|}{ Run 8609181453} \\
\hline 1 & 0.014 & 0.108 & 0.209 & 0.284 & 0.395 & 0.557 & 0.735 & & \\
\hline 2 & 0.014 & 0.083 & 0.169 & 0.251 & 0.359 & 0.556 & 0.744 & & \\
\hline 3 & 0.014 & 0.105 & 0.210 & 0.314 & 0.517 & 0.844 & 1.181 & & \\
\hline 4 & 0.014 & 0.118 & 0.223 & 0.340 & 0.413 & 0.547 & 0.763 & 1.080 & \\
\hline 5 & 0.014 & 0.115 & 0.204 & 0.321 & 0.426 & 0.607 & 0.810 & 1.012 & \\
\hline 6 & 0.014 & 0.099 & 0.191 & 0.311 & 0.514 & 0.644 & 0.854 & 1.053 & 1.266 \\
\hline 7 & 0.014 & 0.124 & 0.220 & 0.343 & 0.512 & 0.744 & 0.919 & 1.150 & \\
\hline 8 & 0.014 & 0.088 & 0.210 & 0.336 & 0.447 & 0.562 & 0.772 & 0.981 & \\
\hline 9 & 0.014 & 0.099 & 0.210 & 0.324 & 0.432 & 0.642 & 0.855 & & \\
\hline 10 & 0.014 & 0.092 & 0.203 & 0.310 & 0.428 & 0.625 & 0.822 & & \\
\hline \multicolumn{10}{|c|}{ Run 8609191016} \\
\hline 1 & 0.014 & 0.067 & 0.153 & 0.279 & 0.397 & 0.578 & 0.791 & 1.063 & \\
\hline 2 & 0.014 & 0.111 & 0.197 & 0.311 & 0.467 & 0.648 & 0.845 & 1.051 & \\
\hline 3 & 0.014 & 0.073 & 0.143 & 0.257 & 0.368 & 0.587 & 0.810 & 1.019 & \\
\hline 4 & 0.014 & 0.079 & 0.185 & 0.346 & 0.546 & 0.838 & 1.146 & & \\
\hline 5 & 0.014 & 0.083 & 0.194 & 0.333 & 0.540 & 0.750 & 0.960 & & \\
\hline 6 & 0.014 & 0.096 & 0.211 & 0.321 & 0.524 & 0.737 & 0.928 & & \\
\hline
\end{tabular}

(Continued) 
Table A2 (Continued)

\begin{tabular}{|c|c|c|c|c|c|c|c|c|c|}
\hline \multirow{2}{*}{$\begin{array}{l}\text { Trap } \\
\text { Number }\end{array}$} & \multicolumn{9}{|c|}{ Streamer Number } \\
\hline & 1 & 2 & 3 & 4 & 5 & 6 & 7 & 8 & 9 \\
\hline \multicolumn{10}{|c|}{$\underline{\text { Run } 8609191230}$} \\
\hline 1 & 0.014 & 0.064 & 0.144 & 0.261 & 0.360 & 0.544 & 0.747 & & \\
\hline 2 & 0.014 & 0.070 & 0.153 & 0.263 & 0.371 & 0.562 & 0.756 & 1.076 & \\
\hline 3 & 0.014 & 0.080 & 0.207 & 0.359 & 0.543 & 0.740 & 0.950 & & \\
\hline 4 & 0.014 & 0.064 & 0.172 & 0.311 & 0.486 & 0.731 & 1.042 & & \\
\hline 5 & 0.014 & 0.089 & 0.232 & 0.393 & 0.565 & 0.788 & 0.982 & 1.150 & \\
\hline 6 & 0.014 & 0.057 & 0.149 & 0.256 & 0.396 & 0.555 & 0.711 & 0.860 & 1.051 \\
\hline 7 & 0.014 & 0.080 & 0.157 & 0.267 & 0.382 & 0.551 & 0.748 & 1.008 & \\
\hline 8 & 0.014 & 0.048 & 0.140 & 0.241 & 0.362 & 0.626 & 0.807 & 0.943 & \\
\hline
\end{tabular}

\section{Run 8609201045}

0.014

0.069

0.285

0.409

0.578

0.785

$0.014 \quad 0.067$

0.178

0.295

0.403

0.565

0.753

0.626

0.833

$0.014 \quad 0.080$

0.182

0.302

0.496

0.633

0.843

$\begin{array}{ll}0.014 & 0.080 \\ 0.014 & 0.092\end{array}$

0.179

0.305

0.404

0.574

0.781

0.781

0.991

0.555

0.752

0.554

0.764

0.971

0.245

0.403

0.600

0.014

0.080

0.172
0.179

0.299

0.401

0.764

0.987

1.171

0.958

0.970

\section{Run 8609201500}

1

2

3

4

5

6

7

8

9

10

1

2
0.014
0.014
0.014
0.014
0.014
0.014
0.014
0.014
0.014
0.014

0.071

0.086

0.095

0.108

0.099

0.114

0.079

0.060

0.102

0.102

0.186
0.187
0.203
0.222
0.232
0.229
0.168
0.168
0.210
0.219

0.284

0.424

0.308

0.451

0.330

0.540

0.400

0.661

0.375

0.565

0.362

0.572

0.295

0.435

0.265

0.370

0.324

0.534

0.324

0.537

0.605

0.819

0.626

0.743

0.857

0.702

0.727

0.645

0.551

0.743

0.740

0.867

0.953

1.067

0.854

0.918

0.838

0.773

0.953

0.949

1.070

1.010

1.089

1.042

0.976

Run 8609211046

\begin{abstract}
$0.014 \quad 0.086$
\end{abstract}
0.014

0.086
0.080

0.194

0.182

0.311

0.289

0.387

0.394

0.540

0.556

0.743

0.763

0.946

(Continued) 
Table A2 (Continued)

\begin{tabular}{|c|c|c|c|c|c|c|c|c|c|}
\hline \multirow{2}{*}{$\begin{array}{c}\text { Trap } \\
\text { Number }\end{array}$} & \multicolumn{9}{|c|}{ Streamer Number } \\
\hline & 1 & 2 & 3 & 4 & 5 & 6 & 7 & 8 & 9 \\
\hline \multicolumn{10}{|c|}{ Run 8609211345} \\
\hline 1 & 0.014 & 0.089 & 0.159 & 0.261 & 0.394 & 0.565 & 0.765 & & \\
\hline 2 & 0.014 & 0.092 & 0.187 & 0.314 & 0.422 & 0.664 & 0.867 & 1.070 & \\
\hline 3 & 0.014 & 0.089 & 0.175 & 0.302 & 0.534 & 0.767 & 0.940 & & \\
\hline 4 & 0.014 & 0.108 & 0.219 & 0.330 & 0.432 & 0.648 & 0.959 & & \\
\hline 5 & 0.014 & 0.095 & 0.197 & 0.292 & 0.422 & 0.594 & 0.753 & 0.937 & \\
\hline 6 & 0.014 & 0.064 & 0.162 & 0.270 & 0.384 & 0.581 & 0.765 & 0.969 & 1.153 \\
\hline 7 & 0.014 & 0.102 & 0.210 & 0.327 & 0.413 & 0.591 & 0.794 & 0.997 & \\
\hline 8 & 0.014 & 0.089 & 0.181 & 0.276 & 0.387 & 0.556 & 0.673 & 0.873 & \\
\hline 9 & 0.014 & 0.102 & 0.210 & 0.324 & 0.537 & 0.743 & 0.956 & & \\
\hline 10 & 0.014 & 0.095 & 0.210 & 0.318 & 0.527 & 0.737 & 0.940 & & \\
\hline 11 & 0.014 & 0.089 & 0.191 & 0.302 & 0.384 & 0.635 & 0.838 & & \\
\hline 12 & 0.014 & 0.105 & 0.213 & 0.324 & 0.438 & 0.594 & 0.803 & 1.105 & \\
\hline 13 & 0.014 & 0.092 & 0.175 & 0.308 & 0.524 & 0.788 & 1.029 & & \\
\hline 14 & 0.014 & 0.099 & 0.200 & 0.318 & 0.470 & 0.711 & 0.950 & & \\
\hline 15 & 0.014 & 0.099 & 0.187 & 0.308 & 0.410 & 0.676 & 0.904 & 1.114 & \\
\hline 16 & 0.014 & 0.076 & 0.178 & 0.257 & 0.346 & 0.530 & 0.689 & 0.845 & 1.007 \\
\hline \multicolumn{10}{|c|}{ Run 860922073} \\
\hline 1 & 0.014 & 0.095 & 0.184 & 0.299 & 0.407 & 0.629 & 0.896 & & \\
\hline 2 & 0.014 & 0.076 & 0.153 & 0.245 & 0.397 & 0.638 & 0.842 & 1.045 & \\
\hline 3 & 0.014 & 0.086 & 0.178 & 0.308 & 0.521 & 0.724 & 0.927 & & \\
\hline 4 & 0.014 & 0.092 & 0.162 & 0.305 & 0.416 & 0.629 & 0.838 & & \\
\hline 5 & 0.014 & 0.073 & 0.206 & 0.324 & 0.400 & 0.562 & 0.765 & 1.019 & \\
\hline 6 & 0.014 & 0.083 & 0.165 & 0.276 & 0.391 & 0.537 & 0.708 & 0.854 & 1.013 \\
\hline 7 & 0.014 & 0.105 & 0.181 & 0.283 & 0.429 & 0.740 & 0.943 & 1.121 & \\
\hline 8 & 0.014 & 0.076 & 0.191 & 0.305 & 0.451 & 0.648 & 0.861 & 1.067 & \\
\hline \multicolumn{10}{|c|}{ Run 8609221600} \\
\hline 1 & 0.014 & 0.095 & 0.203 & 0.283 & 0.397 & 0.575 & 0.816 & & \\
\hline 2 & 0.014 & 0.070 & 0.172 & 0.286 & 0.403 & 0.549 & 0.759 & 0.965 & \\
\hline 3 & 0.014 & 0.083 & 0.191 & 0.311 & 0.470 & 0.632 & 0.943 & & \\
\hline 4 & 0.014 & 0.095 & 0.194 & 0.321 & 0.400 & 0.534 & 0.743 & & \\
\hline 5 & 0.014 & 0.095 & 0.203 & 0.305 & 0.419 & 0.584 & 0.784 & 0.988 & \\
\hline 6 & 0.014 & 0.060 & 0.200 & 0.318 & 0.378 & 0.524 & 0.702 & 0.899 & 1.165 \\
\hline 7 & 0.014 & 0.089 & 0.197 & 0.330 & 0.457 & 0.613 & 0.759 & 0.965 & \\
\hline 8 & 0.014 & 0.076 & 0.165 & 0.264 & 0.391 & 0.537 & 0.756 & 0.962 & \\
\hline 9 & 0.014 & 0.102 & 0.213 & 0.327 & 0.537 & 0.743 & 0.940 & & \\
\hline 10 & 0.014 & 0.089 & 0.178 & 0.308 & 0.524 & 0.734 & 0.930 & & \\
\hline
\end{tabular}

(Continued) 
Table A2 (Concluded)

\begin{tabular}{|c|c|c|c|c|c|c|c|c|c|}
\hline \multirow{2}{*}{$\begin{array}{c}\text { Trap } \\
\text { Number } \\
\end{array}$} & \multicolumn{9}{|c|}{ Streamer Number } \\
\hline & 1 & 2 & 3 & 4 & 5 & 6 & 7 & 8 & 9 \\
\hline \multicolumn{10}{|c|}{ Run 8609221750} \\
\hline 1 & 0.014 & 0.092 & 0.194 & 0.289 & 0.394 & 0.565 & 0.743 & & \\
\hline 2 & 0.014 & 0.095 & 0.187 & 0.302 & 0.419 & 0.549 & 0.762 & & \\
\hline 3 & 0.014 & 0.083 & 0.191 & 0.368 & 0.534 & 0.740 & 1.045 & & \\
\hline 4 & 0.014 & 0.089 & 0.194 & 0.318 & 0.451 & 0.657 & 0.861 & 1.070 & \\
\hline 5 & 0.014 & 0.102 & 0.219 & 0.337 & 0.438 & 0.616 & 0.819 & 1.067 & \\
\hline 6 & 0.014 & 0.095 & 0.191 & 0.305 & 0.397 & 0.559 & 0.718 & 0.972 & \\
\hline 7 & 0.014 & 0.099 & 0.216 & 0.337 & 0.448 & 0.607 & 0.756 & 0.965 & 1.181 \\
\hline 8 & 0.014 & 0.095 & 0.203 & 0.299 & 0.422 & 0.562 & 0.772 & 1.077 & \\
\hline 9 & 0.014 & 0.121 & 0.216 & 0.330 & 0.543 & 0.753 & 0.962 & & \\
\hline 10 & 0.014 & 0.089 & 0.213 & 0.315 & 0.524 & 0.737 & 0.934 & & \\
\hline \multicolumn{10}{|c|}{ Run 8609231035} \\
\hline 1 & 0.014 & 0.108 & 0.219 & 0.327 & 0.391 & 0.594 & 0.882 & & \\
\hline 2 & 0.014 & 0.080 & 0.156 & 0.266 & 0.406 & 0.571 & 0.762 & 0.964 & \\
\hline 3 & 0.014 & 0.089 & 0.207 & 0.365 & 0.543 & 0.746 & 1.051 & & \\
\hline 4 & 0.014 & 0.096 & 0.204 & 0.324 & 0.432 & 0.642 & 0.852 & & \\
\hline 5 & 0.014 & 0.099 & 0.210 & 0.324 & 0.429 & 0.655 & 0.855 & 1.054 & \\
\hline
\end{tabular}


Table A3

Water Levels

\begin{tabular}{lrr}
\hline Time & \multicolumn{2}{c}{$\begin{array}{r}\text { Water Le } \\
\text { EDST }\end{array}$} \\
\cline { 3 - 3 } & Run . NGV \\
1342 & Run151345 \\
1348 & -0.25 \\
1354 & -0.22 \\
1400 & & -0.20 \\
1406 & & -0.17 \\
1412 & & -0.17 \\
& & -0.14 \\
1630 & & \\
1636 & & 0.52 \\
1642 & & 0.53 \\
1648 & & 0.55 \\
1654 & & 0.58 \\
& & 0.60
\end{tabular}

Run 8609181225

1224

1230

1236

1242

1248

1254

$-0.14$

$-0.16$

$-0.20$

$-0.23$

$-0.27$

$-0.29$

Run 8609181453

1448

1454

1500

1506

1512

1518

1524

$-0.49$

$-0.49$

$-0.45$

$-0.44$

$-0.46$

$-0.45$

$-0.44$

(Continued) 
Table A3 (Concluded)

Water Leve1s

\begin{tabular}{|c|c|}
\hline $\begin{array}{l}\text { Time } \\
\text { EDST }\end{array}$ & $\begin{array}{l}\text { Water Leve1 } \\
\text { m. NGVD } \\
\end{array}$ \\
\hline \multicolumn{2}{|c|}{ Run 8609201045} \\
\hline $\begin{array}{l}1042 \\
1048 \\
1054 \\
1100 \\
1106 \\
1112 \\
1118 \\
1124 \\
1130 \\
1136\end{array}$ & $\begin{array}{l}0.63 \\
0.64 \\
0.63 \\
0.62 \\
0.59 \\
0.56 \\
0.57 \\
0.52 \\
0.50 \\
0.48\end{array}$ \\
\hline \multicolumn{2}{|c|}{ Run 8609201500} \\
\hline $\begin{array}{l}1500 \\
1506 \\
1512 \\
1518 \\
1524 \\
1530 \\
1536 \\
1542 \\
1548\end{array}$ & $\begin{array}{l}-0.40 \\
-0.41 \\
-0.41 \\
-0.43 \\
-0.46 \\
-0.49 \\
-0.45 \\
-0.47 \\
-0.41\end{array}$ \\
\hline
\end{tabular}


Table A4

Horizontal Coordinates of the Photopoles*

\begin{tabular}{rcc}
\hline Pole No. & $\begin{array}{c}\text { Offshore Coordinate } \\
\text { Distance, m }\end{array}$ & $\begin{array}{c}\text { Longshore Coordinate } \\
\text { Distance, m }\end{array}$ \\
\cline { 2 - 2 } 1 & 101.3 & 941.6 \\
2 & 107.3 & 941.6 \\
3 & 112.8 & 941.9 \\
4 & 118.5 & 941.8 \\
5 & 125.0 & 941.7 \\
6 & 131.5 & 941.5 \\
7 & 137.4 & 941.5 \\
8 & 143.3 & 941.8 \\
9 & 148.8 & 941.6 \\
10 & 155.0 & 941.9 \\
11 & 160.2 & 942.0 \\
12 & 166.4 & 941.8 \\
13 & 172.0 & 941.9 \\
14 & 178.1 & 941.8 \\
15 & 184.4 & 941.8 \\
16 & 190.0 & 942.0 \\
17 & 196.0 & 942.2 \\
18 & 202.8 & 942.4 \\
19 & 208.0 & 942.4 \\
20 & 213.7 & 942.4 \\
21 & 219.0 & 943.0 \\
22 & 225.5 & 943.1 \\
& &
\end{tabular}

* From Ebersole and Hughes (in preparation). 
Table A5

Grain Size Statistics

\begin{tabular}{|c|c|c|c|c|c|c|c|c|c|c|}
\hline \multirow[b]{2}{*}{$\begin{array}{l}\text { Run ID and } \\
\text { Trap No. }\end{array}$} & \multirow[b]{2}{*}{$\begin{array}{r}\text { Streamer } \\
\text { No. } \\
\end{array}$} & \multicolumn{4}{|c|}{ Moment Statistics } & \multicolumn{5}{|c|}{ Folk Inclusive Graphic Statistics } \\
\hline & & $\begin{array}{l}\text { First } \\
\text { PHI } \\
\end{array}$ & $\begin{array}{l}\text { Second } \\
\text { PHI } \\
\end{array}$ & $\underline{\text { Third }}$ & Fourth & $\begin{array}{l}\text { Median } \\
\text { PHI } \\
\end{array}$ & $\begin{array}{r}\text { Mean } \\
\text { PHI } \\
\end{array}$ & $\begin{array}{l}\text { Standard } \\
\text { Deviation } \\
\text { PHI } \\
\end{array}$ & Skewness & Kurtosis \\
\hline \multicolumn{11}{|l|}{8609111745} \\
\hline 1 & 1 & 2.21 & 0.80 & 0.00 & 6.00 & 2.34 & 2.32 & 0.56 & -0.22 & 1.38 \\
\hline 3 & 1 & 2.56 & 0.41 & -2.07 & 13.19 & 2.59 & 2.60 & 0.31 & -0.10 & 1.04 \\
\hline 4 & 1 & 2.55 & 0.56 & -2.67 & 15.56 & 2.66 & 2.62 & 0.41 & 0.32 & 0.71 \\
\hline 5 & 1 & 2.65 & 0.46 & -2.01 & 14.13 & 2.69 & 2.68 & 0.34 & -0.12 & 0.99 \\
\hline \multicolumn{11}{|l|}{8609121037} \\
\hline \multirow[t]{6}{*}{1} & 1 & 2.51 & 0.43 & -1.44 & 11.52 & 2.53 & 2.53 & 0.30 & 0.06 & 0.00 \\
\hline & 2 & 2.58 & 0.49 & -2.40 & 15.30 & 2.64 & 2.62 & 0.38 & -0.16 & 0.98 \\
\hline & 3 & 2.54 & 0.48 & -2.64 & 18.31 & 2.51 & 2.50 & 0.36 & 0.12 & 0.00 \\
\hline & 4 & 2.60 & 0.38 & -0.73 & 4.21 & 2.63 & 2.62 & 0.35 & -0.11 & 0.90 \\
\hline & 5 & 2.58 & 0.42 & -2.62 & 25.35 & 2.61 & 2.61 & 0.34 & -0.11 & 0.88 \\
\hline & 6 & 2.63 & 0.41 & -0.87 & 4.83 & 2.68 & 2.65 & 0.37 & -0.20 & 0.86 \\
\hline \multirow[t]{5}{*}{2} & 1 & 2.06 & 0.74 & -1.66 & 7.44 & 2.15 & 2.13 & 0.63 & 0.17 & 1.23 \\
\hline & 2 & 2.36 & 0.52 & -1.08 & 6.26 & 2.40 & 2.39 & 0.46 & -0.09 & 0.95 \\
\hline & 3 & 2.50 & 0.55 & -2.33 & 15.39 & 2.55 & 2.54 & 0.43 & -0.13 & 0.87 \\
\hline & 4 & 2.63 & 0.46 & -1.67 & 8.85 & 2.74 & 2.66 & 0.37 & -0.42 & 0.82 \\
\hline & 5 & 2.69 & 0.42 & -0.86 & 4.42 & 2.78 & 2.71 & 0.36 & -0.41 & 0.81 \\
\hline \multirow[t]{4}{*}{3} & 1 & 2.29 & 0.48 & -1.41 & 11.28 & 2.32 & 2.31 & 0.43 & 0.03 & 1.02 \\
\hline & 2 & 2.39 & 0.48 & -2.03 & 14.01 & 2.42 & 2.42 & 0.40 & -0.03 & 1.01 \\
\hline & 3 & 2.44 & 0.48 & -2.01 & 14.31 & 2.46 & 2.47 & 0.40 & -0.02 & 0.97 \\
\hline & 4 & 2.58 & 0.41 & -0.37 & 3.41 & 2.60 & 2.59 & 0.39 & -0.11 & 0.83 \\
\hline \multirow[t]{5}{*}{4} & 1 & 2.42 & 0.61 & -3.11 & 18.12 & 2.50 & 2.49 & 0.40 & -0.14 & 1.04 \\
\hline & 2 & 2.69 & 0.34 & -0.88 & 5.56 & 2.73 & 2.71 & 0.30 & -0.21 & 0.85 \\
\hline & 3 & 2.72 & 0.36 & -1.88 & 11.16 & 2.79 & 2.74 & 0.30 & -0.32 & 0.82 \\
\hline & 4 & 2.74 & 0.36 & -1.92 & 12.13 & 2.79 & 2.76 & 0.30 & -0.23 & 0.99 \\
\hline & 5 & 2.68 & 0.46 & -2.59 & 14.01 & 2.78 & 2.73 & 0.33 & -0.36 & 1.00 \\
\hline \multirow[t]{6}{*}{5} & 1 & 2.72 & 0.49 & -4.99 & 37.43 & 2.77 & 2.77 & 0.26 & 0.12 & 0.96 \\
\hline & 2 & 2.76 & 0.49 & -5.29 & 42.08 & 2.03 & 2.79 & 0.22 & 0.35 & 0.84 \\
\hline & 3 & 2.57 & 0.68 & -2.41 & 9.81 & 2.76 & 2.68 & 0.51 & -0.50 & 1.76 \\
\hline & 4 & 2.77 & 0.35 & -2.44 & 16.15 & 2.82 & 2.79 & 0.24 & -0.33 & 0.93 \\
\hline & 5 & 2.82 & 0.29 & -1.32 & 10.63 & 2.85 & 2.82 & 0.22 & -0.33 & 0.76 \\
\hline & 6 & 2.80 & 0.27 & -0.78 & 5.32 & 2.82 & 2.80 & 0.23 & -0.22 & 0.83 \\
\hline \multirow[t]{3}{*}{6} & 1 & 2.65 & 0.41 & -3.04 & 19.75 & 2.70 & 2.70 & 0.27 & -0.12 & 0.96 \\
\hline & 2 & 2.67 & 0.38 & -3.87 & 32.35 & 2.70 & 2.70 & 0.24 & 0.05 & 0.07 \\
\hline & 3 & 2.65 & 0.61 & -3.14 & 15.43 & 2.80 & 2.75 & 0.38 & -0.39 & 1.35 \\
\hline \multicolumn{11}{|l|}{8609151345} \\
\hline \multirow[t]{5}{*}{3} & 1 & 1.81 & 1.23 & -1.39 & 3.72 & 2.34 & 1.75 & 1.21 & 0.70 & 1.63 \\
\hline & 2 & 2.47 & 0.44 & -2.26 & 16.55 & 2.48 & 2.51 & 0.34 & 0.04 & 1.05 \\
\hline & 3 & 2.46 & 0.43 & -1.83 & 11.73 & 2.40 & 2.40 & 0.35 & 0.07 & 1.10 \\
\hline & 4 & 2.47 & 0.52 & -3.31 & 21.57 & 2.52 & 2.53 & 0.34 & 0.06 & 1.07 \\
\hline & 5 & 2.50 & 0.41 & -2.76 & 20.24 & 2.51 & 2.53 & 0.30 & 0.03 & 1.14 \\
\hline \multirow[t]{2}{*}{4} & 1 & 2.51 & 0.64 & -3.65 & 21.82 & 2.61 & 2.60 & 0.39 & -0.18 & 1.24 \\
\hline & 2 & 2.57 & 0.78 & -3.75 & 18.66 & 2.73 & 2.71 & 0.37 & -0.25 & 1.32 \\
\hline
\end{tabular}

(Continued) 
Table AS (Continued)

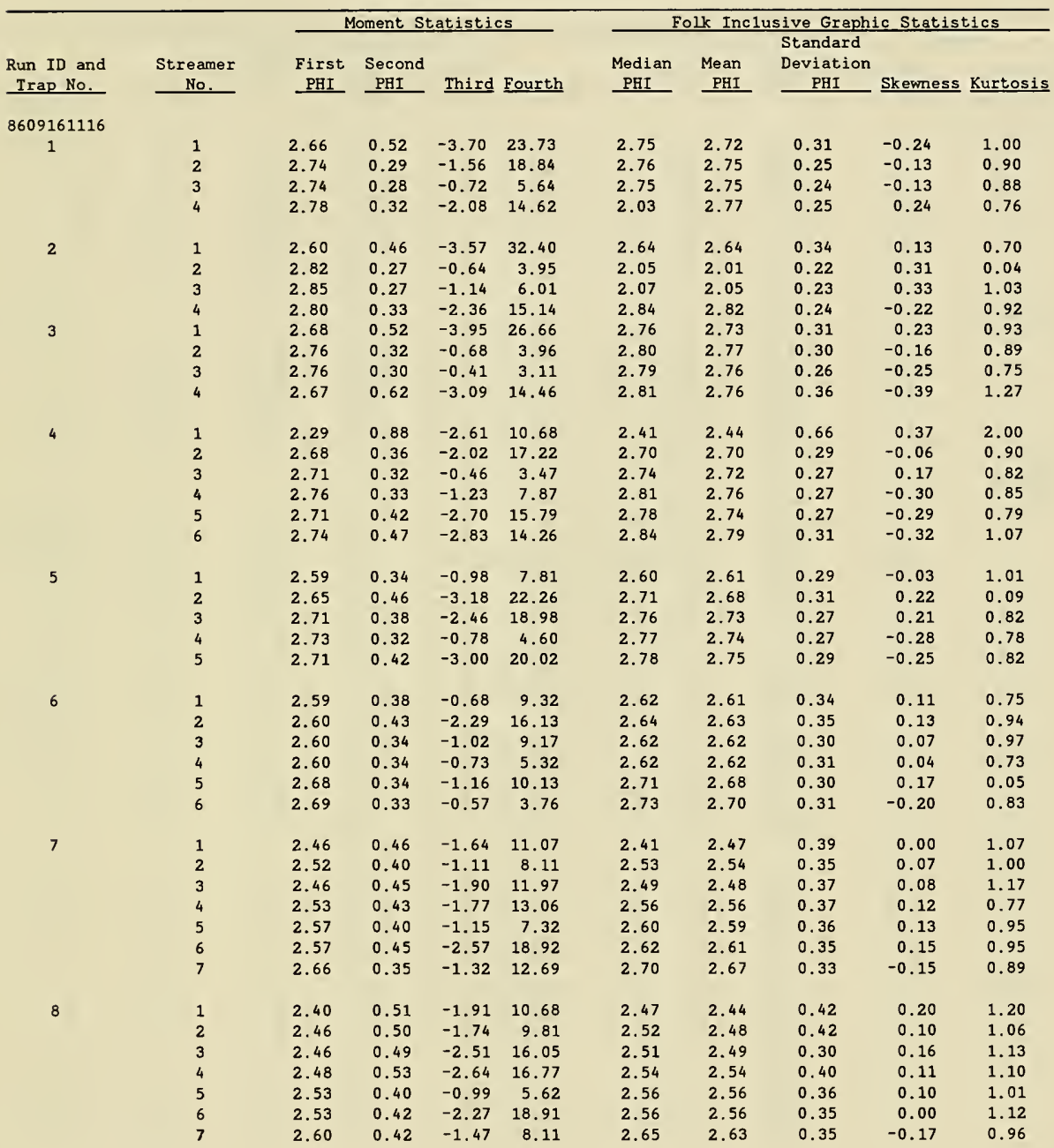

(Continued) 
Table A5 (Continued)

\begin{tabular}{|c|c|c|c|c|c|c|c|c|c|c|}
\hline \multirow[b]{2}{*}{$\begin{array}{l}\text { Run ID and } \\
\text { Irap No. }\end{array}$} & \multirow[b]{2}{*}{$\begin{array}{c}\begin{array}{c}\text { Streamer } \\
\text { No. }\end{array} \\
\end{array}$} & \multicolumn{4}{|c|}{ Moment Statistics } & \multicolumn{5}{|c|}{ Folk Inclusive Graphic Statistics } \\
\hline & & $\begin{array}{l}\text { First } \\
\text { PHI } \\
\end{array}$ & $\begin{array}{l}\text { Second } \\
\text { PHI } \\
\end{array}$ & Third & Fourth & $\begin{array}{c}\text { Median } \\
\mathrm{PHI} \\
\end{array}$ & $\begin{array}{c}\text { Mean } \\
\text { PHI } \\
\end{array}$ & $\begin{array}{l}\text { Standard } \\
\text { Devietion } \\
\text { PHI } \\
\end{array}$ & Skewness & Kurtosis \\
\hline \multicolumn{11}{|l|}{8609181453} \\
\hline \multirow[t]{7}{*}{5} & 1 & 2.60 & 0.43 & -3.56 & 35.82 & 2.64 & 2.63 & 0.33 & 0.16 & 0.94 \\
\hline & 2 & 2.64 & 0.39 & -2.57 & 20.40 & 2.67 & 2.67 & 0.31 & 0.06 & 0.97 \\
\hline & 3 & 2.68 & 0.34 & -1.45 & 16.35 & 2.70 & 2.61 & 0.30 & 0.09 & 0.10 \\
\hline & 4 & 2.66 & 0.32 & -1.61 & 19.84 & 2.68 & 2.68 & 0.20 & 0.01 & 0.94 \\
\hline & 5 & 2.68 & 0.30 & -0.37 & 3.38 & 2.69 & 2.69 & 0.28 & -0.05 & 0.88 \\
\hline & 6 & 2.74 & 0.31 & -0.83 & 4.83 & 2.70 & 2.75 & 0.27 & 0.27 & 0.03 \\
\hline & 7 & 2.71 & 0.53 & -4.46 & 31.96 & 2.81 & 2.78 & 0.28 & -0.24 & 1.03 \\
\hline \multicolumn{11}{|l|}{8609191230} \\
\hline \multirow[t]{6}{*}{7} & 1 & 2.49 & 0.55 & -3.09 & 18.43 & 2.57 & 2.55 & 0.38 & -0.15 & 1.15 \\
\hline & 2 & 2.55 & 0.47 & -2.49 & 15.54 & 2.60 & 2.59 & 0.35 & 0.14 & 1.04 \\
\hline & 3 & 2.62 & 0.38 & -1.80 & 13.91 & 2.64 & 2.64 & 0.31 & 0.13 & 0.93 \\
\hline & 4 & 2.65 & 0.33 & -0.64 & 4.06 & 2.68 & 2.66 & 0.30 & 0.11 & 0.92 \\
\hline & 5 & 2.62 & 0.45 & -4.35 & 36.42 & 2.65 & 2.65 & 0.29 & 0.05 & 0.96 \\
\hline & 6 & 2.68 & 0.31 & -0.57 & 4.16 & 2.69 & 2.69 & 0.21 & 0.01 & 0.00 \\
\hline \multicolumn{11}{|l|}{8609201045} \\
\hline \multirow[t]{7}{*}{1} & 1 & 2.52 & 0.49 & -2.30 & 14.31 & 2.50 & 2.57 & 0.30 & 0.15 & 1.02 \\
\hline & 2 & 2.50 & 0.41 & -1.81 & 12.21 & 2.52 & 2.53 & 0.34 & -0.05 & 1.11 \\
\hline & 3 & 2.46 & 0.55 & -2.70 & 14.94 & 2.51 & 2.52 & 0.38 & -0.11 & 1.27 \\
\hline & 4 & 2.52 & 0.44 & -2.34 & 17.60 & 2.54 & 2.55 & 0.35 & -0.07 & 0.91 \\
\hline & 5 & 2.52 & 0.38 & -1.32 & 9.76 & 2.52 & 2.54 & 0.33 & 0.02 & 1.11 \\
\hline & 6 & 2.38 & 0.75 & -2.36 & 10.30 & 2.56 & 2.48 & 0.60 & -0.40 & 1.54 \\
\hline & 7 & 2.40 & 0.78 & -2.54 & 10.15 & 2.59 & 2.54 & 0.61 & -0.42 & 2.01 \\
\hline \multirow[t]{3}{*}{2} & 1 & 2.53 & 0.41 & -2.05 & 15.17 & 2.53 & 2.56 & 0.33 & 0.02 & 0.96 \\
\hline & 3 & 2.55 & 0.50 & -3.75 & 27.81 & 2.60 & 2.60 & 0.34 & -0.10 & 0.96 \\
\hline & 4 & 2.60 & 0.40 & -1.71 & 10.77 & 2.65 & 2.65 & 0.35 & -0.15 & 0.99 \\
\hline \multirow[t]{5}{*}{3} & 1 & 2.30 & 0.76 & -2.69 & 11.88 & 2.45 & 2.41 & 0.55 & 0.31 & 1.67 \\
\hline & 3 & 2.55 & 0.46 & -3.43 & 31.06 & 2.59 & 2.58 & 0.35 & -0.11 & 0.99 \\
\hline & 4 & 2.59 & 0.34 & -0.31 & 3.01 & 2.59 & 2.60 & 0.33 & -0.01 & 0.93 \\
\hline & 5 & 2.45 & 0.87 & -3.51 & 15.75 & 2.64 & 2.60 & 0.39 & -0.24 & 1.14 \\
\hline & 6 & 2.54 & 0.39 & -0.73 & 4.02 & 2.58 & 2.56 & 0.37 & -0.15 & 1.03 \\
\hline \multirow[t]{5}{*}{4} & 1 & 2.57 & 0.51 & -3.04 & 20.51 & 2.64 & 2.63 & 0.36 & -0.15 & 0.99 \\
\hline & 2 & 2.62 & 0.47 & -1.94 & 7.95 & 2.70 & 2.71 & 0.35 & -0.17 & 1.30 \\
\hline & 3 & 2.67 & 0.41 & -2.87 & 22.31 & 2.73 & 2.70 & 0.32 & -0.19 & 0.98 \\
\hline & 4 & 2.60 & 0.55 & -3.28 & 19.67 & 2.71 & 2.68 & 0.36 & -0.31 & 1.21 \\
\hline & 5 & 2.58 & 0.57 & -2.91 & 16.41 & 2.70 & 2.64 & 0.40 & -0.32 & 1.11 \\
\hline \multirow[t]{3}{*}{5} & 1 & 2.59 & 0.44 & -2.25 & 14.90 & 2.65 & 2.62 & 0.37 & -0.20 & 1.02 \\
\hline & 2 & 2.62 & 0.45 & -4.70 & 46.48 & 2.67 & 2.65 & 0.32 & -0.16 & 1.01 \\
\hline & 3 & 2.69 & 0.33 & -0.70 & 3.49 & 2.73 & 2.70 & 0.31 & -0.23 & 0.94 \\
\hline \multirow[t]{3}{*}{6} & 1 & 2.58 & 0.35 & -0.72 & 4.33 & 2.61 & 2.60 & 0.32 & -0.10 & 1.02 \\
\hline & 2 & 2.67 & 0.34 & -0.65 & 3.41 & 2.71 & 2.68 & 0.33 & -0.19 & 0.96 \\
\hline & 4 & 2.62 & 0.41 & -1.92 & 10.67 & 2.68 & 2.66 & 0.33 & -0.22 & 1.02 \\
\hline 7 & 1 & 2.68 & 0.34 & -1.69 & 14.41 & 2.72 & 2.70 & 0.30 & -0.16 & 0.93 \\
\hline
\end{tabular}

(Continued) 
Table A5 (Concluded)

\begin{tabular}{|c|c|c|c|c|c|c|c|c|c|c|}
\hline \multirow[b]{2}{*}{$\begin{array}{l}\text { Run ID and } \\
\text { Irap No. }\end{array}$} & \multirow[b]{2}{*}{$\begin{array}{c}\text { Streamer } \\
\text { No. }\end{array}$} & \multicolumn{4}{|c|}{ Moment Statistics } & \multicolumn{5}{|c|}{ Folk Inclusive Graphic Statistics } \\
\hline & & $\begin{array}{c}\text { First } \\
\text { PHI } \\
\end{array}$ & $\begin{array}{c}\text { Second } \\
\mathrm{PHI} \\
\end{array}$ & Third & Fourth & $\begin{array}{l}\text { Median } \\
\text { PHI } \\
\end{array}$ & $\begin{array}{r}\text { Mean } \\
\text { PHI }\end{array}$ & $\begin{array}{l}\text { Standard } \\
\text { Deviation } \\
\text { PHI } \\
\end{array}$ & Skewness & Kurtosis \\
\hline \multicolumn{11}{|l|}{8609201045} \\
\hline \multirow[t]{6}{*}{8} & 1 & 2.58 & 0.44 & -3.80 & 31.14 & 2.61 & 2.62 & 0.30 & -0.05 & 1.10 \\
\hline & 2 & 2.54 & 0.40 & -3.14 & 24.81 & 2.56 & 2.59 & 0.28 & 0.04 & 1.20 \\
\hline & 3 & 2.59 & 0.51 & -3.16 & 19.71 & 2.65 & 2.65 & 0.34 & -0.14 & 1.12 \\
\hline & 4 & 2.69 & 0.33 & -0.71 & 3.95 & 2.73 & 2.71 & 0.31 & -0.15 & 1.02 \\
\hline & 5 & 2.71 & 0.32 & -0.75 & 3.81 & 2.75 & 2.72 & 0.30 & -0.20 & 0.98 \\
\hline & 6 & 2.74 & 0.31 & -0.62 & 3.34 & 2.78 & 2.76 & 0.30 & -0.17 & 1.00 \\
\hline \multicolumn{11}{|l|}{8609201500} \\
\hline \multirow[t]{4}{*}{9} & 1 & 2.41 & 0.73 & -2.55 & 11.80 & 2.55 & 2.50 & 0.52 & -0.30 & 1.14 \\
\hline & 2 & 2.67 & 0.49 & -3.05 & 20.53 & 2.75 & 2.71 & 0.35 & 0.29 & 1.00 \\
\hline & 3 & 2.76 & 0.38 & -1.50 & 10.40 & 2.84 & 2.78 & 0.34 & -0.31 & 0.97 \\
\hline & 4 & 2.81 & 0.36 & -1.12 & 4.58 & 2.89 & 2.83 & 0.33 & -0.33 & 1.03 \\
\hline \multirow[t]{4}{*}{10} & 1 & 2.58 & 0.55 & -3.06 & 19.35 & 2.67 & 2.64 & 0.31 & 0.23 & 0.91 \\
\hline & 2 & 2.73 & 0.30 & -1.75 & 13.05 & 2.77 & 2.74 & 0.23 & -0.18 & 0.93 \\
\hline & 3 & 2.86 & 0.49 & -6.23 & 57.01 & 2.95 & 2.88 & 0.21 & -0.60 & 1.30 \\
\hline & 4 & 2.72 & 0.53 & -3.75 & 24.66 & 2.87 & 2.77 & 0.33 & -0.58 & 1.20 \\
\hline \multicolumn{11}{|l|}{8609211345} \\
\hline \multirow[t]{2}{*}{15} & 1 & 2.46 & 0.87 & -2.75 & 11.36 & 2.69 & 2.61 & 0.61 & -0.48 & 1.77 \\
\hline & 3 & 2.86 & 0.26 & -2.03 & 11.87 & 2.92 & 2.88 & 0.19 & -0.40 & 1.17 \\
\hline \multirow[t]{5}{*}{16} & 1 & 2.49 & 0.74 & -3.08 & 16.30 & 2.65 & 2.58 & 0.49 & -0.36 & 1.11 \\
\hline & 2 & 2.73 & 0.44 & -2.14 & 10.67 & 2.85 & 2.75 & 0.32 & -0.56 & 1.05 \\
\hline & 3 & 2.74 & 0.60 & -3.93 & 24.29 & 2.89 & 2.79 & 0.32 & -0.62 & 1.25 \\
\hline & 4 & 2.75 & 0.47 & -2.02 & 8.46 & 2.89 & 2.79 & 0.36 & -0.51 & 1.32 \\
\hline & 5 & 2.86 & 0.40 & -5.17 & 54.37 & 2.93 & 2.86 & 0.22 & -0.54 & 1.23 \\
\hline \multicolumn{11}{|l|}{8609221600} \\
\hline \multirow[t]{7}{*}{1} & 1 & 2.72 & 0.34 & -2.88 & 31.00 & 2.75 & 2.74 & 0.26 & 0.14 & 0.00 \\
\hline & 2 & 2.71 & 0.32 & -2.57 & 33.79 & 2.72 & 2.72 & 0.27 & 0.09 & 0.06 \\
\hline & 3 & 2.66 & 0.42 & -3.97 & 32.39 & 2.70 & 2.70 & 0.28 & 0.01 & 0.91 \\
\hline & 4 & 2.66 & 0.51 & -4.32 & 31.12 & 2.74 & 2.72 & 0.21 & 0.11 & 0.92 \\
\hline & 5 & 2.66 & 0.37 & -3.51 & 33.64 & 2.61 & 2.60 & 0.57 & 0.09 & 0.94 \\
\hline & 6 & 2.69 & 0.41 & -3.72 & 30.97 & 2.73 & 2.72 & 0.27 & 0.15 & 0.03 \\
\hline & 7 & 2.75 & 0.31 & -1.68 & 12.66 & 2.78 & 2.76 & 0.26 & -0.20 & 0.80 \\
\hline \multirow[t]{8}{*}{2} & 1 & 2.84 & 0.32 & -2.60 & 19.78 & 2.01 & 2.04 & 0.21 & 0.41 & 0.95 \\
\hline & 2 & 2.79 & 0.46 & -3.66 & 23.14 & 2.01 & 2.03 & 0.26 & 0.47 & 1.14 \\
\hline & 3 & 2.80 & 0.37 & -4.14 & 32.81 & 2.86 & 2.84 & 0.21 & -0.29 & 0.97 \\
\hline & 4 & 2.85 & 0.23 & -0.63 & 5.54 & 2.87 & 2.86 & 0.18 & -0.26 & 0.88 \\
\hline & 5 & 2.86 & 0.22 & -0.35 & 4.70 & 2.87 & 2.86 & 0.19 & -0.11 & 1.00 \\
\hline & 6 & 2.90 & 0.41 & -4.84 & 35.31 & 2.98 & 2.93 & 0.19 & -0.48 & 1.26 \\
\hline & 7 & 2.88 & 0.42 & -4.20 & 28.98 & 2.97 & 2.91 & 0.22 & -0.54 & 1.39 \\
\hline & 8 & 2.61 & 0.86 & -2.39 & 8.86 & 2.95 & 2.71 & 0.65 & -0.76 & 2.18 \\
\hline \multicolumn{11}{|l|}{8609231035} \\
\hline 2 & 1 & 2.45 & 0.51 & -2.98 & 18.72 & 2.50 & 2.50 & 0.36 & -0.09 & 1.05 \\
\hline
\end{tabular}





\begin{tabular}{|c|c|}
\hline$\alpha$ & Empirical coefficient \\
\hline B & Empirical coefficient \\
\hline c & $\begin{array}{l}\text { Empirical coefficient to convert wet weight to dry } \\
\text { weight }\end{array}$ \\
\hline$d H_{\mathrm{rms}} / d \mathbf{x}$ & Local cross-shore gradient of wave height \\
\hline DW & Dry weight of sediment, $\mathrm{kg}$ (force) \\
\hline$\Delta a$ & Distance between nozzles, m \\
\hline$\Delta h$ & Height of streamer nozzle, m \\
\hline$\Delta t$ & Sampling time interval, sec \\
\hline$\Delta w$ & Width of streamer nozzle, $m$ \\
\hline$F$ & Sand flux (measured), $\mathrm{kg} /\left(\mathrm{m}^{2}-\mathrm{sec}\right)$ \\
\hline$F E$ & Sand flux (estimated), $\mathrm{kg} /\left(\mathrm{m}^{2}-\mathrm{sec}\right)$ \\
\hline$g$ & Acceleration due to gravity, $\mathrm{m} / \mathrm{sec}^{2}$ \\
\hline $\mathrm{H}$ & Mean wave height, m \\
\hline $\operatorname{Hmax}$ & Maximum wave height, m \\
\hline Hmin & Minimum wave height, m \\
\hline $\mathrm{H}_{\mathrm{mo}}$ & Spectrally based significant deepwater wave height, $m$ \\
\hline $\mathrm{H}_{\mathrm{rms}}$ & Root-mean-square wave height (also Hrms), m \\
\hline $\mathrm{H}_{\mathrm{s}}$ & $\begin{array}{l}\text { Significant wave height (also } \mathrm{Hs} \text { ), average of the } \\
\text { highest one-third wave heights, } \mathrm{m}\end{array}$ \\
\hline H10 & Average of the highest one-tenth wave heights, m \\
\hline$i$ & Transport rate density, $\mathrm{kg} /(\mathrm{m}-\mathrm{sec})$ \\
\hline$k$ & Streamer number \\
\hline$\kappa$ & Empirical coefficient \\
\hline $\operatorname{Kurt}(\mathrm{H})$ & Kurtosis of wave height elevations relative to mean \\
\hline $\operatorname{Kurt}(\mathrm{T})$ & Kurtosis of wave period relative to mean \\
\hline$N$ & Total number of streamers in a trap \\
\hline$\rho$ & Density of seawater, $\mathrm{kg} / \mathrm{m}^{3}$ \\
\hline$r^{2}$ & Squared correlation coefficient \\
\hline$S$ & Weight of sand, $\mathrm{kg}$ (force) \\
\hline $\mathrm{S}(\mathrm{H})$ & Standard deviation in wave height, $\mathrm{m}$ \\
\hline $\mathrm{S}(\mathrm{T})$ & Standard deviation in wave period, sec \\
\hline Skew $(H)$ & Skewness of wave height elevations relative to mean \\
\hline
\end{tabular}




$\begin{array}{ll}\text { Skew }(\mathrm{T}) & \text { Skewness of wave period relative to mean } \\ \sigma_{\mathrm{v}} & \text { Standard deviation of longshore current speed, } \mathrm{m} / \mathrm{sec} \\ \mathrm{T} & \text { Mean wave period, sec } \\ \mathrm{Tmax} & \text { Maximum wave period, sec } \\ \mathrm{Tmin} & \text { Minimum wave period, sec } \\ \mathrm{T}_{\mathrm{p}} & \text { Spectral peak wave period, sec } \\ \mathrm{Trms} & \text { Root-mean-square wave period, sec } \\ \mathrm{Ts} & \text { Average of the highest one-third wave periods, sec } \\ \mathrm{T} 10 & \text { Average of the highest one-tenth wave periods, sec } \\ V & \text { Average longshore current speed, m/sec } \\ \operatorname{Var}(\mathrm{H}) & \text { Variance in wave height relative to mean, } \mathrm{m}^{2} \\ \operatorname{Var}(\mathrm{T}) & \text { Variance in wave period relative to mean, sec } \\ \text { WW } & \text { Weight of sediment in drip-free condition, } \mathrm{kg}^{2} \text { (force) } \\ \mathrm{x} & \text { Distance offshore, } \mathrm{m} \\ \mathrm{y} & \text { Distance alongshore, m }\end{array}$






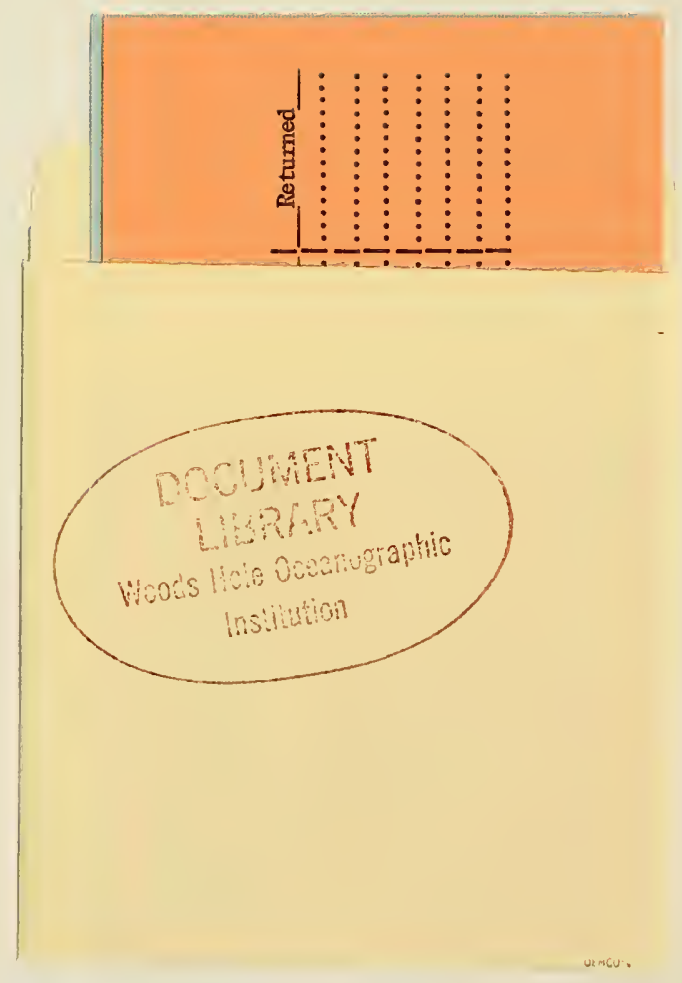


